University of Latvia

Faculty of Humanities

\title{
Baltic Journal of English Language, Literature and Culture
}

\author{
Volume 9
}

Riga 2019 
Baltic Journal of English Language, Literature and Culture, Volume 9.

Riga: University of Latvia, 2019. 130 pages.

Baltic Journal of English Language, Literature and Culture is a multidisciplinary international scientific journal in general linguistics, applied linguistics, literature and culture.

Editor-in-Chief: Andrejs Veisbergs (University of Latvia, Latvia)

Issue editor: Monta Farneste (University of Latvia, Latvia)

EDITORIAL BOARD

Sigma Ankrava (University of Latvia, Latvia)

Trevor G. Fennell (Flinders University, Australia)

Ann Hodgson (University of London, United Kingdom)

Larisa Iljiinska (Riga Technical University, Latvia)

Vilmantè Liubinienè (Kaunas University of Technology, Lithuania)

Indra Karapetjana (University of Latvia, Latvia)

Jurgita Mikelionienè (Kaunas University of Technology, Lithuania)

JoAnne Neff van Aertselaer (Complutense University of Madrid, Spain)

Irina Novikova (University of Latvia, Latvia)

Gunta Rozina (University of Latvia, Latvia)

Ömer Şekerci (Suleyman Demirel University, Turkey)

Jānis Sīlis (Ventspils University College, Latvia)

Visiting reviewers:

Kristina Aurylaité (Vytautas Magnus University, Lithuania; Bergen University, Norway)

Anna Branach-Kallas (Nicolaus Copernicus University, Poland)

Maria del Mar Robisko Martin (Madrid Polytechnic University, Spain)

Christina Dokou (The National and Kapodistrian University of Athens, Greece)

Nadezhda Emelianova (Astrahan State University, Russia)

Dafina Genova (University of Veliko Turnovo, Bulgaria)

Oleksandr Kapranov (Western Norway University of Applied Sciences, Norway)

Lauma Terēze Lapa (University of Latvia, Latvia)

Svetlana Manik (Ivanovo State University, Russia)

Sandra Meškova (Daugavpils University, Latvia)

Elita Saliņa (Latvian Academy of Culture, Latvia)

Aleksejs Taube (University of Latvia, Latvia)

Aristi Trendel (University of Maine, in Le Mans, France)

Enn Veldi (University of Tartu, Estonia)

Zigrīda Vinčela (University of Latvia, Latvia)

No part of this journal may be reproduced, stored in a retrieval system or transmitted in any form or by any means, including photocopying, recording or otherwise, without the prior written permission of the publisher.

Web site: http://www.bjellc.lu.lv

$$
\text { https://doi.org/10.22364/BJELLC.09.2019 }
$$

The journal is covered in ERIH PLUS; NSD Index (since 2018); Web of Science: Emerging Sources Citation Index, provided by a Clarivate Analytic company (since 2017); EBSCO: Central and Eastern European Academic Source, Central and Eastern European Academic Source (since 2015), Google Scholar (since 2011), the MLA Directory of Periodicals and indexed in the MLA International Bibliography.

(C) University of Latvia, 2019 


\section{TABLE OF CONTENTS}

\section{Jekaterina Čerñevska}

Lexical Concept Adjustment in Mechanical Engineering Discourse 4

\section{Milda Danytè}

All Writers Are Border Walkers: Emma Donoghue Between History

and Fiction in Astray and The Woman Who Gave Birth to Rabbits

Monta Farneste, Olga Pašinska

Developing Peer Corrective Skills in Business Letter Writing in English as a Foreign Language

\section{Jana Kuzmina}

Use of Tense-Aspect Forms in Cordis Project Reports

\section{Laurence Machet}

'Come Roam With Me Columbia's Forests': Representations

of the Forest in Alexander Wilson's The Foresters

\section{Christophe Premat}

The Survivance in the Literature of the First Nations in Canada

\section{Anastasija Ropa}

Songs of Life and Death in Walker Percy's Lancelot (1977)

\section{Andrejs Veisbergs}

The Fuzzy Concept of Idiom and What It Might Mean

for Bilingual Dictionaries 


\title{
LEXICAL CONCEPT ADJUSTMENT IN MECHANICAL ENGINEERING DISCOURSE
}

\author{
JEKATERINA ČERN̦EVSKA
}

University of Latvia, Latvia

\begin{abstract}
The lexical concept adjustment represents a significant aspect of the pragmatic meaning and has been approached from several perspectives in literature. As the semantics-pragmatics interface is a matter that attracts numerous debates among pragmaticians, the boundary between cases of polysemy and the semantic meaning adjustment in the context is also blurred. There has been no agreement whether a lexical concept adjustment can be regarded as a primary (necessary) or a secondary (optional) pragmatic process. The present article discusses cases of meaning disambiguation and lexical narrowing. The aim of the article is to demonstrate how a lexical concept adjustment contributes to the pragmatic meaning construction in the discourse under analysis. The present paper deals with the data obtained from the chapters on woodworking and metal processing borrowed from the Encyclopaedia of Occupational Health and Safety. The findings indicate that there is no clear-cut boundary between the processes of the lexical meaning disambiguation and a lexical concept adjustment as they both elaborate on the linguistic (semantic) meaning of a word or an expression taking into consideration all aspects of the contextual information available. Further research can be conducted to approach the issue from the quantitative perspective.
\end{abstract}

Key words: pragmatic meaning, a lexical concept, polysemy, lexical broadening, lexical narrowing, mechanical engineering discourse

\section{INTRODUCTION}

The construction of a word meaning has received a considerable amount of attention from different fields of study including linguistics, philosophy of language and the multidisciplinary perspective of cognitive science. The standard accepted account can be referred to as 'literalism' (e.g. Recanati, 2004: 3; Evans, 2009: 5), the belief that words have a linguistic ('what is said') and a non-linguistic ('what is meant') parts of meaning. The main linguistic unit of the semantic analysis is a sentence, which expresses a full proposition of a statement. A sentence differs from an utterance in the respect that the former does not include contextual factors in its meaning analysis. Saeed (2003: 12-13) proposes to set a distinction between a sentence and an utterance: utterances 'are created by speaking or writing a piece of language', whereas sentences are 'abstract grammatical elements obtained from utterances'.

One of the theoretical issues concerns the boundary between the semantic and the pragmatic parts of meaning, or the semantics-pragmatics interface. 
Thus, there have been numerous debates regarding the nature of the relationship between language and context. There has been no agreement in the literature regarding the extent to which the linguistically encoded (semantic) part of meaning interacts with contextual factors (the pragmatic part) in the process of meaning construction.

The present research supports the complementary view on the semanticspragmatics interface as argued by Leech (1983: 6, quoted in Mey, 2001: 7): 'the view that semantics and pragmatics are distinct, though complementary and interrelated fields of study, is easy to appreciate subjectively, but is more difficult to justify in an objective way. It is best supported negatively, by pointing out the failures or weaknesses of alternative views'. In other words, meaning is constructed as a result of interconnectedness between its linguistic and nonlinguistic (or contextual) parts.

The paper utilises the notion of a 'lexical concept', which can be used interchangeably with 'a word'. It should be noted that in cognitive linguistics words are often viewed not as 'fully-fledged atomic concepts, but rather schemas for the construction of such concepts' (Carston, 2002: 322). Evans (2009: 74) defines lexical concepts as 'linguistically encoded concepts, i.e. highly schematic knowledge encoded in a form that can be externalized via language'. Therefore, a lexical concept or a word is only a schematic representation, which cannot form meaning in isolation from the context where it is used.

On balance, pragmatic theories identify ad hoc concepts which can be described as adjustment of a lexical concept in the context. These are concepts that are 'constructed pragmatically by a hearer in the process of utterance comprehension' (Carston, 2002: 322). Generally speaking, a schematic representation encoded by a lexical concept undergoes a number of pragmatic processes for the meaning to be constructed in each occasion-specific use of a word.

The aim of the present paper is to investigate the processes that result in the ad hoc concept construction such as meaning disambiguation, lexical broadening and lexical narrowing. It has been hypothesised that the greater the impact the linguistic part has on the ad hoc concept construction, the more explicit the utterance is. The hypothesis is rooted in the relevance-theoretic approach, which argues that 'an assumption communicated by utterance $U$ is explicit if and only if it is a development of a logical form encoded by U' (Sperber and Wilson, 1995: 182).

Although the pragmatic meaning construction has been in the focus of the applied linguistic study in recent decades, mechanical engineering discourse has not been sufficiently analysed from this perspective yet. The author's previous publications deal with several aspects of the pragmatic meaning construction in the discourse under analysis - linguistic politeness (Černevska, 2014) and linguistic scalarity (Černevska, 2016). The analysis of a lexical concept adjustment continues the author's previous research on the pragmatic meaning construction in mechanical engineering discourse. 
The research question has been set: does the degree of utterance explicitness differ in cases of polysemy and a lexical concept broadening and narrowing? The paper offers the discussion of the theoretical contributions on meaning construction of lexical concepts in the context. The focus of the empirical part is on the selected instances of a lexical concept adjustment obtained from the mechanical engineering discourse.

\section{LITERATURE REVIEW}

Since a lexical concept serves as part of meaning, the analysis of the meaning construction process occurs at the semantic and pragmatic levels and their interaction. At the semantic level a word is part of a sentence, which is formed according to the grammatical rules of a language (Huang, 2012: 282) or a proposition, i.e. the content a sentence expresses when it is uttered. A proposition is analysed in terms of truth values, i.e. whether some state of affairs is true or false (ibid.: 250). The same sentence can be true in one context and false in another, depending on the relation between its propositional content and the world at each particular moment.

In the classical semiotic approach, communication is achieved based on a code model, which deals with encoding and decoding messages (Sperber and Wilson, 1995: 2-5). A proposition encoded by a speaker/writer is an input, which is decoded by the recipient. In the cognitive communication theories such as the Relevance Theory by Sperber and Wilson $(1986,1995)$ language ('what is said') constitutes only part of the communicated message ('what is meant').

It was traditionally assumed that the semantic level is a starting point for meaning construction. For instance, Sperber and Wilson (1995: 183) claim that 'the hearer's first task in recovering the explicatures of an utterance is to identify its propositional form'. However, this view has been challenged by Recanati, who argues for the availability-based approach, where not only saturation or 'the contextual assignment of values to indexicals and free variables in the logical form of the utterance' (Recanati, 2004: 21), but also other primary pragmatic processes participate in the determination of 'what is said' or a logical form of an utterance (ibid.). Therefore, it remains a matter of theoretical discussion whether the semantic and pragmatic components of meaning are processed sequentially or simultaneously.

In his LCCM (Lexical Concepts and Cognitive Models) Theory (2009), Evans distinguishes between lexical representation and semantic composition. 'Lexical representation' is knowledge of a language and consists of a symbolic unit (a linguistic form and a linguistically encoded concept, i.e. a lexical concept) and a cognitive model that is accessed through a lexical concept. A lexical concept is a 'semantic pole' of a symbolic unit, or schematic knowledge, which provides access to the non-linguistic information associated with the word (a cognitive 
model) (Evans, 2009: 75). Similarly, Carston (2002: 321) argues that 'an atomic concept consists of an address or node in memory which may make available three kinds of information: logical content, encyclopaedic or general knowledge, and lexical properties'. Thus, a lexical concept itself provides access to both the semantic and the pragmatic (non-linguistic) parts of meaning.

Consequently, the information, which can be accessed by a lexical concept, has to be specified in a particular context of use and interpreted taking into account a number of factors. Evans (2009: 4) enlists some of them: other words in an utterance, the speaker's and the hearer's shared background knowledge, the physical and temporal context and the speaker's communicative intention recognised by the addressee. Eventually, a lexical concept is processed by an addressee and an ad hoc concept is constructed.

The present paper deals with three of the pragmatic processes that are associated with a word meaning construction in the context. The first process is meaning disambiguation. In pragmatic literature ambiguity is defined as 'the property that a word or a sentence has two or more different meanings assigned by the language system' (Huang, 2012: 27). Ambiguity can be lexical, syntactic, semantic scope (arising from the use of certain logical operators, e.g. quantifiers and negation) and pragmatic (arises from the built-in duality of language in use) (ibid.: 27, 230, 280).

Ariel (2010: 154) argues that 'choosing the appropriate meaning of an ambiguous word is clearly a pragmatic matter, where, based on considerations of relevance, addressees try to select that semantic meaning which was intended by the speaker'. Thus, the combination of the linguistic form and the pragmatic inference is necessary in order to construct an ad hoc concept.

In the relevance-theoretic framework (Sperber and Wilson, 1986, 1995), disambiguation contributes to the explicit part of an utterance meaning since it can be considered to be the development of a logical form of a sentence. If we support the idea that the utterance cannot be transferred from a language of thought into a linguistic form without losing part of its meaning, it can be hypothesised that most if not all utterances contain a degree of ambiguity. However, most of ambiguity can be resolved in the context.

The next two pragmatic processes that impact a lexical concept adjustment in context are lexical narrowing and lexical broadening. These are types of enrichment that 'target a particular lexical item and strengthen the concept it encodes' (Carston, 2002: 324). The process of free enrichment describes how the linguistically decoded form is conceptually enriched by the addressee (Huang, 2012: 122). It is 'free' because it is context-driven; therefore, each individual can construct a unique ad hoc concept in his or her mind. Recanati also claims that free enrichment is an unconscious process in the sense that an ordinary language user does not notice it (2004: 23).

Recanati (2004) distinguishes between two subtypes of free enrichment: strengthening and expansion or loosening (Huang, 2007: 220-223). Similarly, 
Carston (2002: 322-364) identifies such pragmatic processes of ad hoc concept construction as lexical narrowing and lexical broadening.

In strengthening (or lexical narrowing), a lexical concept entails the original input proposition, i.e. the linguistic form and the contextual constituents which have been added because of saturation. On balance, in expansion (or lexical broadening or loosening), the output does not need to entail the input proposition. Carston (2002: 329) argues that 'a logical or a defining feature of the lexically encoded concept is dropped in the process of arriving at the intended interpretation'. In other words, the application of a lexical concept is constrained by the context in lexical narrowing and is widened by the context in lexical broadening. In both cases, a lexical concept is enriched pragmatically in order to construct its meaning.

It remains a matter of a theoretical discussion whether lexical narrowing and lexical broadening are symmetric processes.

On the one hand, both processes are used to build ad hoc concepts. The addressee builds a mental representation which is based on the lexically encoded information, while this representation maintains the properties relevant solely in the specific context. Certainly, ad hoc concepts constructed by different individuals can resemble one another to a great extent and be practically identical. However, if ad hoc concepts are constructed by the human cognitive system, we can assume that there cannot exist two absolutely identical ad hoc concepts as this would require the existence of two identical minds.

On the other hand, in the relevance-theoretic framework, explicature is a development of the logical form of an utterance (Sperber and Wilson, 1995: 181-182). Although the term 'development' is not specified, it is assumed that explicit meaning is tied to the linguistic form of a sentence.

Thus, strictly speaking, lexical broadening is not a development of the logical form as it is not entailed by the linguistic part of an utterance ('what is said'). It can be argued that if a lexical concept is not included in 'what is meant' (as opposed to 'what is said'), it is not entailed and we cannot therefore refer to the logical form of an utterance in its classical sense. But if 'development' denotes 'concept adjustment' as Carston proposes (2002: 342), narrowing and broadening can be considered to be symmetric processes.

\section{METHODS}

At the empirical level the research is approached from the qualitative perspective. First, the discourse for analysis was selected. It comprises a chapter borrowed from the Encyclopaedia of Occupational Health and Safety that deals with wood processing. The corpus selection was based on the author's background knowledge of the areas obtained while teaching English for Specific Purposes within a Wood Processing study programme. The corpus comprises 32 pages and approximately 8,500 words. The subchapters include the general 
profile of wood industry, the description of woodworking processes, routing machines, wood planing machines and health effects and disease patterns associated with the industry.

Second, discourse analysis is applied as a research method. The analysed instances of a lexical concept adjustment are offered to illustrate such aspects of the pragmatic meaning construction as meaning disambiguation, lexical narrowing and lexical broadening. The relevance-theoretic framework serves as a tool for conducting the empirical part of the research.

\section{RESULTS AND DISCUSSION}

Numerous instances of a lexical concept adjustment can be observed in the discourse under analysis. The present section deals with the discussion of the selected instances drawn from Chapter 86 of Encyclopaedia of Occupational Health and Safety (2011: Online).

1. With the increased cost of labour in industrialized countries, more furniture production, which is labour intensive, has shifted to Far Eastern countries. It is likely that this movement will continue unless more automated equipment can be developed.

The preceding utterance in the discourse suggests that 'this movement' refers to furniture production having shifted to Far Eastern countries. In the same context, 'equipment' should mean 'the equipment for furniture production'. It can be observed that, since 'movement' can be defined as 'an act of moving from one place to another or of moving something from one place to another' (Oxford Learner's Dictionaries, n.d.: Online), its semantic meaning can be distinguished from other meanings offered by the dictionary such as 'progress' or 'music'. This could be considered a case of meaning disambiguation in the context as the word 'movement' gives access to a number of semantic (i.e. documented in a dictionary) meanings and the relevant meaning has to be selected in the context. It is linguistically encoded, but the meaning disambiguation relies on the reader's background knowledge of how business enterprises can be relocated due to various reasons, including the economic ones.

Therefore, the lexical concept 'movement' provides access to both linguistic and non-linguistic information associated with the word itself. Although the semantic meaning is linguistically encoded, meaning disambiguation of a polysemantic word involves the use of the contextual information. This demonstrates that both the semantic and pragmatic parts of meaning participate in the meaning construction process.

A lexical concept 'equipment' serves as a category word. Oxford Learner's Dictionary (n.d.: Online) states that 'equipment' can be described as 'the things that are needed for a particular purpose or activity'. Thus, its semantic part of meaning entails the presence of a specific purpose, but it can be identified only 
in the context. The word meaning should be narrowed in the context to infer 'furniture equipment'. This narrow part of the meaning is not linguistically encoded as the lexical narrowing occurs as a result of the broader discourse context. The proposition can be enriched as a result of lexical narrowing. For instance, a relative clause could be added: '... more automated equipment, which is required for furniture production, can be developed'.

Although 'movement' has to undergo a process of the semantic meaning disambiguation, while 'equipment' is lexically narrowed, both meaning disambiguation and lexical narrowing occur only in the context of a lexical concept use. There might be more encyclopaedic information associated with a polysemantic word as a lexical concept has a greater 'semantic potential' and provides access to a number of cognitive models or various areas of background knowledge. For instance, 'an act of moving from one place to another' might have different associations triggered in a human mind rather than 'music' or 'progress', which are also the definitions of the word 'movement'. However, ad hoc concepts are constructed in both cases, which suggests that the processes of meaning disambiguation and lexical narrowing are pragmatic in nature.

2. Because production lines for assembling furniture are costly, most manufacturers do not supply an exceptionally large range of items.

'Costly' requires a context to be fully inferred by the reader. Whereas its semantic meaning can be defined as 'not cheap', the definition of 'cheap' is contextdependent. Therefore, the reader is expected to adjust the lexical meaning to his or her mental representation of 'costly' based on the background knowledge of the production line costs. The pragmatic inference occurs through the process of free enrichment and lexical narrowing, in particular. The semantic part of the word meaning does not offer any explanation as regards the ad hoc concept construction besides the fact that the production lines are not cheap. The reader should be aware of the particular professional context in order to infer the pragmatic meaning of the word.

On balance, 'items' can be narrowed to 'furniture items', which is an instance of a lexical concept narrowing or strengthening to infer a contextually more specific word meaning. 'Item' is a category word; however, its meaning is vague without a context as any 'single object' can be meant by 'an item'. Therefore, its meaning is too general and can be inferred solely in the context.

The lexical concept 'equipment' in the previous example undergoes a similar meaning construction process as both these lexical concepts are category words and are, therefore, broadly used in various contexts.

3. For the purposes of this article, the processes of the woodworking industry will be considered to start with the reception of converted timber for the sawmill and continue until the shipping of a finished wood article or product. 
The utterance contains a polysemantic word 'article' in two different meanings. This represents an instance of meaning disambiguation; however, the context is required to assign the particular meaning to the word. 'This article' refers to the text the writer is constructing, whereas 'wood article' refers to an item made of wood. The reader is unlikely to misunderstand the use of the word in this context as the background knowledge required to identify the meaning is embedded in the linguistic structure as well. For instance, a text is not modified by the adjective 'wood', whereas the construction 'for the purposes of' does not usually imply furniture. As it can be observed, meaning disambiguation of polysemy in the context relies more on other co-textual (i.e. linguistically encoded) features rather than on the lexical concept adjustment in the utterance.

It can be argued that since the polysemantic word meaning disambiguation in the present example depends on the lexical and grammatical form of the utterance, i.e. other words and their combination, the meaning of the word 'article' becomes more explicit than the meaning of 'equipment' or 'an item' in the previous examples. Thus, it might be suggested that it is rather the combination of words governed by the rules of grammar than the polysemantic nature of a particular word that determines the degree of explicitness of an utterance.

4. In many instances, the design of furniture pieces requires bending of certain wooden parts. This occurs after the planing process, and usually involves the application of pressure in conjunction with a softening agent, such as water, and increased atmospheric pressure. After bending into the desired shape, the piece is dried to remove excess moisture.

'The desired shape' is a subjective concept that heavily depends on the context. The lexical concept adjustment should be applied in order to build a mental representation of this image in the reader's mind. This fragment could undergo a process of the proposition enrichment, for instance, 'into the desired shape that has been intended for a specific furniture piece construction', in which case the lexical concept of a 'desired shape' could be used across different contexts without the necessity to adjust it to a specific occasion of use.

'The piece' as a category word requires narrowing to 'a piece of furniture' that is not linguistically encoded in the present utterance. However, 'furniture pieces' are mentioned earlier in the paragraph, thereby allowing the reader to construct the pragmatic meaning based on the preceding linguistic information.

5. Once the lumber is dried, it is sawed and otherwise machined into the shape of the final furniture part, such as a table leg. In a normal plant, the wood stock moves from rough planer, to cut-off saw, to rip saw, to finish planer, to moulder, to lathe, to table saw, to band saw, to router, to shaper, to drill and mortiser, to carver and then to a variety of sanders. 
'Plant' is a polysemantic word, which is used in the meaning of 'machinery' in this utterance. The reader is unlikely to assign the meaning 'a living thing that grows' to the word 'plant' in this context. However, the meaning 'factory' can be presupposed, and meaning disambiguation depends on the reader's background knowledge. This example demonstrates that the polysemantic nature of a lexical concept can interfere with the ad hoc concept construction in case the reader's encyclopaedic knowledge is not sufficient for the professional discourse comprehension.

6. After initial sanding, an even smoother surface is attained by spraying, sponging or dipping the furniture part with water to cause the wood fibres to swell and "raise". After the surface has dried, a solution of glue or resin is applied and allowed to dry.

7. A ripsaw should have anti-kickback fingers installed to prevent the stock from reversing its direction and striking the operator. Also, the operator should wear a padded apron to lessen the impact if a kickback does occur.

8. Surface finishing may involve the use of a large variety of coatings. These coatings are applied after the product is assembled or in a flat line operation before assembly. Coatings could normally include fillers, stains, glazes, sealers, lacquers, paints, varnishes and other finishes.

In example 6, the word 'glue' refers to a particular type of glue - wood glue; therefore, the lexical concept should be narrowed to infer the contextual meaning. 'Apron' in example 7 refers to the piece of clothing used for protection in the workshop, not an apron for cooking. In example 8, the reader is not likely to assume that 'coatings' refer to, for instance, pizza coatings. This can be achieved by the linguistic information provided in the utterance - varnishes and alike are not edible - as well as by the context which describes the mechanical engineering professional discourse. It can therefore be argued that both the linguistic and the contextual part of the discourse interact in order to construct the meaning of an utterance. The distinguishing characteristics of these words are not part of the semantic meaning. Rather, the lexical concept is expected to be adjusted in the context of wood processing, and it is narrowed from the general term to a more specific one.

The examples only illustrate the meaning construction process and we cannot make any generalizations based on them. However, the aim of the Results and Discussion section is to show that even seemingly non-ambiguous lexical concepts have to be adjusted in the context of discourse in order to infer the writer's message.

Whereas meaning disambiguation is considered to be closely related to the domain of semantics and deals with the notion of semantic ambiguity, lexical adjustment is a pragmatic matter. If ad hoc construction could be calculated by semantics, then it should be agreed that each lexical concept can have an indefinite number of semantic meanings. However, if any lexical concept could 
be decoded based solely on its linguistic form, this would suggest that any human mind would infer the same meaning providing that a person knows the language.

The question remains whether lexical adjustment requires more mental effort than meaning disambiguation. In other words, it is unclear whether these pragmatic processes are similar and both belong to the explicit content of the utterance.

For instance, it can be hypothesised that the mental representation of an apron in example 7 is constructed similarly to the mental representation of a plant in example 5 because both lexical concepts interact with the local context of the utterance and the global context of the discourse.

If a reader is familiar with the professional context of the discourse, the mental representation of a plant will undergo the same meaning disambiguation process as the mental representation of an apron. On the one hand, an apron for cooking and an apron for protection when working in industry have similarities in their appearance, whereas a plant as a factory, machinery and a herb do not share any representational similarities. Moreover, meaning disambiguation occurs within the particular language, not cross-culturally. On the other hand, the lexical concepts still interact with the context and the mental representations have to be built in both cases.

The distinction between concept adjustment and disambiguation is in the mental representation of the lexical concept. While meaning disambiguation implies that the human cognitive system has to choose between semantic homonyms: the use of a semantic entity that is more relevant in the particular discourse, a lexical concept adjustment does not deal with distinguishing between homonyms. Rather, it deals with the formation of a unique mental representation of a concept in the addressee's mind.

Certainly, this representation is affected both by the reader's background assumptions about the world and the immediate context available to him or her. In the context of our professional discourse, the reader is aware of the context of professional engineering discourse. Therefore, it is likely that both semantic meaning disambiguation and ad hoc concept construction rely on the context and are therefore considered to be pragmatic phenomena.

\section{CONCLUSIONS}

The analysis of the theoretical background demonstrates that it is generally accepted that the linguistic and non-linguistic parts of a word meaning participate in the meaning construction process. The mental representation of a lexical concept relies on the linguistically encoded information, but is expected to be adjusted taking the context into consideration.

The research results suggest that ad hoc concept construction is required both in cases of polysemy and other lexical meaning disambiguation. Linguistically encoded information is closely interconnected with the contextual factors and 
the degree of explicitness is unlikely to depend on whether the word or expression is polysemantic.

Numerous cases of lexical narrowing and meaning disambiguation can be observed in the mechanical engineering discourse. However, expansion or lexical broadening seem to be non-existent in the discourse under analysis. This may suggest that the professional discourse and the genre of encyclopaedia aim to be as specific as possible and the context fulfils the function of providing even more specific meaning to the linguistically available information. Lexical broadening implies losing some of the semantic properties of a lexical concept in order to construct a 'broader' meaning of a word. While it can meet the reader's expectations in other discourse, the discourse under analysis deals with technical matters that require high precision to be inferred adequately. Lexical broadening would increase the degree of imprecision that is expected to be avoided in mechanical engineering discourse.

It should be noted that while polysemy is considered to be a semantic matter as the semantic meaning is described in dictionaries, a reader has to disambiguate the polysemantic meaning of a lexical concept similarly to the adjustment of a lexical concept in a context through the pragmatic processes of lexical broadening and narrowing. In both cases a word meaning is based on the linguistically encoded information, which has to be specified in the context of a particular utterance.

Since 'explicitness' is the development of a linguistic form of an utterance, there is no distinction in this respect between meaning disambiguation of polysemantic words and lexical narrowing and broadening. While a reader has the access to the encyclopeadic information associated with a particular lexical concept, he or she has to select the relevant aspects of the available information in order to construct the pragmatic meaning of a word. Therefore, it can be argued that the degree of explicitness does not depend on whether the word meaning has to be selected from the appropriate semantic meaning available in a dictionary or a lexical concept should strenghten or lose some of the properties associated with its logical form. This is also supported by the fact that polysemy is language-specific, whereas the pragmatic processes are universal.

\section{REFERENCES}

Ariel, M. (2010) Defining Pragmatics. Cambridge: Cambridge University Press.

Carston, R. (2002) Thoughts and Utterances. Oxford: Blackwell Publishing.

Černevska, J. (2014) Linguistic politeness in English for engineering. In A. Veisbergs and M. Farneste (eds.) Language for International Communication: Linking Interdisciplinary Perspectives (pp. 39-45). Riga: University of Latvia Press.

Černevska, J. (2016) Scalarity in mechanical engineering discourse. In A. Veisbergs and M. Farneste (eds.) Language for International Communication: Linking Interdisciplinary Perspectives (pp. 31-40). Riga: University of Latvia Press. 
Evans, V. (2009) How Words Mean. Oxford: Oxford University Press.

Huang, Y. (2007) Pragmatics. Oxford: Oxford University Press.

Huang, Y. (2012) The Oxford Dictionary of Pragmatics. Oxford: Oxford University Press.

Mey, J. L. (2001) Pragmatics. Oxford: Blackwell Publishers.

Oxford Learner's Dictionary (n.d.). Available from https://www.oxfordlearnersdictionaries.com [Accessed on 4 September 2018]

Recanati, F. (2004) Literal Meaning. Cambridge: Cambridge University Press.

Saeed, J. I. (2003) Semantics. Oxford: Blackwell Publishing.

Sperber, D. and Wilson, D. (1986) Relevance: Communication and Cognition. Oxford: Blackwell. ( $2^{\text {nd }}$ ed.1995)

\section{TEXTS ANALYSED}

Stellman, J. M. and Parish, J. (eds.), (2011) Encyclopaedia of Occupational Health and Safety, Chapter 86. Geneva: International Labour Organization. Available from: http://www.iloencyclopaedia.org/part-xiii-12343/woodworking [Accessed on 9 March 2018].

Jekaterina Čerņevska ( $\mathrm{PhD}$ Candidate, Lecturer) is currently working at the University of Latvia. Her research interests include pragmatics and the use of English in professional discourse. The PhD dissertation discusses the pragmatic meaning construction in mechanical engineering discourse. Email: jekaterina.cernevska@gmail.com 


\title{
ALL WRITERS ARE BORDER WALKERS: EMMA DONOGHUE BETWEEN HISTORY AND FICTION IN ASTRAY AND THE WOMAN WHO GAVE BIRTH TO RABBITS
}

\author{
MILDA DANYTE் \\ Vytautas Magnus University, Lithuania
}

\begin{abstract}
Historical fiction has gained a degree of popularity among readers in the last two decades it has not enjoyed since the fashion for writing novels about national history was set by Sir Walter Scott in the early $19^{\text {th }}$ century. Later in that same century, however, the value of historical fiction as such was challenged by historians who were eager to make history a science; they claimed that academic historical writing provided an objective view of the past based on archival research and was therefore fundamentally superior to historical novels. A devaluation of historical fiction took place which is still felt today. In the context of this opposition of history and fiction, Emma Donoghue's recent historical fiction offers a fresh approach to the genre. The aim of this article, after reviewing the issue of its relationship to history, is to analyze Donoghue's innovative combination of fiction and the archive in two collections of short historical fiction, The Woman Who Gave Birth to Rabbits (2002) and Astray (2012). Donoghue's own reflections on her work are applied in this analysis, as well as the theoretical approach to this kind of fiction by Lubomir Doležel.
\end{abstract}

Key words: history and fiction, historical fiction, Lubomir Doležel, Emma Donoghue's historical fiction, minor and marginal historical figures

\section{INTRODUCTION}

Emma Donoghue has concluded one interview with the evocative statement: 'I suspect writers always feel like border-walkers' (Fantaccini and Grassi, 2011: 406). Among the borders that Emma Donoghue walks, one is that of national identity. In 1998 this Irish writer moved to Canada to join her partner and start a family, finding in Canada, as she has stated, a more tolerant atmosphere for same-sex couples (Swilley, 2004). However, this study focuses more on a different kind of border, that between the fields of history and literature, which Donoghue crosses in a manner very much her own. Internationally she is celebrated for Room (Donoghue, 2010), a psychological novel set in the present, but she is also wellknown for historical fiction that uses a great deal of research to provide a detailed picture of the past. Among this kind of writing, the most formally innovative are her two collections of short historical fiction, The Woman Who Gave Birth to Rabbits (2002) and Astray (2012). 
Donoghue enjoys her dual national identity, just as she enjoys writing what she calls 'hybrid fiction' (Jordan, 2012), historical narratives not quite like any other work in the genre. This analysis begins by looking at historical fiction and the problematic relationship between the historic and the fictional, referring to the recent boom in historical fiction as well as to the hostility which the genre still provokes among literary critics. This context makes it easier to recognize how distinctive Donoghue's method of bringing together the fictional and the historical is in two collections of short historical fiction, The Woman Who Gave Birth to Rabbits (2002) and Astray (2012). These are unusual literary works that merit more critical attention than they have so far received.

\section{ON HISTORICAL FICTION}

Although there are single works that can be given this label earlier, literary history tends to consider Sir Walter Scott (1771-1832) as the founder of the historical novel (see, for example, Lukacs, 1962: 38-39; Baldick, 1991: 99-100; Cuddon 1991: 411). His novels celebrating the national past of Scotland and England created a literary fashion in many European countries, inspiring major novels like those by Alessandro Manzoni, Stendhal, Balzac and Alexandre Dumas, Leo Tolstoy and Henryk Sienkiewicz (Lukacs, 1962: 39-45). Beginning with Scott's Waverley in 1814, these novels re-consider events in the national past that are held to be especially meaningful, whether they are defeats or triumphs. Scott's success came in part from the way in which he deviates from the norms for non-fictional historical writing by giving the major roles in his narratives to fictional characters. As critics explain, his narrative formula is to place an invented character, most often a very ordinary person, alongside historical figures participating in major historical events; this fictional character, with whom readers can identify, transports readers to the past in a way that academic historical texts cannot (Lukacs, 1962: 41; Danyte, 2008: 54-55).

After their period of success in the $19^{\text {th }}$ century, historical novels appeared again as a major literary genre during the period of postmodernism, although in this period writers were more likely to approach the national past ironically. As Linda Hutcheon notes, such novels are more concerned with those who did not fight in national struggles or who appeared on the losing side (Hutcheon, 1989: 51). Nevertheless, although questioning national myths, these novels still use Scott's narrative formula with invented fictional characters serving as protagonists, narrators and focalizers that participate in past events alongside real historical figures. It is in this respect that Donoghue makes a radical change, for instead of centring her narratives around fictional characters, her protagonists are almost always historical figures themselves. However, they are not leading players in events of national significance: some are minor figures in historical events, while others are extremely obscure and even marginal, 'written off', as she explains in the foreword to The Woman Who Gave Birth to Rabbits, 'as cripples, children, half-breeds, freaks and nobodies' (Donoghue, 2002: ix). For example, 
in this collection The Fox on the Line does not direct her readers' attention to Frances Power Cobbe, a $19^{\text {th }}$ century activist in animal rights, but to a much less documented woman, Cobbe's long-time companion, Mary Lloyd, while in Looking for Petronilla she gives equal room to a woman who was known as a powerful witch in $14^{\text {th }}$ century Ireland and to her faithful servant who was burnt at the stake, but about whom nothing beyond her existence is really known.

Furthermore, Donoghue uses a two-part structure that emphasizes how much the text is her own creation, bringing fiction and the archive very close together. First one reads a brief fictionalized narrative about the past, and then what is titled as a 'Note', in which Donoghue as a historian comments on her sources and the gaps in her knowledge. In this Note, which Sarah Crown usefully calls a postscript (Crown, 2012), readers are moved very abruptly from the fictional domain to an academic one. Acknowledgements of sources are not uncommon in many genres of fiction, but in the case of Donoghue's works, the academic text follows, often on the same page, as the final sentences of the fictional story. Where most authors of historical fiction are concerned not to break the illusion of reality by such direct archival references, Donoghue feels there is much to be gained in confronting history and fiction. She calls the long labour of searching through printed and archival sources, 'ten years of sporadic grave-robbing', and concludes cheerfully, 'I have tried to use memory and invention together, like two hands engaged in the same muddy work of digging up the past' (Donoghue, 2002: ix). She also makes her double allegiance evident: 'I'm aware that what I'm doing is simultaneously research and fiction. [...] Plus, ethically, I don't own these cases: I'm drawing on the scholarship of others and the lives of the dead' (Crown, 2012). In her unabashed readiness to bring together two ways of representing the past, academic history and fiction, Donoghue is very unusual in the current controversy about the relationship between the historical novel and works of history.

\section{CONFLICT BETWEEN HISTORY AND HISTORICAL FICTION}

Donoghue's texts have appeared in the context of a boom in historical fiction which has taken place since the late 1990s; lately, in addition to novels, films and television series that fictionalize history have attracted large audiences. In the English-speaking market, for example, the British are prolific producers of both print fiction and filmed historical narratives like the BBC series The Tudors (2007-2008) which are popular beyond the United Kingdom itself. Within Britain, however, these productions are seen not only as entertainment but also as treatments of the national heritage. Literary specialists like Tim Gauthier have argued that these celebrations of the English Renaissance and $19^{\text {th }}$-century imperial history are linked to the widespread feeling known as 'declinism', the difficulties the British have today in accepting the way their country has lost status and power since the mid- $20^{\text {th }}$ century: 'Generally perceived as having 
relinquished its position as a global and economic power, the country reconsiders regretfully its diminished place in the world' (Gauthier, 2006: 3). Gauthier treats such fictionalized history as a desire to compensate for national decline by regaining 'contact with the country's glorious past' (ibid.: 4).

It might be expected that the literary world would welcome any new trend that draws the public to reading novels, yet not all critics are happy with the rise in popularity of historical fiction. Most often this dissatisfaction seems to spring from the belief that, by nature, historical fiction is an inferior genre that cannot be treated like academically elite works. In an article titled 'Can a Historical Novel Also Be Serious Literature?', the American writer Alexander Chee admits that he was made to feel he had broken a 'literary taboo' by moving from fiction set in the present time to historical novels (Chee, 2016). The same is said in an interview, though in sharper terms, by a well-established historical novelist, Philippa Gregory: 'I think it's really funny how the genre is [...] despised by critics'; she enjoys pointing out that now that it has become so very popular, those who earlier labelled it as written by 'rather stupid women writers' find themselves without much to say (Taylor, 2011). Gregory is ironical about how she and other historical novelists have been criticized both for being too historical and not historical enough, with some reviewers complaining that using historical plots shows little imagination and others condemning novelists for interpreting the past too imaginatively (ibid.).

Examples of this elitist approach to the genre of historical fiction can be found even in sources that one would expect to maintain a neutral position like on-line Encyclopaedia Britannica articles. One of these states flatly that many historical novels 'are written to mediocre standards' ('Historical novel', n.d.), while another begins contemptuously: 'for the hack novelist, to whom speedy output is more important than art, thought or originality, history provides ready-made plots and characters' ('Types of novels', n.d.). Furthermore, this second writer asserts, without providing any examples, that 'the technical conservatism of most European historical novels' puts them into a 'second place' category among kind of fiction (ibid.).

In the English-speaking world, these elitist convictions about the relative value of different sub-genres of the novel were shaken when the very prestigious Booker Prize went to Hilary Mantel for historical novels in both 2009 and 2012. Mantel's career shows how views are changing, for in 1979 she was unable to get her first historical novel published and had to turn to writing realistic fiction set in the contemporary period. There was still unease in 2009 when Mantel's Wolf Hall took the Booker Prize away from well-established writers like J. M. Coetzee and A.S. Byatt who are analysed in academic programs (Edemariam, 2009). Even in 2012 the chair of the Booker Prize jury was defensive about its decision, and not only because Mantel was the first British author to win the Booker twice. He later denied that an additional criterion was used by this jury, 'readability', and insisted that a 'rigorous process of literary criticism' was applied; he did admit no vote had been taken and that the decision had not been unanimous, suggesting 
that discomfort with ranking a historical novel as equal to those seen as having greater literary merit has not disappeared (Singh, 2012).

In a broader context, the denigration of the genre of historical fiction can be linked to an on-going attempt by historians to present the writing of history as a social science that is based on strictly factual sources. Trying to raise the status of history to a science is considered to have begun in the $19^{\text {th }}$ century with the demands for a clearly documented presentation of the past by Leopold von Ranke (1795-1886). Ranke propagated scrupulous analysis of multiple archival sources so that an objective historical account could be written (Boldt, 2014). For a time, this attempt to give history a higher intellectual status than literature was successful, but by the later $20^{\text {th }}$ century, specialists in rhetoric and narrative theory had turned their attention to non-fiction texts and undermined the claim that historical writing were fundamentally more objective than historical novels. A leading figure in analyzing the rhetoric of texts, Hayden White, concludes that historical studies have failed to achieve the status of a science; he notes that historians tend to use narrative as a structuring device and so encounter the same problems as historical novelists, 'the problem of the too much and not enough' and of 'what to leave out in their treatment of real events and processes in the past' (White, 2005). Richard Slotkin focuses on the same problem, that of making a choice from available and often conflicting evidence: 'What we call 'history' is $[\ldots]$ a story we choose to tell about things [...] facts must be selected and [...] made to resolve some sort of question which can only be asked subjectively and from a position of hindsight' (Slotkin, 2005). He argues that 'all history writing requires a fictive or imaginary representation of the past', implying that there is no fundamental difference between the work of historians and that of novelists (ibid.). As a historian himself, Slotkin deals with the problems raised by the kind of archival research that Ranke insisted on: 'Anyone who has worked with historical records knows that the documentation of any large, complex human event is never fully adequate or reliable' (ibid.). Moreover, if one moves from trying to establish the facts of a past event to the motives that made people act as they did, 'information becomes even more slippery' (ibid.). He sees the difference between history and literature as merely 'a difference of genre' which predisposes readers to adopt different approaches to what they read (ibid.).

Both he and Richard Carroll see the fundamental goals of history and a historical novel as the same; in Slotkin's words, it is to 'create in the reader a vivid sense of what it may have been like to live among such facts' (Slotkin, 2005; Carroll, 2011). In his review of the conflict between history and fiction, Carroll concludes that these two fields 'are still struggling to clarify a number of core issues', in part because they have not only differences but also similarities (Carroll, 2011). 'Who owns the past?' asks another specialist, Ludmilla Jordanova, raising a sensitive issue especially where the national past is concerned (Jordanova, 2006: 143). Both historians and writers of historical novels act like owners of the past, shaping their texts to convince readers that their interpretation is correct. 
What is interesting about Emma Donoghue's attitude to her work is that, in comparison with writers like Alexander Chee or even Philippa Gregory, she is neither troubled nor defensive. She locates herself as both a writer of fiction and a historian, not feeling any contradiction between the two roles. As the former, she needs to entertain readers: 'I'd never start with the facts $[. .$.$] that would$ be too much like a history lesson' (Crown, 2012). As a historian, she finds it imperative to include her sources in a postscript: 'But I had to put them in' (ibid.). Donoghue does not ignore the duality of historical fiction and historical study; she puts them side by side in her work, believing that her readers are sophisticated enough to enjoy the movement between the two fields.

\section{LUBOMIR DOLEŽEL ON ANALYSING HISTORICAL FICTION}

One of the most useful approaches to the analysis of historical fiction has been developed by Lubomir Doležel, writing within the context of possible worlds theory. He states that historical fiction creates worlds that have a 'dyadic structure', 'two domains that are clearly distinguishable by their different relationships to the actual world of the past' (Doležel, 2010: 84). One domain is that of elements in the narrative like characters, events, settings and cultural contexts 'that do not have counterparts in the actual past', calling these 'fictional entities', while the second includes those elements that 'have counterparts' in the historic past, 'fictionalized entities'. Despite this distinction, Doležel emphasizes that when any entities, especially characters, enter fictional worlds, all of them 'have to change into the fictional possible', a 'general transformation' (Doležel, 2010: 85). In this way, he explains that 'in the realm of fiction, historical fact is a construct', which makes it easy for writers to combine history and fiction (ibid.: 87). Finally, he asserts that it is the right of the creator of historical fiction to make decisions: this writer 'gathers as much historical knowledge as he or she wishes and transforms it in ways that correspond to the general order of the world under construction' (ibid.: 85) In this way writers of historical fiction, in Doležel's terms, produce a confrontation between history and fiction within a single text.

What is happening in Donoghue's short historical narratives becomes clearer when Doležel's theory is applied to her stories. A good example is The Last Rabbit, the text that opens and gives a title to the first collection, The Woman Who Gave Birth to Rabbits. This begins with the first-person narrator, Mary Toft, deciding to play a joke on her husband by pretending to give birth to a rabbit: 'We were at home in Godalming, though some call it Godlyman, and I can't tell which is right, I say it the same way my mother said it. I was pregnant again, and cutting up a rabbit for our dinner, I don't know what sort of whim took hold of me to give a scare to my husband' (Donoghue, 2002: 1). Encouraged by others, she becomes involved in a scheme to make money from a gullible public by apparently giving birth to rabbits. The story ends when she realizes she will have to admit the truth 
to an investigator: 'So I turned and walked back to the room where Sir Richard was waiting for my story’ (ibid.:13).

Then comes the postscript, which gives the historical evidence for Mary Toft's life; Donoghue writes: 'For “The Last Rabbit", which was inspired by William Hogarth's famous engraving of Mary Toft (1703-63) giving birth, I have drawn on many contradictory medical treatises, witness statements, pamphlets and poems' (ibid.:14). She goes on to name five of them. The postscript concludes with what is known about Mary's life after she spent a few months in jail for the hoax: 'Back in Godalming with her husband, Mary had another baby in 1728 [...] and was occasionally shown off as a novelty at local dinners [...] she lived to the age of sixty' (ibid.). Stylistically, the fictional domain is narrated in Mary's relaxed and colloquial style, while the historical domain has a more academic style with an abundance of dates and the specific titles of the pamphlets and poems which are Donoghue's sources.

According to Doležel's distinction, the first part, the story, combines fictional and fictionalizing entities: in one sense, Mary Toft is a 'fictionalizing entity' with a real counterpart in $18^{\text {th }}$-century English history, while the character who reflects on what happens, along with the whole of the opening scene are 'fictional entities' invented by the writer. The postscript emphasizes Mary Toft's historical status, with the information about her later life making her historicity credible. Yet most of the story must be fictional, as very little precise information about Toft's actions, let alone her feelings, has survived, and even this, as Donoghue states, is 'contradictory' (ibid.).

\section{DISTINCTIVE CHARACTERISTICS OF DONOGHUE'S SHORT HISTORICAL FICTION}

One of the features of her narratives that heightens the apparent reality of her characters is the abrupt way that many of her stories begin. There are no lengthy introductory descriptions of time or place to warn the readers that they are entering a world of the distant past. In the second collection, Astray, Donoghue does precede each story with an identification of where and when it takes place, while in the earlier collection, there is not even this. Instead, the fictional texts plunge readers into the historic past in a kind of baptism through immersion, with the shock of hearing a distinctive voice that in its diction and cadences is not that of the $21^{\text {st }}$ century. Readers have to make an effort to identify the historical period through occasional brief references, which is more difficult because the stories in each collection are not given in any kind of chronological order. Nevertheless, they are encouraged to make this effort by Donoghue's skill in beginning her stories in dramatic ways. One reviewer comments on the startling energy these obscure figures demonstrate, emphasizing how the 'people of these tales come hurtling off the page from the deep past with the emotional force of the newly awakened dead' (Brown). For example, Last Supper at Brown's, which 
relates how an African-American slave poisons his master and runs off with his master's wife, opens like this: 'Before the War there's two women in the house but last year Marse done took them to auction. Now's just me, the cook and all-round boy. My name Nigger Brown, I don't got no other, I was born here' (Donoghue, 2012: 65). The young African American addresses the readers abruptly as though they already understand his situation and the historical context from which he speaks. Readers can pick up clues, combining references to 'the War', people sold at auction and the casual use of the term 'nigger' to guess that the action takes place during the American Civil War, in a southern part of the United States where slavery still exists.

In another case, that of a girl whose mother was an African slave made mistress to a British aristocrat, the speech patterns are completely different because she has been brought up in the upper class. Nevertheless, the effect of the opening sentences is also surprisingly direct: 'I was in the Orangery at Kenwood that June morning, picking plums and grapes. I knew nothing. My name was Dido Bell' (Donoghue, 2002: 170). The second and third very short sentences sound taut with emotion: Dido is describing the day that she comes to a brutal understanding of her true status in a racist society.

In the postscripts to these stories, Donoghue explains that 'Nigger Brown', as he is called, survived historical oblivion only as a single entry in a newspaper of his time (Donoghue 2012: 72). Dido Bell was both more celebrated and more elusive. Donoghue refers to the evidence of her father's and great-uncle's wills to show that she was loved and provided for, but admits that everything else in her story is a series of probabilities, not hard facts: she was probably the young black woman painted by Johan Zoffany in a remarkable portrait of the period, allegedly showing her with her white-skinned cousin; she was probably the reason that her great-uncle, in a famous legal judgement, took a step towards making slavery illegal in Britain (Donoghue 2002: 183).

At least Dido exists in many sources, while some of Donoghue's most vivid characters are known only through a single sentence they spoke. There is Minnie Hall in Daddy's Girl, whose father, a pillar of the Democratic Party in New York City, died in 1901, and was then discovered to have been a woman. Minnie refuses to acknowledge his biological condition in public, snapping at the judge, 'I will never say she' (Donoghue, 2012: 239). In The Necessity of Burning in 1381, when the Peasants' Revolt saw hundreds of hand-written manuscripts set ablaze in the streets of Cambridge, Margery Starre, further identified only as an 'old woman', enthusiastically pitched volumes into the flames, shouting: 'Away with the learning of the clerics, away with it!' (Donoghue 2002: 198). Minnie's and Margery's declarations are documented historical facts, but Donoghue creates their personalities, fills in earlier events and provides motivation for their actions.

Donoghue explains her evident interest in marginal historical figures through two formative events in her personal life. One was preparing her doctoral thesis at Cambridge University on the concept of friendship between men and women in 
the $18^{\text {th }}$ century. This work was part of a new movement to make women a central subject in historical research, something that made her feel it was legitimate to go beyond monarchs and politicians: 'Looking through history for the women also led to the Other: the slave, the witch, the whore, the freak, the poor, the criminal, the victim, the disenfranchised, the child, the migrant' (Palko, 2017). She also links her interest in the marginal through her uncomfortable awakening to her homosexuality: 'I grew up in Dublin [...] Pretty much everyone I knew was white, had two Irish parents, and was a practicing Catholic. I had no objection at all to this until, at about fourteen, I realized I was a lesbian, and therefore, in my society's terms, a freak' (Fantaccini and Grassi, 2011: 400). She calls this 'the trickiest border I've ever crossed [...] I wasn't bothered by religious guilt, only social shame; I found it hard to accept being socially abnormal' (ibid.: 401). She refers in more than one interview to the determining nature of this experience. It was this 'moment of alienation' that she feels 'turned me into a writer': 'I've remained fascinated by the things that make us feel at home, or out of place, or even monstrous' (Palko, 2017). In another interview she states: 'This theme not just homosexuality but the clash between individual and community, norm and 'other' - has marked many of my published works' (Fantaccini and Grassi, 2011: 400). Then, in a characteristically ironic comment, she concludes: 'to know yourself to be the Other is very educational' (ibid.: 402).

In her historical fiction Donoghue writes about men, women and children who were not leading figures in their own societies, but who acted out some form of difference. She is interested in same-sex unions, fictionalizing some that may or may not have been consciously homosexual. For example, in the first collection, The Woman Who Gave Birth to Rabbits, there are Mary Lloyd and Frances Power Cobbe, trying to pass a law against animal vivisection in Victorian England (The Fox on the Line), while in Astray readers encounter the Americans Frances Loring and Florence Wyle, who led a successful career as sculptors in Canada (What Remains). In general, she is fascinated by those who go against the norms of their society. There are a great variety of eccentric figures from the past in her stories, like Elspeth Buchan who as the charismatic 'Friend Mother' led a suicidal religious sect in Scotland in the late $18^{\text {th }}$ century (Revelations in The Woman Who Gave Birth to Rabbits) and Mollie Sanger in The Long Way Home in Astray) who, dressed in men's clothing, successfully worked for many years as a prospector in mid-1 $19^{\text {th }}$ century Arizona.

In other cases, she is attracted to fragmentary historical records, accounts of people's lives which she can complete through fiction. As she puts it, many of these stories 'are woven around the known facts, and could be considered history as well as fiction, especially as my source notes are included, to insist on the reality of the stories' (Swilley, 2004). In her first collection she sensitively develops what a blind poet's childhood must have been like in Night Vision; in the second, her story The Gift supplements letters that have survived about $19^{\text {th }}$-century American adoptions, depicting a man who refuses to give up the child he and his wife had adopted despite later claims by the birth mother. 
Donoghue's postscripts also vary and do more than provide a list of sources. Historical novelists often receive criticism from reviewers and readers about what are perceived as factual inaccuracies, but Donoghue's protagonists are mostly so obscure that readers make their way through her narratives without any sense of which details are historical and which invented. Reading the postscripts then provides a new kind of pleasure; the readers have identified with the main characters and inevitably want to know more precisely what their later lives were like. The story Salvage in The Woman Who Gave Birth to Rabbits describes two cousins known as the 'Cottage Ladies' directing attempts to save sailors drowning on their shore. One may believe that their lives in the early $19^{\text {th }}$ century would have been very limited by gender norms, especially given that one of them, Anna, can move about only in a wheelchair. It is refreshing to find out in the postscript that Anna was a noted Anglo-Saxon scholar and, as the last sentence lists triumphantly, the two 'acted as their relative Fowell Buxton's secretaries in his long campaign to end the slave trade, founded a school, travelled to Rome and Athens, and were finally buried together in the seaside graveyard at Overstrand' (Donoghue, 2002: 105). Another variety of story leads readers to sympathize with those who broke laws; in such cases, they may be relieved in reading postscript that, for example, Margery Starre in The Necessity of Burning, who participated in the Peasants' Revolt of 1381 at least does not figure in the lists that Donoghue's research turned up of those imprisoned or executed (Donoghue, 2002: 199). Similarly, the postscript to Last Supper at Brown's reassures readers that the African American slave and his white mistress who murder her husband seem to have escaped punishment. After his dramatic escape from being re-sold by his master, any possible romance seems to have ended: he apparently took up with a Mexican woman, while she married a man with whom she 'ran a boardinghouse, then worked mining claims and set up a goat ranch', rather a mundane conclusion to their story (Donoghue, 2012: 72).

However, among so many sympathetic and even celebratory accounts of those who deviated from social norms, the postscript to The Long Way Home in Astray shows that society could be unexpectedly harsh on rebels against norms like the swaggering prospector Mollie. After depicting her forcing a man who has abandoned his family to return to them, in the historical postscript Donoghue decides this story is possibly true but adds that three years later 'she was the first woman in Arizona committed for insanity, which probably translates as crossdressing, promiscuity and alcoholism'. After twelve years in an asylum Mollie escaped but was tracked down trying to survive in the desert 'on one bottle of water and a few crackers'; she spent her remaining years back in the insane asylum (ibid.:122). In this way contemporary readers, who have become accustomed by previous stories in the collections about strong women successfully breaking norms, are brought up suddenly and even brutally with the reality of women's unequal status in an earlier historical period.

Only in one case, How a Lady Dies in The Woman Who Gave Birth to Rabbits does Donoghue use the historical postscript to extend the narrative she has focused on in her story. It is the $18^{\text {th }}$ century: Frances Sheridan is a mother and 
the middle-aged wife of a theatre director, but she leaves husband and children temporarily to take her beloved friend Elizabeth, younger, wealthier and dying of tuberculosis, for treatment to Bath. Elizabeth toys with the idea that death will be welcome but is shocked when she coughs up blood and determines to make the most of her remaining days. The fictional story ends at this point in her life, but the postscript, after referring to historical sources, ends with an additional detail about the pair of women: 'On their return from Bath to London, Elizabeth died in Frances's arms' (Donoghue, 2002: 162). The sentence concludes this historical narrative as high romance. However, this kind of extension of the emotional narrative is a single example, as in all other postscripts the tone is much cooler and more academic.

\section{CONCLUSION}

In the present context of conflicting opinions about the value of historical fiction and its relationship with history as an academic discipline, Emma Donoghue's declarations on the subject are refreshingly confident. She feels no guilt about her use of the historic past. 'To me all of history is a kind of warehouse of stories for me to burgle. I don't feel I should be restricted to my own era,' she states in one interview (Richards, 2008). Nor does she apologize for her manipulations of past events or the way she plays with her readers' feelings. She sees herself as rescuing the minor and the marginal for a new life as literary characters: 'to me what feels good is to give these characters subjectivity, agency, a chance to rule the page even if I can't always grant them happy endings' (Palko, 2017). In her hands this kind of fictional narrative does not deny the limits that people's sex, race, class or physical disabilities set on their lives. Her historical fiction does not erase pain or reverse the defeats which they experienced in the past. However, it does give them a kind of power over the past: 'That's a second life you're granting a longdead person in fiction: a chance to show what they're made of, strut their stuff, have their say' (ibid.). She selects for her stories people that academic historians might include, if they did at all, in statistical reports or footnotes to the main narrative. In this way Emma Donoghue moves away from the dominant tradition in the writing of both history and historical fiction, the analysis and celebration of major events and figures from the national past. She does not deny the value of those texts that take a more traditional approach, but her sympathies are with those 'whose lives exist as only minor, almost anonymous footnotes in history's back drawer' (Brown, 2002). In comparison to critics who find historical fiction in general trivial or un-historic, she sees it in a very different way: 'yes, trying to write the past into life will always be in some sense an impossible task, but I find it a thrilling and even rather heroic one' ('Emma Donoghue and Laird Hunt on writing historical women', 2016). Her historical fiction defies the traditional principles of the genre developed by Walter Scott and his followers as well as those critics who see history and fiction as hostile to each other rather than neighbouring genres. 


\section{REFERENCES}

Baldick, C. (1991) The Oxford Concise Dictionary of Literary Terms. Oxford: Oxford University Press.

Boldt, A. (2014) Ranke: objectivity and history. The Online Journal of Theory and Practice 18 (4). Available from www.tandfonline.com/doi/cull/ [Accessed on 29 September 2018].

Brown, C. (2002) Cabinet of wonder. The Washington Post, 19 May. Available from https://www.washingtonpost.com/archive/entertainment/books/cabinet/ [Accessed on 8 June 2018].

Carroll, R. (2011) The trouble with history and fiction. M/C Journal 14 (3). Available from https://journal.media_culture.org.au/index.php/mcjournalarticle/view1372 [Accessed on 13 June 2018].

Chee, A. (2016) Can a historical novel also be serious literature? The New Republic, 3 February. Available from https://newrepublic.com/article/128877 [Accessed on13 June 2018].

Crown, S. (2012) Emma Donoghue: the book interview. The Guardian, 19 October. Available from https://www.theguardian.com/books/2012/ [Accessed on 16 February 2018].

Cuddon, J. A. (1992) The Penguin Dictionary of Literary Terms and Literary Theory. $3^{\text {rd }}$ ed. London: Penguin Books.

Danyte, M. (2008) National past/personal past: recent examples of the historical novel by Umberto Eco and Antanas Sileika. In R. Rudaitytè (ed.) Postmodernism and After: Visions and Revisions (pp.54-64). Newcastle: Cambridge Scholars Publishing.

Doležel, L. (2010) Possible Worlds of Fiction and History: The Postmodern Stage. Baltimore: The Johns Hopkins University Press.

Donoghue, E. (2002) The Woman Who Gave Birth to Rabbits. London: Virago Press.

Donoghue, E. (2012) Astray. London: Picador.

Edemariam, A. (2009) Interview with Hilary Mantel. The Guardian, 12 September. Available from https://www.theguardian.com/2009/sept/12 [Accessed on 13 June 2018].

Emma Donoghue and Laird Hunt on writing historical women (2016) Literary Hub. Available from https://lithub.com/ [Accessed on 21 April 2018].

Fantaccini, F. and Grassi, S. (2011) Emma in borderlands: Q\&A with Emma Donoghue. Studi Irlandesi: A Journal of Irish Studies 1(1): 397-406. Available from www. fupress.com/fsfm_sijis [Accessed on 8 June 2018].

Gauthier, T. (2006) Narrative Desire and Historical Reparations: A. S. Byatt, Ian McEwan, Salman Rushdie. New York and London: Routledge.

Historical novels (n.d.) Encyclopaedia Britannica. Available from https://www. britannica.com/art/historical-novel [Accessed on 13 June 2018].

Hutcheon, L. (1989) The Politics of Postmodernism. London and New York: Routledge. Jordan, J. (2012) Astray by Emma Donoghue: review. The Guardian, 9 November. Available from www.theguardian.com/books/2012/nov/09 [Accessed on 12 June 2018].

Jordanova, L. (2006) History in Practice, $2^{\text {nd }}$ ed. London: Hodder Arnold.

Lukacs, G. (1962) The Historical Novel (trans. H. Mitchell and S. Mitchell). London: Merlin.

Palko, A. (2017) Emma Donoghue in conversation with Abby Palko. Breac: A Digital Journal of Irish Studies, 17 July. Available from https://breac.nd.edu/ [Accessed on 8 June 2018]. 
Richards, L. (2008) January interview: Emma Donoghue. January Magazine. Available from www.januarymagazine.com/profiles/donoghue.html [Accessed on 6 June 2018].

Singh, A. (2012) Hilary Mantel wins Man Booker Prize for a record second time. The Telegraph 16 October. Available from https://www.telegraphy.co.uk/culture/ books/booker-prize/9613496 [Accessed on 2 June 2018].

Slotkin, R. (2005) Fiction for the purpose of history. Rethinking History: The Journal of Theory and Practice 9 (2-3): 147-157. Available from https://www.tandfonline. $\mathrm{com} / \mathrm{doi} /$ full/10.1080 [Accessed on 4 June 2018].

Swilley, S. (2004) Dangerous liaisons: interview with Emma Donoghue. Book Page, October. Available from https://bookpage.com/interviews/8275 [Accessed on 2 June 2018].

Taylor, K. (2011) Truth, lies and historical fiction: how far can an author go? The Globe and Mail. Available from https://www.theglobeandmail.com/arts/books-andmedia/ [Accessed on 13 June 2018].

Types of novels (n.d.) Encyclopaedia Britannica. Available from https://www.britannica. com/art/historical-novel [Accessed on 13 June 2018].

White, H. (2005) Introduction: historical fiction, fictional history and historical reality. Rethinking History: The Journal of Theory and Practice 9 (2-3): 6-24. Available from https://www.tandfonline.com/doi/full/10.1080 [Accessed on 4 June 2018].

Milda Danytė (PhD, Prof. in English Philology) has been teaching at Vytautas Magnus University since 1990. Her research covers two parallel fields, Lithuanian immigrant history and literary criticism, especially narrative studies. Email:milda.danyte@vdu.lt 


\title{
DEVELOPING PEER CORRECTIVE SKILLS IN BUSINESS LETTER WRITING IN ENGLISH AS A FOREIGN LANGUAGE
}

\author{
MONTA FARNESTE \\ University of Latvia, Latvia
}

\section{OLGA PAŠINSKA}

The Red Cross Medical College of Riga Stradiņš University, Latvia

\begin{abstract}
Peer corrective feedback (PCF) implementation is a topical issue in writing skills development at tertiary level. Those researchers who explore the application of PCF in higher education (e.g. Liu and Sadler, 2003; Hyland, K. and Hyland, F., 2006) admit that students face difficulties in providing qualitative feedback that determines the effectiveness of this teaching tool. Therefore, the goal of this paper was to investigate what actions could be taken in order to develop students' PCF skills and, consequently, foster the quality of PCF. The primary research method was a case study in which the participants were 24 second-year undergraduates majoring in English as a Foreign Language (EFL) at a university in Latvia. The materials of the case study involve the genre of a business letter, which plays a vital role in people's professional and everyday life. The results of the research revealed that providing students with an assessment scale and teaching how to apply it increase the quality of PCF.
\end{abstract}

Key words: peer corrective feedback, feedback quality, writing skills, undergraduates, EFL case study

\section{INTRODUCTION}

In the process of language acquisition, an error is an unavoidable and temporary 'simplified or distorted representation of the target competence', which appears due to 'failure to learn', 'inefficient teaching' as well as students' desire to communicate in the target language (Council of Europe, 2001: 155). According to the Common European Framework of Reference for Languages, advanced students of a foreign language are expected to be competent in spotting errors and assessing their written output 'on a complex academic or professional topic' 'within his/her field of interests' (Council of Europe, 2017: 76). In order to become competent in these tasks, peer-corrections, which include analysis and explanations, could be regularly implemented during English as a Foreign Language (EFL) classes (Council of Europe, 2001: 155).

With the aim to ensure assessment skills development, Peer Corrective Feedback (PCF) has been used in the classes of EFL since the 1980s (Chang, 
2016: 82), and even now lively discussions about its effectiveness take place. It is emphasized that PCF, as a teaching tool, could be implemented during classes, due to its aid not only in developing one's writing skills, but also in contributing to other skills of great importance in the $21^{\text {st }}$ century, namely, in helping students to develop critical thinking (Rollinson, 2005: 29), promoting learner autonomy and responsibility (Maas, 2017: 128) as well as collegial ties (Nassaji and Kartchava, 2017: 66).

Fiona Hyland (2000: 50-52) points out that students face difficulties when they are asked to detect errors and provide qualitative feedback on each others' texts. Those researchers who investigate the disadvantages of PCF admit that when a text is given for peer editing, students 'tend to deal primarily with surface errors' (Leki, 1990: 9), such as grammar, spelling, vocabulary and punctuation (Farneste, 2005: 31). It is challenging for them to provide feedback to global aspects of a text, such as 'content, organization, and idea development', and, as a result, they comment papers quite ambiguously (Liu and Sadler, 2003: 194). Moreover, they are unable to provide appropriate (Amores, 1997), comprehensive and helpful feedback (Leki, 1990: 9), differentiate valid and invalid peer feedback as well as identify text's 'strengths and weaknesses' (Tsui and Ng, 2000: 168). One of the reasons for the above-mentioned student actions is their unpreparedness to provide PCF. The findings of Berg (1999) and Min (2005) show that prepared and trained students produce significantly more relevant, specific and meaningbased comments and suggestions and, thus, can be considered to be more qualitative (discussed in Hyland, K. and Hyland, F., 2006: 85). Thus, the goal of the present paper is to investigate what could be undertaken to develop students' PCF skills and, therefore, promote the quality of PCF. In order to reach the goal, two research questions have been formulated:

1. How does the application of the assessment scale influence the quality of PCF by student writers?

2. What tasks could be used to develop student writers' PCF skills?

\section{THE NOTION OF QUALITATIVE PEER CORRECTIVE FEEDBACK}

Liu and Hansen (2002: 1) define peer feedback as 'the use of learners as sources of information and interactants for each other in such a way that learners assume roles and responsibilities [...] in commenting on and critiquing each other's drafts in both written and oral formats in the process of writing. Corrective feedback, including the peer one, can be considered as qualitative if it

1) helps to clarify what good performance is (goals, criteria, expected standards);

2) facilitates the development of self-assessment (reflection) in learning;

3) delivers high quality information to students about their learning; 
4) encourages teacher and peer dialogue around learning;

5) encourages positive motivational beliefs and self-esteem;

6) provides opportunities to close the gap between current and desired performance;

7) provides information to teachers that can be used to help shape teaching. (Nicol and MacFarlane-Dick, 2006: 205).

There are different perspectives on the quality of PCF. One of the perspectives defines PCF in terms of accuracy and consistency (Gielen et al., 2010: 306). In this case quality criteria are the number of errors detected from the total number of errors', 'the number of errors accurately and completely corrected and justified out of the total number of errors' as well as 'a holistic score for the correctness, exhaustiveness and explicitness of peer comments' (ibid.). Another perspective is defined in terms of content and/or style of a piece of writing (ibid.). It implies that the more students focus on content and style characteristics, the more qualitative PCF.

Sluijsmans, Brand-Gruwel and van Merriënboer (2002) combined those two perspectives and considered PCF quality in terms of accuracy and consistency, as well as in terms of content and style. In order to analyse the quality of the feedback provided by students, they suggest the rating form which includes seven variables:

1) use of criteria;

2) positive comments;

3) negative comments;

4) constructive comments;

5) posed questions;

6) naive word use;

7) structure (Sluijsmans et al., 2002: 446).

The first variable, called 'use of criteria', deals with the students' adherence to a specific assessment scale proposed by a teacher to learners before starting revision.

As the focus of the present research is on a business letter as a genre, a business letter assessment scale offered by Cambridge English Language Assessment was chosen for the present study (see Table 1 in Appendix 1). It is used for assessing candidates' business letters who take the international examination Business English Certificates. The criteria in the assessment scale draw students' attention to such aspects as 'content', 'communicative achievement', 'organisation' and 'language', providing them a detailed description of the aspects (Cambridge English Language Assessment, 2016: 3).

Four other variables proposed by Sluijsmans et al. (2002) are related to the presence of additional information to peers from which they can benefit and improve works, namely, 'positive comments', 'negative comments', 'constructive comments' and 'posed questions'. 
When one provides additional information to a peer, they can appeal to correction codes, for example, the ones proposed by Vyatkina (2011: 73) for a better understanding of the nature of an error (see Table 1).

Table 1 Correction codes (Vyatkina, 2011: 73)

\begin{tabular}{|l|l|}
\hline Correction codes & Meaning \\
\hline C & content \\
\hline SO $(\mathrm{T})$ & structural organization (text level) \\
\hline SO $(\mathrm{S})$ & structural organization (sentence level) \\
\hline GA & grammatical accuracy \\
\hline LA & lexical appropriateness \\
\hline P & punctuation \\
\hline S & spelling \\
\hline
\end{tabular}

According to Hyland, correction codes enable a reviewer 'to provide implicit feedback and reduce negative and disheartening effects of indicating writing errors without reducing the effects of error correction' (Hyland, 1998, discussed in Azizi et al., 2014: 56). The variable 'structure' implies the assessment of peer's performance in general, which means that a reviewer is expected to summarise their feedback in the form of points and/or comments.

By the variable 'naïve word use', Sluijsmans et al. (2002) understand the proper formulation of comments, questions and a summary of corrective feedback. It implies that comments, questions and/or a summary are clear, concise and at the same time comprehensive (ibid.).

As the quality of corrective feedback is the most important criterion in determining how much writers can benefit from peer work (Sackstein, 2017: 65), it is suggested that students should be prepared for it (Hyland, K. and Hyland, F., 2006: 91). First, students should be provided guidelines for revision (Grabe and Kaplan, 1996: 387), e.g. an assessment scale, so that they would be aware of what they should look for and understand how to comment. Further, PCF is to be modelled (Hyland, 2003: 203).

In addition, constant practice, which is controlled by a teacher, is significant for qualitative PCF (Grabe and Kaplan, 1996: 387; Hyland, 2003: 203). According to Andrade and Evans (2013: 116), students are 'unaccustomed to evaluating each other's academic performance or even their own performance'. Therefore, training is needed not only to train students to edit and assess peers' works, but also to change students' negative attitude to PCF which may appear due to the reason that they do not know how to use their present knowledge (Farneste, 2005: 23) and/or 'lack confidence in their abilities' (Andrade and Evans, 2013: 116). Students' reluctance to assess peers also influences the quality of PCF. Reluctance appears due to the negative influence that peer assessment may have on interpersonal relationships, e.g. 'break up relationships between 
friends' and 'aggravate animosity between the students who are not on good terms with each other' (Mahmoud, 2012: 1989). Practice is essential to give students the necessary training in order to teach them to detect errors in a letter written by a person they do not know, without worrying about offending a peer and/or being offended.

\section{METHOD}

In order to investigate the ways to influence writers' PCF quality, 24 secondyear undergraduates majoring in English at a university in Latvia were chosen for the current case study. Six classes of ninety minutes duration were allocated to teaching business English correspondence, namely complaint, recommendation and enquiry letters, and developing students' PCF skills.

The procedure of the present research had the following steps:

1) First, the analysis of the responses in the pre-questionnaire (see Appendix 3 ), which included two questionnaire items about the writing aspects to which the students pay their attention to when revising peers' papers and the reasons for students' resistance to provide feedback to peers, was carried out and analysed.

2) Further, a pre-test was used to identify the students' ability to provide PCF on one of the types of a business letter, namely a complaint letter. The pre-test results were analysed, and the gaps in peer-editing were identified, in order to trace the changes in students' PCF quality after they had been introduced to a business letter assessment scale and corrective codes.

3) After the identification of the problems the students face in peer-editing, they were introduced to a business letter assessment scale by Cambridge English Language Assessment (2016) and correction codes by Vyatkina (2011). The students were asked to apply these criteria when doing the tasks discussed below.

4) During the research the students were offered different tasks aimed to develop PCF skills, e.g. to modify a letter's tone and/or style, adjusting them to the proper ones (see Task 1 in Appendix 2); to revise a letter consisting of the errors of various types (see Task 2 in Appendix 2); to compare letters (see Stephens, 2005: 9); to provide corrective feedback to a business letter and evaluate it (see Task 3 in Appendix 2). When doing the tasks, the students were asked to provide implicit comments in order give them an impetus to discover errors themselves and thus avoid them in further papers. The tasks were implemented to give the students the possibility of practicing error detection and of assessing business letters; as well as they offered an opportunity to explain to them that PCF is just a part of the learning process, and corrections and comments should not be taken personally. 
5) Then, the adapted assessment model proposed by Sluijsmans et al. (2002) was used to analyse the quality of PCF (see Table 1). In this study, the section 'use of criteria' was not included in the table, as it was not clear whether the students adhered to a particular assessment scale when assessing business letters. Special attention was devoted to whether the students added various comments, including the positive, negative and constructive ones, as well as whether they posed questions to the writer. It was explored whether the comments and questions were clearly formulated and could be easily understood by the receiver of PCF. In addition to this, the inclusion or exclusion of a summary in the provided feedback was examined.

6) The analysis of 71 samples of students' feedback, gathered from 24 research participants, was carried out.

7) Finally, a post-questionnaire, which included three questionnaire items about the writing aspects to which the students began to pay their attention after being taught the genre peculiarities, the changes of their attitude to PCF after the present research as well as students' opinions concerning the effectiveness of the proposed tasks, was administered (see Appendix 3 ).

\section{RESULTS AND DISCUSSION}

This section presents the results of the analysis of 71 samples of students' feedback as well as their responses provided in the pre- and post-questionnaires.

\section{THE IMPACT OF ASSESSMENT SCALE APPLICATION}

In the present subsection the changes in the research participants' PCF quality are presented, as one of the research questions was to find out how the application of a business letter assessment scale influences the quality of PCF. The discussion includes the analysis of the students' feedback provided on the complaint letters, which were used as a pre-test in the present study, then followed the analysis of the recommendation and enquiry letters. Particular attention was devoted to the inclusion of different types of comments, summaries as well as their clear formulation. The results of the changes in PCF quality on three business letters are displayed in Table 2.

Table 2 Changes in PCF quality

\begin{tabular}{|l|c|c|c|}
\hline Letter & $\begin{array}{c}\text { Relevant positive/negative/ } \\
\text { constructive comments / } \\
\text { posed questions (\%) }\end{array}$ & $\begin{array}{c}\text { Summary (e.g. } \\
\text { in a form of } \\
\text { a table) (\%) }\end{array}$ & $\begin{array}{c}\text { Proper formulation } \\
\text { of comments and } \\
\text { summaries (\%) }\end{array}$ \\
\hline Complaint (pre-test) & 79 & 4 & 79 \\
\hline Recommendation & 71 & 71 & 67 \\
\hline Enquiry & 71 & 96 & 67 \\
\hline
\end{tabular}


The students' ability to provide PCF were tested by giving them a possibility to write a letter of complaint. With regard to the presence of positive, negative and/or constructive comments as well as questions posed, 79 per cent of the students added at least one comment providing feedback to the complaint letters, which was the pre-test. However, it was noticed that the research participants did not manage to identify all errors present in the peers' papers.

As to the inclusion of a summary of feedback on a peer-edited letter, 92 per cent of the research participants did not reveal the general impression about the complaint letters they reviewed. There was only one student who provided a summary: 'You should mention some additional information of the product. [...] I think your letter should have a better structure. [...] I think you used a word 'your' too much. [...]'

The comments of 79 per cent of the research participants were formulated in an understandable way, as their receivers took them into consideration when revising their papers. For example, the peers used such comments as 'This phrase is usually used with a "with", rather than "of", 'I think "yours sincerely" would be more appropriate' and 'Repetition of "with". Seventeen per cent of the peers did not provide any comments, but just coded errors, and remaining 4 per cent (one student) did not provide any feedback to their peer at all.

Concerning the PCF provided on the recommendation letters, the analysis of different types of comments and questions in them shows that 71 per cent of the research participants provided comments, e.g. 'GA (capital letters, check other places, too)', 'SO: The structure of this sentence sounds a bit awkward.' and 'LA (try using more cohesive devices)'. It is 8 per cent less in comparison with the PCF provided on the complaint letters, when the students were unaware of the above-mentioned scale and codes. It was established that the students identified more errors in comparison to a complaint letter; however, they did not comment on all of them but just coded them.

As students were asked to provide a summary of their feedback on a recommendation letter in the form of a table, 71 per cent of the students did it, so that a receiver could understand what the reviewer's general impression was. Some of the students just allocated points for three aspects, while others, being asked, explained the number of points they gave. The following is an example of a summary provided by one of the students:

'Content and communicative achievement: 3 points. Everything is done very well. [...]', 'Organisation: 3 points. Every paragraph has its own function. Different transitional words are used. [...]' [and] 'Language: 3 points. Formal vocabulary (for instance), as well as simple sentence construction, which is needed in a business letter. [...]'

As far as the formulation of the comments is concerned, 67 per cent of the participants did it comprehensively. Four per cent of them, however, did it vaguely, which means that it was difficult for the students to understand what 
a problem in this or that aspect was. Twenty-nine per cent did not add any remarks and suggestions.

Regarding the third letter, i.e. a letter of enquiry, 71 per cent of the students provided comments, but 29 per cent of them - did not. The quantity of the identified errors increased. The following is an example from the commentaries of one of the students:

'SO (T). Think about the order of the information of the sender and recipient.', 'C: Maybe try a different approach in this paragraph, at least in the first half. Because it sounds like you are making demands, not requests.' [and] 'LA, maybe choose an expression of a higher register.'

Ninety-six per cent of the peers included a summary at the end of the text commenting on all three writing aspects of an enquiry letter. The following is the summary by one of the research participants:

'Content and communicative achievement: 3 points. You fully explain your situation. An alternative is present. Reason is explained.', 'Structure: 3 points. The text was organized just fine with a coherent organization' [and] 'Language: 1 point. There were a few grammatical errors and other things that can be improved upon like selection of words.'

It was seen that 67 of peers formulated their comments and summaries understandably for their receivers as they were considered. The remarks of 8 per cent of the participants were vague. Twenty-five per cent did not support their feedback with judgements and used only correction codes.

\section{THE IMPACT OF TASKS}

One of the research questions was to identify what types of tasks could be used to develop the participants' PCF skills. Such tasks as modification letter's tone and/or style, revision of a business letter consisting of the errors of various types, comparison of business letters, and provision of corrective feedback to a business letter and its evaluation helped to develop students' PCF skills, namely to teach them to detect errors, formulate comments clearly, summarize their ideas about a paper and differentiate qualitative and not qualitative papers as well as valid and invalid feedback. The above-mentioned conclusions were drawn after the analysis of the responses in the pre- and post-questionnaires and 71 samples of PCF.

The results of the data analysis of the students' responses to the third question in the post-questionnaire (Appendix 3) indicate that the participants have found the tasks 'useful', 'beneficial' and 'helpful' for understanding the assessment scale. According to the analysis of the second group of items in the postquestionnaire, the participants were not afraid to offend their peers by critical comments. Since the number of the participants who felt uncomfortable by PCF comments had decreased by 30 per cent, it is possible to suggest that the tasks 
helped the participants to realize the benefits of peer review comments and peer feedback in general.

Also notable was the change in the students' focus upon corrective peers' writing. According to the analysis of the first items in the pre- and the postquestionnaires, before the students had been introduced to the genre peculiarities of the types of business letters covered during the present research and had done the proposed tasks, the students had focused more on the surface errors. The majority of the students, that is 87 per cent, focused on grammar when providing corrective feedback on the papers of their peers. Another writing aspect on which a substantial number of the students $(79 \%)$ provided PCF appeared to be vocabulary. The next aspect which the students $(63 \%)$ did not hesitate to review was spelling. As concerns punctuation, in 58 per cent of the cases PCF was provided on this aspect. After the students had become aware of other features of the genre and had been trained, they began to pay their attention to such aspects as layout, organisation and content when providing feedback to the recommendation and enquiry letters. Being asked to tick the aspects that were the most difficult for them to edit in peers' letters, only 20 per cent of the students admitted that it was challenging for them to identify and edit errors connected with the writing aspect 'layout'. Only 25 per cent of the participants claimed it was difficult to review organisation of a letter and 33 per cent of the students found it difficult to comment on the content of a business letter.

The analysis of the data showed that the participants' feedback on the complaint letters was wordy because of the presence of a substantial number of comments. After the introduction of the scale and codes as well as fulfilment of tasks, the number of comments and questions decreased. One of the reasons for such decrease might be that the participants followed the example of the teacher's feedback, in which comments were added, if an error was not self-explanatory and could not be easily understood by a receiver of feedback. Another reason might be that they became more skilful at providing PCF and began to consider the appropriateness and/or usefulness of a comment. As to their formulation, it was noticed that the comments became clearer, and the feedback more complete, which might be also due to the experience gained.

PCF demonstrated that the tasks had been helpful in teaching the students to provide genre-based feedback. It was noticed that the comments and summaries that the students had given in the pre-test were provided using mainly the tool recast, in which an 'error is always reformulated without providing any metalinguistic information about it' (Lyster and Ranta, 1997: 46-47). It means that the peers were aware of what had been changed and recommend in what way it could be done. As to the PCF given on the recommendation and enquiry letters, it became the metalinguistic one, respectively, it contained 'either comments, information, or questions related to the well-formedness of the student's utterance, without explicitly providing the correct form' (ibid.: 47). It follows that the receivers of the feedback elicited information from the peers' comments by themselves. 


\section{CONCLUSIONS}

The results of the case study presented here, although limited in generalisability, showed that after the students were presented an assessment scale and had been trained to revise business letters with the help of tasks such as error identification, letter revision, letter comparison and assessment, the students began to provide fewer non-surface level suggestions and more comprehensive, constructive and, thus, qualitative PCF. That is, they began to give more relevant comments and pose leading questions, which were clear and concise and not confusing for the receivers of feedback. Student feedback became more objective, as the participants adhered to the proposed assessment scale. They started to deliver the summary of feedback, which gave its receiver a new insight into their business letter. Additionally, the participants started to focus on such aspects as content, organisation and layout when providing feedback to a peer. However, the number of comments decreased, which means that PCF became less detailed after the introduction of the assessment scale. Moreover, the comments and summaries became less comprehensive in some cases, presumably, due to the reason that the research participants appealed predominantly to the correction codes.

Despite the small number of participants in the sample selected, the narrow field of students' studies and a few examples of the genre chosen, the findings could be treated as useful for developing further, more wide-ranging peerassessing skills in EFL at tertiary level. In order to make wider generalisations, more studies linked with PCF at tertiary level could be applied in other study programmes. Moreover, the number of students and genre types could be increased to fully explore the issue.

\section{REFERENCES}

Amores, M. (1997) A new perspective on peer editing. Foreign Language Annals 30 (4): 513-523.

Andrade, S. M. and Evans, N. W. (2013) Principles and Practices for Response in Second Language Writing: Developing Self-Regulated Learners. New York: Routledge.

Azizi, M., Behjat, F. and Sorahi, M. (2014) Effect of metalinguistic teacher corrective feedback on writing performance of Iranian EFL learners. International Journal of Language and Linguistics, 2 (6): 54-63.

Cambridge English Language Assessment (2016) Cambridge English Business Certificates Handbook for Teachers. Cambridge: The University of Cambridge.

Chang, C. Y. H. (2016) Two decades of research in L2 peer review. Journal of Writing Research, 8 (1): 81-117.

Council of Europe (2001) The Common European Framework of Reference for Languages: Learning, Teaching, Assessment. Cambridge: Cambridge University Press.

Council of Europe (2017) The Common European Framework of Reference for Languages: Learning, Teaching, Assessment. Companion Volume with New Descriptors. Cambridge: Cambridge University Press.

Farneste, M. (2005) Benefits and drawbacks of peer co-operation in the course of academic writing. Contrastive and Applied Linguistics, XIII: 20-37. Riga: Moderno valodu fakultāte, Sastatāmās valodniecības un tulkošanas nodaļa. 
Gielen, S., Peeters, E., Dochy, F., Onghena, P. and Struyven, K. (2010) Improving the effectiveness of peer feedback for learning. Learning and Instruction, 20 (4): 304-315.

Grabe, W. and Kaplan, R. B. (1996) Theory and Practice of Writing. Pearson Education, Longman.

Hyland, F. (2000) ESL writers and Feedback: Giving more autonomy to students. Language Teaching Research, 4 (1), 33-54.

Hyland, K. (2003) Second Language Writing. Cambridge: Cambridge University Press.

Hyland, K. and Hyland, F. (2006) Feedback on second language students' writing. Language Teaching, 39 (2): 83-101.

Leki, I. (1990) Potential problems with peer responding in ESL writing classes. CATESOL Journal, 3, 5-17.

Liu, J. and Hansen, J. (2002) Peer Response in Second Language Writing Classrooms. Ann Arbor: The University of Michigan Press.

Liu, J. and Sadler, R. W. (2003). The effect and affect of peer review in electronic versus traditional modes on L2 writing. Journal of English for Academic Purpose, 2 (3), 193-227.

Lyster, R. and Ranta, L. (1997) Corrective feedback and learner uptake: negotiation of form in communicative classrooms. Studies in Second Language Acquisition, 19: 37-66.

Maas, C. (2017) Receptivity to learner-driven feedback in EAP. ELT Journal, 71 (2): $127-140$.

Mahmoud, A. (2012) Strategy-based peer assistance in EFL writing. Theory and Practice in Language Studies, 2 (10): 87-92.

Nassaji, H. and Kartchava, E. (2017) Corrective Feedback in Second Language Teaching and Learning: Research, Theory, Applications, Implications. New York: Routledge.

Nicol, D. J. and MacFarlane-Dick, D. (2006) Formative assessment and self-regulated learning: A model and seven principles of good feedback practice. Studies in Higher Education, 31 (2): 199-218.

Rollinson, P. (2005) Using peer feedback in the ESL writing class. ELT Journal, 59: 23-30.

Sackstein, S. (2017) Peer Feedback in the Classroom: Empowering Students to Be the Experts. Virginia: ASCD.

Sluijsmans, D.M.A., Brand-Gruwel, S. and van Merriënboer, J.J.G. (2002) Peer assessment training in teacher education: effects on performance and perceptions. Assessment \& Evaluation in Higher Education, 27 (5): 443-454.

Tsui, A.B.M. and Ng, M. (2000) Do secondary L2 writers benefit from peer comments? Journal of Second Language Writing, 9: 147-170.

Vyatkina, N. (2011) Writing instruction and policies for written corrective feedback in the basic language sequence. L2 Journal, 3: 63-92.

\section{SOURCES USED FOR TASKS DEVELOPMENT}

Ashley, A. (2003) Oxford Correspondence Workbook. New York: Oxford University Press.

Carey, J. A. (ed.), (2002) Business English for Busy People: Time Saving, Ready-to-use Letters for Any Occasion. New York: The Career Press.

Stephens, M. (2005) New Proficiency Writing. Harlow: Pearson Education Limited. 


\section{APPENDIX 1}

\section{BUSINESS LETTER ASSESSMENT SCALE}

Table 1 The assessment scale of a business letter (modified from Cambridge English Language Assessment, 2016: 96)

\begin{tabular}{|c|c|c|}
\hline Aspect & Description & Points \\
\hline \multirow[t]{3}{*}{$\begin{array}{l}\text { Content } \\
\text { and } \\
\text { commu- } \\
\text { nicative } \\
\text { achieve- } \\
\text { ment }\end{array}$} & $\begin{array}{l}\text { All content is relevant to the task. } \\
\text { Target reader is fully informed. } \\
\text { All structural elements of a particular type of letter are present. } \\
\text { The tone and style of a letter are appropriate. They help a writer } \\
\text { to hold the target reader's attention with ease, fulfilling all } \\
\text { communicative purposes. }\end{array}$ & 3 \\
\hline & $\begin{array}{l}\text { Minor irrelevances and/or omissions are present. } \\
\text { Target reader is, on the whole, informed. } \\
\text { Almost all structural elements of a particular type of letter are present. } \\
\text { The tone and style of a letter are appropriate and effective. They help } \\
\text { a writer to hold the target reader's attention. }\end{array}$ & 2 \\
\hline & $\begin{array}{l}\text { A lot of irrelevances are present. } \\
\text { Target reader is minimally informed. } \\
\text { A lot of structural elements of a particular type of letter are not } \\
\text { present. } \\
\text { The tone and style of a letter are appropriate not in all parts of a letter. }\end{array}$ & 1 \\
\hline \multirow[t]{3}{*}{$\begin{array}{l}\text { Organisa- } \\
\text { tion }\end{array}$} & $\begin{array}{l}\text { Text is perfectly organised. } \\
\text { A variety of cohesive devices and organisational patterns are used. }\end{array}$ & 3 \\
\hline & $\begin{array}{l}\text { Text is well organised. } \\
\text { Letter is in general cohesive and coherent. }\end{array}$ & 2 \\
\hline & $\begin{array}{l}\text { Text is not organised in a proper way. } \\
\text { Few linking words and organisational patterns are used. }\end{array}$ & 1 \\
\hline \multirow[t]{3}{*}{ Language } & $\begin{array}{l}\text { A range of vocabulary, including less common lexis, is effectively and } \\
\text { precisely used. } \\
\text { A wide range of simple and complex grammatical forms is used with } \\
\text { full control, flexibility and sophistication. } \\
\text { Only few errors are present. }\end{array}$ & 3 \\
\hline & $\begin{array}{l}\text { A range of everyday vocabulary and some common lexis is used } \\
\text { appropriately. } \\
\text { Simple and sometimes complex grammatical forms are used. } \\
\text { Occasional errors are present, but they do not impede } \\
\text { communication. }\end{array}$ & 2 \\
\hline & $\begin{array}{l}\text { Everyday vocabulary is used, with occasional inappropriate use of less } \\
\text { common lexis. } \\
\text { Only simple grammatical forms are used. } \\
\text { A number of grammatical errors are present. }\end{array}$ & 1 \\
\hline
\end{tabular}




\section{APPENDIX 2}

\section{TASK SAMPLES}

Task 1. Read the letter. Assess the letter, using the assessment scale by Cambridge English Language Assessment (2016). What are the possible tone and style errors in it? Modify it adjusting it to a proper tone and style.

\section{Mr Drissler!!!}

I am writing about the AWFUL facilities, food and service at the holiday dinner JRD Corporation gave for its employees on Tuesday evening, 11 December, at Scripps.

First, Ballroom B was much extremely cold for comfortable dining -with several very strong drafts along the west wall. Was it the method of getting rid of your guest as soon as possible? Moreover, audio systems at parties in Ballrooms A and $\mathrm{C}$ were loud and distracting for our entertainers as well as our guests.

In addition to this, the food service was more than poor - we had contracted for dinner at 6:30 p.m., and the first guests were not served until $8 \mathrm{p} . \mathrm{m}$. They were almost dying from hunger. The main course was cold; our ice cream dessert was melted.

Third, there was no one available from Sales and Catering to offer help, and those we talked to at the front desk were 'not responsible.' Where it you who trained them to treat the guests this manner?

In connection with this you must reduce our room rent and food bill by one-half; I have enclosed our agreement with the original total.

If appropriate measures are not taken, wait for negative consequences!

It was the first and last time I used the service provided by your company.

And be assured that I will do my best and take an advantage of my linkages to inform about its quality as many people as possible.

Janet Coen

(modified from Carey (ed.), 2002: 210) 
Task 2. There are no capitals and punctuation in this enquiry letter (British English format). The organisation of the components is also wrong. Correct all errors.

Clark Fitzpatrick Builders Inc.

Dunstable Road

Luton, Bedfordshire

LU23LM

Kitchen units

Reference KU2345

3 September 2016

Ms Doreen French

Kitchen Comf

386 Winterwood Lane

St. Joseph, MO 94703

Dear Ms French,

thank you for your letter and the enclosed catalogue giving details of your kitchen units the main item we are interested in is the unit on page 22 it appears to meet all our specifications for the apartment block I described in my letter I am sending herewith a plan of a typical apartment which gives the exact dimensions before placing a firm order we would need samples of all materials used in the manufacture of the units could you please confirm that you guarantee all your products for two years against normal wear and tear I would also be grateful for details of your terms regarding payment and of any trade and quantity discounts if the price and qualify of your products are satisfactory we will place further orders as we have several projects at the planning stage

sincerely yours,

Terry Spalding

purchasing manager

(modified from Ashley, 2003: 14) 
Task 3. Assess the letter, using the assessment scale by Cambridge English Language Assessment (2016).

\section{Dear Manager,}

Recently, I booked a holiday with your company and what a waste of money it was! I am very disgusted with you and your staff and I'd like to know what you plan to do about it. The holiday we had was on page 54 of your brochure and we were there from 13-23 July. My parents paid for my friend and me to go on this holiday so that we could enjoy ourselves and have a good time after our exams.

It cost them a lot of money but they didn't mind, they thought we were going to a good place. When we went to the travel agents the man said that the resort was good for young people but when we got there we found it was full of boring grey haired old people, there was nothing to see and do and nowhere for us to go in the evenings so we were really bored. The hotel was not good because there were no disco's just old fashioned singers and entertainers and everything finished by 10.30 in the evening, we just had to go to bed and it was really disappointing.

The travel agent said that we would have a hotel room with a sea view and a balcony but when we got there our room was at the back and the balcony was so small we could only stand we couldn't sit down or sunbathe. And the view from our room was not of the sea, it was of the back of the hotel where they put all the rubbish. It smelt very bad, too.

I expect to get a refund and an apology.

Best wishes,

Sonya Brown

\begin{tabular}{|l|l|}
\hline Aspect & Evaluator's mark (1-3 for each aspect) and comments \\
\hline Content & \\
\hline Organisation & \\
\hline Language & \\
\hline
\end{tabular}

(based on Stephens, 2005: 9) 


\section{APPENDIX 3}

\section{PRE-QUESTIONNAIRE}

Dear Student,

I would appreciate it if you could fill in this questionnaire by writing in or ticking $(\boldsymbol{V})$ your answers. They will be kept confidential and used for the research concerning written peer corrective feedback in business letter writing.

\section{I correct the following aspects in peers' written works.}

\begin{tabular}{|l|l|l|}
\hline 1. & Content & \\
\hline 2. & Organisation & \\
\hline 3. & Grammar & \\
\hline 4. & Vocabulary & \\
\hline 5. & Punctuation & \\
\hline 6. & Layout & \\
\hline 7. & Spelling & \\
\hline 8. & Another variant (name it): & \\
\hline
\end{tabular}

\section{I do not like peer editing, because...}

\begin{tabular}{|l|l|l|}
\hline 1. & I get offended when my classmates correct me. & \\
\hline 2. & I do not trust classmates' comments' and corrections. & \\
\hline 3. & $\begin{array}{l}\text { I feel that I do not have enough knowledge of English to correct someone's } \\
\text { work. }\end{array}$ & \\
\hline 4. & I do not know how to edit someone's works. & \\
\hline 5. & I do not want to offend my friend by correcting him/her. & \\
\hline 6. & $\begin{array}{l}\text { I know that the person who does not like me will try to find a lot of errors in } \\
\text { my work (to hurt me). }\end{array}$ & \\
\hline 7. & Another variant (name it): & \\
\hline
\end{tabular}

\section{POST-QUESTIONNAIRE}

\section{Dear Student,}

I would appreciate it if you could fill in this questionnaire by writing in or ticking $(\boldsymbol{V})$ your answers. They will be kept confidential and used for the research concerning written peer corrective feedback in business letter writing. 
1. Tick the aspects which were the most difficult for you to edit in peers' letters.

\begin{tabular}{|l|l|l|}
\hline 1. & Content & \\
\hline 2. & Organisation & \\
\hline 3. & Grammar & \\
\hline 4. & Vocabulary & \\
\hline 5. & Punctuation & \\
\hline 6. & Layout & \\
\hline 7. & Spelling & \\
\hline 8. & Another variant (name it): & \\
\hline
\end{tabular}

2. I did not like giving peer corrective feedback within the course on business correspondence, because ...

\begin{tabular}{|l|l|l|}
\hline 1. & I got offended when my classmates correct me. & \\
\hline 2. & I did not trust classmates' comments' and corrections. & \\
\hline 3. & $\begin{array}{l}\text { I felt that I do not have enough knowledge of English to correct someone's } \\
\text { work. }\end{array}$ & \\
\hline 4. & I did not know how to edit someone's works. & \\
\hline 5. & I did not want to offend my friend by correcting him/her. & \\
\hline 6. & $\begin{array}{l}\text { I knew that the person who does not like me will try to find a lot of errors in my } \\
\text { work (to hurt me). }\end{array}$ & \\
\hline 7. & Another variant (name it): & \\
\hline
\end{tabular}

3. Which way did the proposed tasks help you to improve your business letter writing and peer corrective feedback skills?

Monta Farneste (Dr. paed., Assoc. prof. in Applied Linguistics) is currently working at the University of Latvia. Her research interests include discourse studies, acquisition of written communication and communicative grammar. Email: Monta.Farneste@lu.lv.

Olga Pašinska (MA philol., lecturer) is currently working at The Red Cross Medical College of Riga Stradinš University. Her research interests include language acquisition at tertiarylevel and ESP.Email: olgapashinskalv@gmail.com 


\title{
USE OF TENSE-ASPECT FORMS IN CORDIS PROJECT REPORTS
}

\author{
JANA KUZMINA \\ University of Latvia, Latvia
}

\begin{abstract}
For several recent decades the Council of Europe and various European authorities have been encouraging various European universities and other institutions to unite research activities resulting in the creation of partnerships with a conventialised genre network of calls for projects, guidelines for proposals and databases of project documentation. Along with Latvia acting in political, economic and social arenas of the European Union, it has also been actively involved in research consortia as coordinator and participant, therefore, setting new objectives for communicative competence development of scholars and project managers in order to reflect the discursive practices. In view of this, the present cross-sectional empirical investigation is intended to explore the written genre of Community Research and Development Information Service (CORDIS) periodic (status) and closure (results in brief) project reports as fundamental documents to account for research results in various economically and socially significant spheres. The selected research methodology is a descriptive case study, involving genre and discourse analysis. The obtained results claim that reports have a rigid generic macro-structure. It explains the use of the selected tense-aspect forms to express the communicative aim in both types of reports; however, periodic reports demonstrate higher variation due to the involvement of a different discourse community. The significance of the study lies in the scarcity of previous research on this genre and wide application of research findings to support the discourse community of researchers.
\end{abstract}

Key words: CORDIS project reports, generic macro-structure, discourse analysis, tense-aspect forms

\section{INTRODUCTION}

Project management has infiltrated numerous branches, research not being an exception. Its popularity is determined by the fact that research and operational business activities undergo constant change and, therefore, require continuous improvement in response to social and market needs, customer feedback, rivals' and partners' actions. Moreover, breakthrough in technologies, governmental financial and information support as well as the accessibility of the European Union funds have also increased the number of projects implemented in companies and institutions.

Describing the research setting, it should be noted that the present study encompasses professional, organisational and institutional discourse as 
the project reports in question reflect research and innovative entrepreneurial activities financially supported by the Council of Europe.

The significance of the study stems from the fact that project management is a comparatively new domain, thus, the network of genres pertinent to it is rather dynamic in its nature reflecting professional discursive processes. Moreover, documentation created across various business domains (IT, telecommunications, banking, pharmaceuticals, design) or academic research setting may vary greatly. Therefore, it is essential that a linguistic analysis of language variation in professional discourse should possess 'the dynamic and context dependent character [...]. Discourse in real life occurs in situated professional events, which in turn take place in a complex set of contextual frameworks' (Gunarsson, 2009: 4).

Moreover, the significance is also determined by the fact that the communicative aims of project reports from the CORDIS database of the Council of Europe have not been outlined. The existing research on the EU project management documentation is fragmented, e.g. Connor and Maurannen's (1999) investigation of the generic macro-structure of grant proposals applying Swalesian genre analysis (Swales, 1990) and a social constructionist theory of genre by Berkenkotter and Huckin (1995) and contributing to both genre research and the teaching of academic writing. The study of the EU institutional language use focuses on the implementation of language policy (House, 2003; Phillipson, 2003), language conflicts (Ammon, 2006), selected linguistic features (Trebits, 2009; Online 1; Online 2) and the relation between language and power (Diez, 2014).

Given this, the present research aims to bridge this gap and explore the use of tense-aspect forms typical of every move of the CORDIS periodic and closure project reports, essential documents which inform about periodic results and achievements upon project closure.

The present study unfolds by looking into the situational context and generic macro-structure, followed by the analysis of tense-aspect forms. The theoretical basis for it has been grounded in the dogmas of professional, organisational and institutional discourse and English for Specific Purposes genre school. The empirical research method is a case study. The corpus for the research covers authentic materials of twenty project reports of Horizon 2020 and FP7 where Latvian researchers were involved as partners.

\section{THEORETICAL BACKGROUND}

\section{SITUATIONAL CONTEXT OF PROJECT REPORTS}

When placing project reports in its situational context, the concepts of professional, organisational and institutional discourse should be addressed. The genre of the project report should be analysed on the basis of all the above- 
mentioned terms as it is located at the intersection of the notions. There is no unanimous opinion among researchers regarding the use of the terms, namely, some scholars use them interchangeably (Grant et al., 2004), others (Mayr, 2008; Thornborrow, 2013) refer to an institution as to public organs of state, whereas organisations signify commercial corporations.

First, project report as a genre is subdued to the principles of institutional discourse, i.e. goal-oriented legitimate contributions of language produced by participants taking particular roles follow conventionalised rules in the EU public space (Illie 2001; Thornborrow 2013). Secondly, it follows the principles of organisational discourse as the participants involved the project management discursive processes are not only research institutions, but also innovative startups and enterprises whose discourse is context sensitive, intertextual and dynamic as it reflects organisational routine resulting in the collections of interactions, media of communication (i.e., oral, print, electronic) and genre networks (Grant et al., 2004). Last but not least, professional discourse is the most general term describing language use which is situated and dynamic, uncovering how professional life functions and also about how language works in different situations and contexts (Gunarsson, 2009).

Being aware of the fact that there is no clear-cut division, Gunarsson (ibid.) proposes the classification of discourse into professional and non-professional, the former possessing the following features: (1) expert discourse related to different domains, (2) goal-oriented, situated discourse, (3) conventionalised form of discourse, (4) discourse in a socially ordered group, (5) discourse dependent on various societal framework system, (6) dynamically changing discourse (ibid: 5). For the needs of the present paper the scholar's classification has been chosen as the main one. It is considered to be complete as it successfully reflects the principles of all three genre schools, i.e. Systemic-Functional, English for Specific Purposes and New Rhetoric. Within the framework of this study CORDIS is a repository and portal aiming to disseminate information on EU-funded research projects (Online 3) to a wide variety of expert discourse community, e.g. researchers, state authorities, project managers, practitioners and other stakeholders. It contains all public information about the projects, namely, project factsheets, periodic reports, final/closure reports, results in brief as well as the information for a broader public (news, events, success stories and hyperlinks) in a socially ordered group. It enables the stakeholders to follow the lifecycle of every project very closely through the relevant documentation which reflects discursive processes starting with grant details and finishing with closure reports or report summaries within a societal framework written by the participants and results in brief prepared by Publications Office of the European Union, on behalf of the European Commission's research Directorates-General and Agencies. When the reports are written by the participants of projects, they are dynamic and do not contribute to generic integrity with repeating discursive patterns and lexico-grammar forming recognisable genre structural identity. They account for variation depending 
on the influence of the situational context. In contrast, closure reports (Results in Brief) written by the scientific editors contain conventionalised structure of obligatory and secondary rhetorical moves forming a stabilised not a dynamic genre.

To summarise, CORDIS project report as a genre is placed at the intersection of institutional, organisational and professional discourse. The unifying features typical of all types are the unquestionable influence of the discursive processes on document creation, discourse community of stakeholders, goal-oriented genres with distinct communicative aim and recognisable macro-structure, and recurrent linguistic features yet with room for dynamic changes.

\section{PROJECT REPORT AS A GENRE}

Bhatia assigns project reports to the colony of reporting genres, defining them as 'reporting development as a part of a project/activity' (Bhatia, 2004: 81). The scholar claims that this colony is the most popular and overly used "generic values" in all contexts of professional discourse across disciplines and domains today' (ibid.). Although numerous research papers have been devoted to the investigation of grammatical, lexical and syntactical peculiarities in science reports, inquiry reports, business reports (White, 1998; Yeung, 2007; Bhatia, 2014), and the investigation of rhetorical organisation and linguistic peculiarities of project reports is scarce, which can be explained by considerable variation within the colony and obscure boundaries among genres because of the changeable nature of the communicative event these reports describe.

Genre studies involve various frameworks used to investigate written genres constructed, recognised, interpreted and used by the members of discourse community. Bhatia states that 'the analyses range from a close linguistic study of texts as discursive products, spanning across to investigations into dynamic complexities of communicative practices of professional and workplace communities, to a broader understanding of socio-cultural and critical aspects often employed in the process of interpreting these textual genres in a real life setting' (Bhatia, 2017: 3). Similarly, Hyland regards genre analysis as

a branch of discourse analysis that explores specific uses of language.

It is driven by a desire to understand the communicative character of discourse by looking at how individuals use language to engage in particular communicative situations. (Hyland, 2004: 195)

In the present empirical study, the grammatical phenomenon of tense-aspect forms is investigated at the level of rhetorical moves as staged communicative goals (Swales, 1990) applying Cohen and Upton's research approach to genre analysis as it allows researchers to systematise the research design and build a consistent research procedure and comprises:

1) determining communicative purpose of the genre;

2) determining communicative aim of each text segment; 
3) segmentation of full set of texts into moves;

4) classification of all moves by move type;

5) conducting linguistic analysis of all moves representing each move type;

6) description of move types in terms of the linguistic features of the moves;

7) analyzing the move structure of each text in terms of move types;

8) describing the corpus of texts in terms of typical and alternate move structures. (Cohen and Upton, 2009: 10)

Stages 7 and 8 will be excluded from the analysis of the empirical part as the focus of the research is rather on the use of the linguistic peculiarities than on genre analysis.

Swales' move and step framework for the analysis of research article introductions has been successfully generalised and transferred to many professional domains to research medical abstracts (Salager-Meyer, 1991), legalese (Bhatia 1997, 2014), advertisements (Bhatia, 2002, 2008) and advertorials (Zhou, 2012). However, it has not been applied to investigate project reports.

Concerning tense-aspect forms, Biber, Conrad and Leech (2002), Biber and Conrad (2009), highlight six major structural distinctions of the verb, namely:

1) tense (e.g. present or past);

2) aspect (e.g. unmarked/ Simple, Perfect, Continuous, Perfect Continuous);

3) voice (e.g. active or passive);

4) modality (e.g. unmarked (tensed) or modal);

5) negation (e.g. positive or negative);

6) clause structure type (e.g. declarative or interrogative).

Conducting the linguistic analysis, all of the above concepts except for modality will be considered. The notion of tense-aspect forms is viewed not only as the cases of 'a morphological change in the base form of the verb' (Lewis, 2002: 50; Biber et al., 2002), but also the relevance between the form of the verb and the notion of time (past, present, or future)' (Leech, 1989; Leech and Svartvik, 2002). There exists a contradiction among researchers if to consider future as tense (ibid.) or as modality (Biber et al., 2002). In the present research the former opinion is adopted.

The preliminary screening of the project reports revealed that most frequently used tense- aspect forms are Present Simple, Past Simple, Present Perfect, Future Simple, Present Continuous and Past Continuous; therefore, their meanings in context need to be investigated:

1) Present Simple to express permanent situations, facts, general truths, opinions, regular or repeated action, series of events/ actions, future in conditional and time clauses, with state verbs, with performative verbs, in headlines, with certain frequency adverbs;

2) Past Simple to describe finished past events, a series of past actions; 
3) Present Perfect to outline experience, a recently finished action (emphasizing its completion), an action which started in the past and is still going on, an action which happened in the past but has present results;

4) Future Simple to present facts about future events;

5) Present Continuous to express the actions happening at the moment of speaking, short-term actions;

6) Past Continuous to describe an action happening at a particular time in the past, an action in the past lasting for some time, an ongoing action with a single event (the Past Simple) which interrupts it (Biber et al., 2002; Emmerson 2002; Huddleton and Pullum, 2006; Foley and Hall, 2012).

To sum up, project report belongs to one of the largest genre colony, yet it has not been analysed in depth. Genre studies propose various frameworks for analysis ranging from close linguistic investigation to complex study of professional practices behind genre creation, socio-cultural and critical perspective. The present empirical study looks at the grammatical phenomenon of tense-aspect forms pertinent to each rhetorical move to convey the communicative aims.

\section{RESEARCH METHODOLOGY AND PROCEDURE}

The goals set at the beginning of the research determined the research methodology, namely, a descriptive case study that was performed, comprising genre analysis and discourse analysis and investigating the use of tense-aspect forms bound with the generic macro-structure. The theoretical framework was established based on the review of the secondary sources on the tenets of organisational, institutional and professional discourse, the ESP Genre School as well as the concepts of tense and aspect, forming the triangulation of theories.

The research unfolded by investigating the situational context in which the genre in question occurs. Afterwards, the generic macro-structure of twenty reports was determined, mapping each move with tense-aspect forms relevant to it of status and closure report was performed and subsequent data comparison was provided.

The preliminary screening of the project reports revealed its rigid generic macro-structure, which is a typical characteristic of the colony of reporting genres in institutional discourse performing transactional language metafunction. Moreover, this phenomenon is observed because periodic reports contain identical text segmentation proposed by the Council of Europe experts, whereas closure reports were created by scientific editors following genre conventions with the aim to popularise research results. It also explains a limited variety of tense-aspect forms to express the communicative aim, therefore, only selected forms were reviewed in the theoretical part. Genre conventional organisation of 
closure reports contributes to the reliability of results, i.e. degree of consistency with which research results may be reproduced (Silverman, 2005).

The primary principles for selection were the involvement of Latvian researchers in the project implementation and report creation, the length and most recent date of publishing or changing. They also imposed limitations on the size of the corpus as not many documents could meet the criteria.

Research descriptive and interpretive validity is achieved by the elaboration of the research design and multi-level analysis resulting in thorough data outline (Maxwell, 1996; Dörnyei, 2007).

\section{RESULTS}

The analysis of the situational context applying Gunarsson's (2009) framework described in section 1 revealed the members of discourse community, their discursive processes within societal framework, the dynamic nature of project management discourse leading to the general communicative purpose of the genre in question, which is to inform about the lifecycle of every project very closely through the relevant documentation reflecting discursive processes from project initiation to closure and dissemination of research results.

\section{ANALYSIS OF PERIODIC REPORTS}

Conducting the analysis further following Cohen and Upton's (2009) genre analysis approach, the communicative aim of each text segment was determined, which is reflected in Table 1 . Moreover, text segmentation of status reports, which is proposed by CORDIS scientific editors, coincided with move structure. However, since the content is generated by the project participants, it explains the fact that it is not homogeneous, e.g. Text 3 contains bullet points and numbered lists where tense-aspect forms are substituted with past participles and gerunds, whereas Text 5 comprises both grammatically complete sentences with the subject and the predicate and bulleted lists with non-finite forms.

\section{Example 1: Leveraging national NCP structures. (Text 3)}

The yielded data demonstrated various length of moves in periodic project reports and lower variation of tense-aspect forms.

The recurrent tense-aspect forms in Move 1, the number referring to the number of instances found, are Present Simple that expresses general facts about the projects, e.g. the project structure or set up and Future Simple to describe upcoming events during various stages (Figure 1).

Example 2: CIMULACT has the main purpose of proving and providing a process of making citizen-based scoping papers and topics for the last phase of Horizon 2020. In the next reporting period 
the "enriched research scenarios" will be produced in a series of experimental methods in all 30 countries. (Text 5)

67

$$
\begin{aligned}
& \text { Present Simple } \\
& \text { Present Perfect } \\
& \text { Future Simple } \\
& \text { Present Continuous }
\end{aligned}
$$

Figure 1 Use of tense-aspect forms in Move 1 of periodic reports

As presented in Figure 2, Move 2 demonstrates the frequent use of Present Perfect to describe a recently finished action (emphasizing its completion) or an action which happened in the past but has present results, for instance, to present the collected research data and describe data collection tools and Past Simple to refer to finished past events. Both forms can even occur in one sentence to draw a line between the completed stage of the project and the stage which will be further developed.

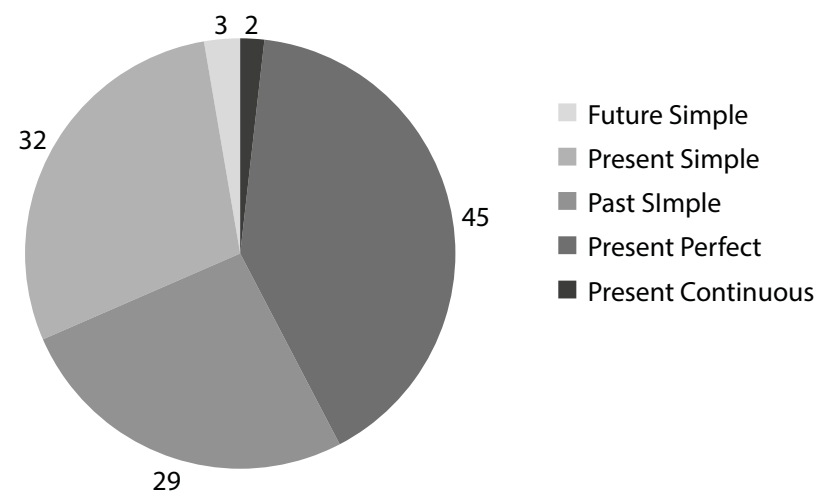

Figure 2 Use of tense-aspect forms in Move 2 of periodic reports

Example 3. The first prototypes of the Maturity Model, the Systemic Risk questionnaire and the engagement toll have been developed. Also, the current communication and engagement practices and existing platforms were reviewed, and a literature overview was made. (Text 4) 
Present Simple is used to describe the research design or project structural elements.

Example 4: The CoP has a homepage that has a forum where all those involved in the industry share ideas, and is a repository for other 4D4F reports, namely the annual Research Priority Report, the Dairy Sensor Research Report, and the Industry Innovations Report. (Text 2)

Move 3 contains the recurrent instances of Past Simple to describe finished past events as above, Present Perfect to represent a recently finished action (emphasizing its completion) in relation to the achieved project results (Figure 3).

Example 5. This has been accomplished in the first reporting period by several activities. First of all, all produced visions, societal needs and research scenarios have been made available to project officers (POs) as they were produced. (Text 5)

Future Simple along with Present Simple in the passive outline forthcoming project activities and expected milestones.

Example 6. In the next reporting period the 'enriched research scenarios' will be produced in a series of experimental methods in all 30 countries. These will be transformed into 'pre-topics', which will be worked upon in collaboration between the consortium and the POs during a working conference in December 2016. The outcome is expected to be several topics, which can be implemented in the next programme period of Horizon 2020. (Text 5)

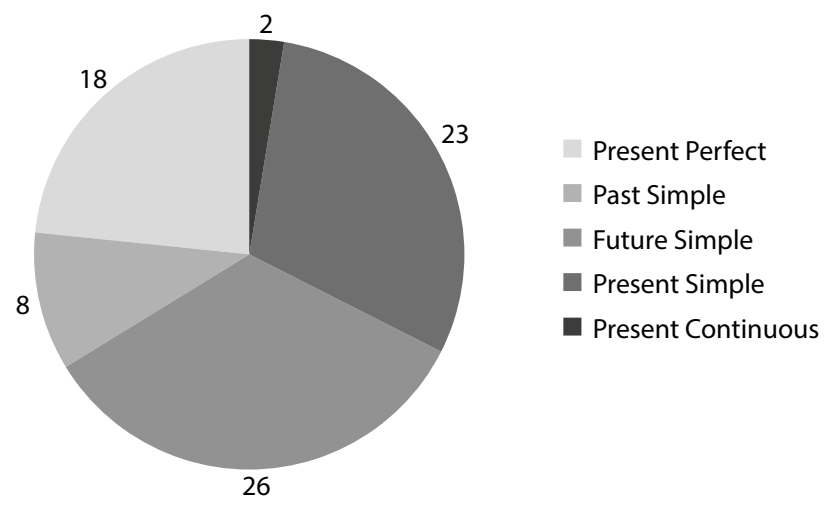

Figure 3 Use of tense-aspect forms in Move 3 of periodic reports

The results of the study are summarised in Table 1 below and demonstrate the dependency of the choice of tense-aspect forms on the communicative aim of the move under analysis. 
Table 1 Text segmentation and move structure in periodic CORDIS project reports

\begin{tabular}{|l|l|l|}
\hline Text segment/ Move & Communicative aim & $\begin{array}{l}\text { Recurrent tense- } \\
\text { aspect forms }\end{array}$ \\
\hline $\begin{array}{l}\text { Summary of the context and } \\
\text { overall objectives of the project }\end{array}$ & $\begin{array}{l}\text { To provide background } \\
\text { information on the project } \\
\text { set up, research participants, } \\
\text { research topicality as well as } \\
\text { research objectives. }\end{array}$ & $\begin{array}{l}\text { Present Simple } \\
\text { Future Simple } \\
\text { Present Perfect }\end{array}$ \\
\hline $\begin{array}{l}\text { Work performed from } \\
\text { the beginning of the project } \\
\text { to the end of the period covered } \\
\text { by the report and main results }\end{array}$ & $\begin{array}{l}\text { To describe project } \\
\text { methodology, procedure and } \\
\text { deliverables. }\end{array}$ & $\begin{array}{l}\text { Past Simple } \\
\text { Prent Perfect }\end{array}$ \\
\hline $\begin{array}{l}\text { Progress beyond the state of } \\
\text { the art and expected potential } \\
\text { impact }\end{array}$ & $\begin{array}{l}\text { To outline the uniqueness of } \\
\text { the project outcomes, socio- } \\
\text { economic impact and wider } \\
\text { societal implications. }\end{array}$ & $\begin{array}{l}\text { Present Perfect } \\
\text { Present Simple } \\
\text { Future Simple }\end{array}$ \\
\hline
\end{tabular}

\section{ANALYSIS OF CLOSURE REPORTS}

The text segmentation of CORDIS closure reports (Results in Brief), which is also very similar to move structure, is proposed by the author of the research and is presented in Table 2 below. Its distinctive feature is a lead sentence or a paragraph, containing the significance of the research to attract the attention of the stakeholders which is marked in bold. Together with the next segment they constitute one move. Its recurrent linguistic features are presented in Figure 4 and comprise Past Simple and Present Perfect to summarise the key initiatives undertaken within the framework of the project and Present Simple to introduce the research context and general facts. The ongoing actions or research background are introduced by Present Continuous.

Example 7. An EU initiative set out to ensure the reliability of pipelines transporting crude oil, natural gas and liquid petroleum products across eastern and western European markets. (Text 11)

Example 8. The science of photonics, where light and electronics meet, has applications in a wide range of industries. (Text 13)

Example 9. Latvia joined the EU in 2004, and the EU has been helping to improve the country's Research Institute of Biotechnology and Veterinary Medicine Sigra. (Text 20)

Example 10. EU funding is being used to help boost Latvian research in the area of food quality, and hence public health. Achievements to date include staff exchanges and equipment upgrades, initiating a fruitful new era of Latvian-EU collaboration. (Text 20) 
Similarly, Past Simple and Present Simple tense-aspect forms are used further to elaborate on the research background, setting and background and aims.

Example 11. As a result the EU-funded 'Baltic popular science TV show Futureshock' (Futureshock) project chose television as its medium of choice to help people get a better sense of scientific achievements. (Text 16)

Example 12. The general objective of the project was to give those who have nothing to do with science more insight into the achievements of scientific endeavour generally. (Text 16)

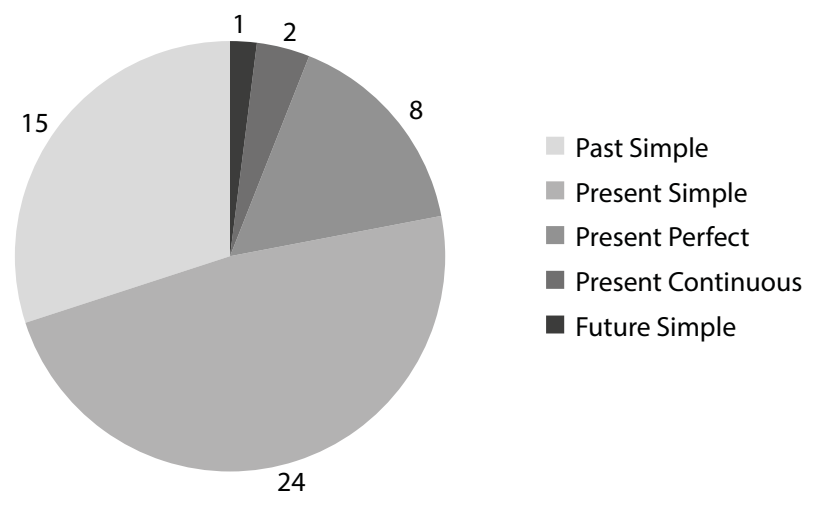

Figure 4 Use of tense- aspect forms in Move 1 of project closure reports

The next move outlines the procedure how the research unfolds and the main deliverables, therefore, Past Simple to describe a series of finished events with some rare cases of Past Perfect to refer to prior actions and Past Continuous to emphasise the duration of the action are used. Present Perfect highlights the accomplished results (Figure 5). This move demonstrates the least variation of forms, whereas it is the longest. The distribution of forms across the reports is not even. The use of Past Perfect appears in only one report (Text 19).

Example 13 It developed various analytical, numerical and numericalexperimental methods to accurately characterise damage found on pipelines using the long-range ultrasonic technique. (Text 12)

Example 14. However, very few Latvian participants had actually taken up the position of coordinator in these research projects. (Text 19) 




Figure 5 Use of tense- aspect forms in Move 2 of project closure reports

The data of the last move is summarised in Figure 6. The move is intended to connect the results with further research; therefore, Past Simple and Future Simple forms prevail. In some instances, Present Perfect is used in combination with Future Simple in this move and the emphasis is put on recently completed events (Example 12). In four project reports this move was not recognised.

Example 15. Scientists have contributed comprehensive computeraided design methodology and protocols for research and evaluation of hybrids. Together with models to predict performance criteria with minimal uncertainty, the tools will support knowledge-based advances in the hybrid aircraft model that has captured global attention. (Text 14)

Example 16. INNOPIPES $\underline{\text { improved existing methods and developed }}$ new ones to better detect and repair volumetric surface defects. This will ensure efficient and safe operation of current pipeline networks spanning Europe. (Text 12)

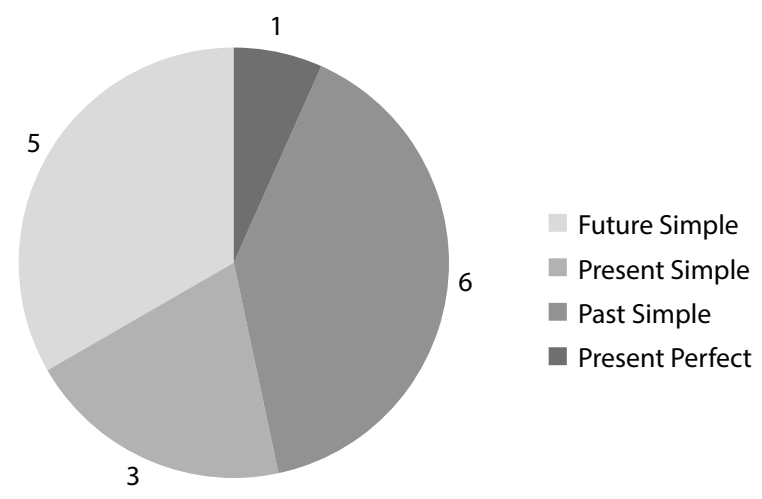

Figure 6 Use of tense-aspect forms in Move 3 of project closure reports 
Table 2 below outlines the data on text segmentation, move structure and recurrent tense aspect forms in CORDIS closure reports.

Table 2 Text segmentation and move structure in CORDIS closure reports

\begin{tabular}{|c|c|c|c|}
\hline Move & Text segment & Communicative aim & $\begin{array}{l}\text { Recurrent tense- } \\
\text { aspect forms }\end{array}$ \\
\hline \multirow[t]{2}{*}{$\begin{array}{l}\text { Establishing project } \\
\text { context }\end{array}$} & Lead & $\begin{array}{l}\text { To express } \\
\text { the topicality of } \\
\text { the research activities }\end{array}$ & $\begin{array}{l}\text { Past Simple } \\
\text { Present Simple } \\
\text { Present Continuous }\end{array}$ \\
\hline & $\begin{array}{l}\text { Describing } \\
\text { project context }\end{array}$ & $\begin{array}{l}\text { To describe } \\
\text { the project aims and } \\
\text { background }\end{array}$ & $\begin{array}{l}\text { Present Perfect } \\
\text { Past Simple } \\
\text { Present Simple }\end{array}$ \\
\hline $\begin{array}{l}\text { Describing project } \\
\text { procedure and } \\
\text { results }\end{array}$ & $\begin{array}{l}\text { Outlining project } \\
\text { procedure and } \\
\text { results }\end{array}$ & $\begin{array}{l}\text { To outline } \\
\text { the research } \\
\text { procedure, flow and } \\
\text { the main outcomes }\end{array}$ & $\begin{array}{l}\text { Past Simple } \\
\text { Past Perfect } \\
\text { Present Simple } \\
\text { Present Perfect }\end{array}$ \\
\hline $\begin{array}{l}\text { Highlighting } \\
\text { further research }\end{array}$ & $\begin{array}{l}\text { Envisaging } \\
\text { further research }\end{array}$ & $\begin{array}{l}\text { To describe future } \\
\text { impact of results and } \\
\text { further research }\end{array}$ & $\begin{array}{l}\text { Present Simple } \\
\text { Present Perfect } \\
\text { Past Simple } \\
\text { Future Simple }\end{array}$ \\
\hline
\end{tabular}

The comparison of the data presented above enables us to conclude that the choice of the tense-aspect forms is determined to a large extent by the communicative aim of each move. Closure reports demonstrate greater variation of linguistic phenomena in comparison with periodic reports, which can be explained by the discourse community members involved in the process of creation. Namely, professional scientific editors generate the former and project participants draw up the latter. Since there are no conventions, there is no consistency among the use of the forms in periodic reports, and the choice sometimes depends on personal preferences, e.g. to describe project context, the authors of Text 13 use Present Simple, while the writers of Text 14 apply Past Simple to express the same communicative aim. Simple forms prevail in all moves as they are aimed at reflecting general facts or scientific phenomena, finished past events outlining the project flow and future research endeavour.

\section{CONCLUSIONS}

The conducted research results suggest both periodic and closure project reports have a relatively similar generic macro-structure, the major moves being the outline of research context, describing the main outcome and envisaging future research. Since the former document is written by the project participants 
themselves, the length and the move structure contribute to genre dynamic nature. The distribution of forms pertinent to each move is not even and depends to a large extent on authors' individual preference. The latter is drawn up by the scientific editors of the Council of Europe, leading to the consistency of move structure and the use of a wider variety of linguistic means. However, last move of closure reports is not recognised in some reports, which contributes to the dynamism of closure report. The choice of tense-aspect forms is correlated with the communicative aim of each move.

The topics for further research might comprise the stylistic diversity of most and least frequently used tense-aspect forms, the sequence of steps in each move or the use of infinitives and participles as they are recognised in abundance. The investigation of the situational context reveals other genres of the communicative event within the same societal framework to reflect other discursive practices; thus, intertextual relation among them as well as their generic macro-structure and recurrent linguistic features might be investigated. The research design might also be attributed to a more extensive corpus, however, according to the preliminary screening the obtained results should not differ considerably.

\section{REFERENCES}

Ammon, U. (2006) Language conflicts in the European Union. International Journal of Applied Linguistics. 16 (3): 319-338.

Berkenkotter, C. and Huckin, T. N. (1995) Genre Knowledge in Disciplinary Communication. Mahwah, NJ: Lawrence Erlbaum Association.

Bhatia, V. K. (1997) Translating legal genres. In A. Trosborg (ed.) Text Typology and Translation. Amsterdam/Philadelphia: John Benjamin Publishing Company.

Bhatia, V. K., (2002) Applied genre analysis: a multi-perspective model. Iberica (3): 3-19.

Bhatia, V.K. (2004) Worlds of Written Discourse: A genre-based view. London: Continuum International.

Bhatia, V. K. (2008) Towards critical genre analysis. In V.K. Bhatia, J. Flowerdew and R. Jones (eds.) Advances in Discourse Studies (pp. 166-177). London: Routledge.

Bhatia, V. K. (2014) Analyzing Genre: Language Use in Professional Settings. New York: Routledge.

Bhatia, V. K. (2017) Critical genre analysis: Investigating interdiscursive performance in implications. English for Specific Purposes, 28 (3): 199-210.

Biber, D., Conrad, S. and Leech, G. (2002) Longman Grammar of Spoken and Written English. Harlow: Longman.

Biber, D. and Conrad, S. (2009) Real Grammar: A Corpus-based Approach to English. Harlow: Longman.

Cohen, M. A. and Upton, T. A. (2009) An approach to corpus-based discourse analysis: the move analysis example. Discourse Studies, 11 (5): 585-605.

Connor, U. and Maurannen A. (1999) Linguistic analysis of grant proposals: European Union research grants. English for Specific Purposes, 18 (1): 47-62.

Diez, T. (2014) Setting the limits: Discourse and EU foreign policy. Cooperation and Conflict, 49 (3): 319-333. 
Dörnyei, Z. (2007) Research Methods in Applied Linguistics. Oxford: Oxford University Press.

Emmerson, P. (2002) Business Grammar Builder. Oxford: Macmillan.

Grant, D., Hardy, C., Oswick, C. and Putnam, L. (eds.) (2004) The Sage Handbook of Organisational Discourse. London: SAGE.

Gunarsson, B-L. (2009) Professional Discourse. London: Continuum International Publishing Group.

Foley M. and Hall D. (2003) Advanced Learner's Grammar. Harlow: Pearson Education.

Foley M. and Hall D. (2012) My Grammar Lab Advanced C1/C2. Harlow: Pearson Education.

House, J. (2003) English as a lingua franca: A threat to multilingualism? Journal of Sociolinguistics, 7 (4) 556-578.

Huddleston, R. and Pullum G. K. (2006) A Student's Introduction to English Grammar. Cambridge: Cambridge University Press.

Hyland, K. (2004) Genre and Second Language Writing. Michigan: University of Michigan Press.

Ilie, C. (2001) Semi-institutional discourse: The case of talk shows. Journal of Pragmatics, 33 (12): 209-254.

Leech, G. (1989) An A-Z of English Grammar and Usage. Surrey: Nelson.

Leech, G. and Svartvik, J. (2002) A Communicative Grammar of English, $3^{\text {rd }}$ ed. Harlow: Pearson Education Limited.

Lewis, M. (2002) The English Verb: An Exploration of Structure and Meaning. Boston: Christopher Wenger.

Maxwell, J.A. (1996) Qualitative Research Design: An interactive approach. Thousand Oaks, CA: Sage.

Mayr, A. (2008) Language and Power: An Introduction to Institutional Discourse. London: Continuum.

Phillipson, R. (2003) English for the globe, or only for globe-trotters? The world of the EU. In C. Mair (ed.) The Politics of English as a World Language. New horizons in postcolonial cultural studies (pp. 19-30). Amsterdam \& New York: Rodopi.

Salager-Meyer, F. (1991) Medical English abstracts: How well structured are they? Journal of the American Society for Information Science), 42 (7): 528-531.

Silverman, D. (2005) Doing qualitative research: A practical guide. Sydney: SAGE.

Swales, J. M. (1990) Genre Analysis: English in Academic and Research Settings. Cambridge: Cambridge University Press.

Thornborrow, J. (2013) Power Talk: Language an Interaction in Institutional Discourse. Abington, New York: Routledge.

Trebits, A. (2009). Conjunctive cohesion in English language EU documents a corpus-based analysis. English for Specific Purposes, 28 (3): 199-210.

Yeung, L. (2007) In search of commonalities: Some linguistic and rhetorical features of business reports as a genre. English for Specific Purposes, 26 (2): 156-179.

Zhou, S. (2012) 'Advertorials': A genre-based analysis of an emerging hybridized genre. Discourse \& Communication, 6 (3): 323-346.

White, P.R.(1998) Telling Media Tales: The news story as rhetoric. Available from: https:// www.researchgate.net/profile/Peter_White17/publication/268256149_Telling Media_Tales_the_news_story_as_rothetoric/links/55508cae08ae956a5 $\bar{d} 24 \mathrm{df} 70$. pdf [Accessed on $\overline{18}$ March $201 \overline{8}]$. 


\section{ONLINE SOURCES}

[Online 1] http://ec.europa.eu/translation/english/guidelines/documents/styleguide_ english_dgt_en.pdf [Accessed on 28 June 2017].

[Online 2] http://eur-lex.europa.eu/content/pdf/techleg/joint-practical-guide-2013en.pdf [Accessed on 28 June 2017].

[Online 3] https://cordis.europa.eu/home_en.html [Accessed on 20 June 2017].

\section{TEXTS ANALYSED}

[Text 1] https://cordis.europa.eu/result/rcn/223943_en.html [Accessed on 24 August 2018].

[Text 2] https://cordis.europa.eu/result/rcn/220302_en.html [Accessed on 24 August 2018].

[Text 3] https://cordis.europa.eu/result/rcn/186648_en.html [Accessed on 24 August 2018].

[Text 4] https://cordis.europa.eu/result/rcn/194965_en.html [Accessed on 24 August 2018].

[Text 5] https://cordis.europa.eu/result/rcn/198074_en.html [Accessed on 24 August 2018].

[Text 6] https://cordis.europa.eu/result/rcn/231093_en.html [Accessed on 24 August 2018].

[Text 7] https://cordis.europa.eu/result/rcn/198059_en.html [Accessed on 24 August 2018].

[Text 8] https://cordis.europa.eu/result/rcn/198275_en.html [Accessed on 24 August 2018].

[Text 9]https://cordis.europa.eu/project/rcn/218796_en.html [Accessed on 24 August 2018].

[Text 10] https://cordis.europa.eu/result/rcn/190238_en.html [Accessed on 24 August 2018].

[Text 11] https://cordis.europa.eu/result/rcn/169470_en.html [Accessed on 23 July 2017].

[Text 12] https://cordis.europa.eu/result/rcn/191178_en.html [Accessed on 23 July 2017].

[Text 13] https://cordis.europa.eu/result/rcn/159597_en.html [Accessed on 23 July 2017].

[Text 14] https://cordis.europa.eu/result/rcn/92724_en.html [Accessed on 23July 2017].

[Text 15] https://cordis.europa.eu/result/rcn/181003_en.html [Accessed on 23July 2017].

[Text 16] https://cordis.europa.eu/result/rcn/90950_en.htm [Accessed on 23 July 2017].

[Text 17] https://cordis.europa.eu/result/rcn/89431_en.html [Accessed on 23July 2017].

[Text 18] https://cordis.europa.eu/result/rcn/88364_en.html [Accessed on 23July 2017].

[Text 19] https://cordis.europa.eu/result/rcn/87421_en.html [Accessed on 23July 2017].

[Text 20] https://cordis.europa.eu/result/rcn/86442_en.html[Accessed on 23July 2017].

Jana Kuzmina (Dr. philol., Asoc. prof. in Linguistics) is currently working at the University of Latvia. Her research interests include the use of English in organisational discourse, applied genre analysis as well as descriptive and prescriptive grammar. Email: jana.kuzmina@lu.lv 


\title{
'COME ROAM WITH ME COLUMBIA'S FORESTS': REPRESENTATIONS OF THE FOREST IN ALEXANDER WILSON'S THE FORESTERS
}

\author{
LAURENCE MACHET \\ Université Bordeaux-Montaigne, France
}

\begin{abstract}
Scottish-born naturalist Alexander Wilson, best known for his multivolume record of the work he did as America's first ornithologist, American Ornithology (published 1808-1814), is also worthy of recognition for his long poem The Foresters, a semi-autobiographical work in which he recounts the journey he took on foot from Pennsylvania to Niagara Falls in 1804. In his poetic treatment of the forest, Wilson contrasts the traditional view of the wilderness (as evident in a typical natural history of the time) with a more nuanced or even apparently contradictory Romantic view of wild nature as sublime and potentially supernatural. The poem, whatever its literary merit, contains the kernel of what Wilson would explore in later writings: the beauty as well as the fragility of the forest and the wilderness; their destruction and his role in that destruction.
\end{abstract}

Key words: Romanticism, epistemological hunting, Native Americans, destruction of nature, wilderness, early American Republic

\section{INTRODUCTION}

Alexander Wilson is best known for his multi-volume work American Ornithology, volume I of which was first published in 1808 , but he was also a poet. True to the love of poetry he had acquired as a youth in Scotland, where he published several poems, he turned to that genre to make an account of his travels to Niagara Falls and wrote The Foresters. In one of the very few essays devoted to the poem, Irving N. Rothman aptly describes it as 'rambling in structure' and varied in styles and purposes (Rothman, 1973: 242). As the subtitle ('A Poem Descriptive of a Pedestrian Journey to the Falls of Niagara in the Autumn of 1804') suggests, this epic, 2,219-line topographical poem details the two-month, 1,300-mile trek on which Wilson set out in late October 1804 with two companions, his nephew William Duncan and one of his students, Isaac Leech. They travelled for the most part on foot from Philadelphia to Niagara Falls via Ovid, in upstate New York, where Wilson and his nephew owned a farm. In December 1804, in a letter to his mentor, the naturalist William Bartram, Wilson recalls

the long circuitous journey [...] through trackless snows, and uninhabited forests; over stupendous mountains, and down dangerous 
rivers; passing over, in a course of thirteen hundred miles, as great a variety of men and modes of living, as the same extent of country can exhibit in any part of North America. (Hunter, 1983: 225)

As another letter to his nephew seems to indicate, writing of the poem was well under way by February 1805:

The solitary hours of this winter I have employed in completing the poem which I originally intended for a description of your first journey to Ovid. It is now so altered as to bear little resemblance to the original; and I have named it the 'Foresters'. (Hunter, 1983: 231.

Wilson kept working on the poem in the first half of 1805 . Originally serially published in 1809-1810 in Joseph Dennie's Port Folio, the country's most important literary magazine, in print between 1801 and 1827, it proved so popular that it was later published as a book. It is the earliest known poem detailing the monumental wonders of the Niagara Falls, still very difficult to reach at the time. The Erie Canal was indeed completed only in 1825 and the Buffalo and Niagara Falls railroad opened in 1834. On a more personal level, the poem also marks a watershed moment in Wilson's life as it represents his first step towards creating the most complete illustrated account of the birds of America that had yet been attempted. As it turns out, the journey recounted in the poem was the first leg of an eventual 10,000 miles that he travelled during his research for American Ornithology, a work that is still considered the foundation of scientific ornithology. Describing himself as he is about to start on his journey, Wilson tells the reader that he is equipped with 'colours, paper, pencils' (Wilson, [1809] 1844: 211), further proof that he intended to draw the scenes he encountered. As he acknowledges in his letter to Bartram, after that first trip, Wilson felt 'more eager than ever to commence some more extensive expedition, where scenes and subjects entirely new, and generally unknown, might reward my curiosity, and where perhaps my humble acquisitions might add something to the stores of knowledge' (Hunter, 1983: 231).

In addition to depictions of the various places the three travelers stayed in and the natural beauty of the landscapes, the poem includes descriptions of the wildlife, with a special focus on the birds Wilson noticed. While providing multi-faceted views of the forests and hinterlands the travelers go through, the poem also chronicles the progression of human settlement along the Susquehanna River, and this topic of settlement is also prevalent in Wilson's letters to friends. With these descriptions, he shows his readers, people from an increasingly urban population, the value and complexity of the natural world. But throughout, Wilson wavers between his reinscribing a traditional view of the forest as a howling wilderness, a wild, dangerous, and frightening place meant to be conquered, and his offering a view of the forest as an untamed, but noble and welcoming part of the natural world. In this apparently paradoxical attitude he shares ideas inherent to the Romantic view of nature. 


\section{‘..THROUGH FORESTS DEEP WE PASSED'}

The forest Wilson invites his readers, those 'sons of the city' (Wilson, [1809] 1844: 208), to explore with him is first and foremost a hostile and frightening place and hence this invitation, as surprising as it seems, signals the poem's ambivalence from the very first line. Wilson's outlook is however congruent with the way colonists perceived the forest between the $17^{\text {th }}$ and the $19^{\text {th }}$ centuries. It was essentially an environment that caused insecurity and discomfort, that threatened the physical integrity of the settlers (Williams 1989: 11), an enemy that had to be conquered. Wilson thus predictably describes the forest as the haunt of dangerous wild beasts, and he repeatedly mentions 'howling' (Wilson, [1809] 1844: 224) or 'midnight' wolves (ibid.: 229) and 'bloody panthers' (ibid.: 224; 229) or 'skulking bears' (ibid.: 235). As etymologically Wilson uses the word wilderness to suggest the place of wild beasts, forest and wilderness seem almost synonymous. Death seems to be lurking everywhere, and even the trees themselves are threatening. Among those listed in the poem, Wilson mentions pines only generically but takes pains to be more specific with the other species of conifer present, 'hemlocks (that) quite shut out the day' (ibid.: 223). Here he may well be playing, and not too subtly, on the polysemy of 'hemlock', both a conifer and a lethal poison; this play on words echoes in the next line: 'Majestic solitudes; all dead and deep' (ibid., my emphasis). The forest is a tomb-like place, tall lofty trees shutting out the light of the sun. Darkness and the power of imagination turn 'the groaning trees' (ibid.) into monstrous shapes that try to trap the travelers 'below dark drooping pines' (ibid.) until they aptly come to a place named 'Shades of Death' (ibid.: 222). This first impression of the forest is definitely that of a hostile environment for man, a place that humans have not yet managed to conquer or put to their use, a wilderness where the forces of nature transform the traveler who survives its real or illusory traps:

The forest is the antithesis of house and hearth, village and field boundary, where the household gods hold sway and where human laws and customs prevail. It holds the dark forbidden things-secrets, terrors, which threaten the protected life of the ordered world of common day. In its terrifying abyss, full of strange forms and whispering voices, it contains the secret of the soul's adventure... (Zimmer, 1975: 182)

In addition, as Roderick Nash points out, 'the idea of a habitat of wild beasts implied the absence of men' (Nash, 1967: 2), or at least of creatures that could be considered human. And, according to Wilson, these creatures can be responsible for gruesome massacres, 'fire, rapine, murder,' the 'bloody bands,' of 'bloodstained savages' (Wilson, [1809] 1844: 242, my emphasis). These descriptions definitely seem to fit that 'invention of the Indian as a beast of the wild wood and devilish fiend' (Bowden, 1992: 187). In several instances in the poem, Wilson systematically refers to the Natives as 'savages'. To call them 'Indians', as he does in some other sections of the poem, or to designate them by the names of their tribes would make them too human for the impression the poet wishes to convey. 
As the word 'savage' comes from silvaticus, 'wild', literally 'of the woods', Wilson plays on both meanings to carry the notion that the wildness of the environment accounts for the Indians' intractability. The wildness of their environment is reflected in the savagery of their behavior and the non-Native inhabitants of the forest are, as a result, constantly in danger of being contaminated by it. As Richard Slotkin puts it, 'the Indian [was seen] as the human embodiment of the devilish essence of the wilderness' (Slotkin, 1973: 201).

The subsequent idea that the forest has the power to dehumanize its nonNative inhabitants is quite common and Hector St. John de Crevecoeur anticipates the same fear when he writes in Letter III that ' $[\mathrm{B}] \mathrm{y}$ living in or near the woods, their [the back settlers'] actions are regulated by the wildness of the neighbourhood', an environment which makes them 'ferocious, gloomy, and unsociable' (Crevecoeur, [1782]2013: 37). To both Crevecoeur and Wilson, then, the wilderness challenges man's very identity as a social being:

Dead lie the lonely woods, and silent shore,

As nature slept and mankind were no more.

How drear! How desolate to ear and eye!

What awful solitudes around us lie! (Wilson, [1809] 1844: 264)

The permeability of the frontier between (white) civilization and (Indian) savagery and the subsequent risk of contamination inform some of Wilson's descriptions of pioneer life. After crossing Tunkhannock's stream, for instance, the three companions find accommodation at 'a famished inn' (ibid.: 231)

unshingled and without a door;

No meat, or drink, or bread, or liquor there;

As Afric's wilds, of every comfort bare (ibid.).

The poet ridicules the place almost to the point of farce. In response to Wilson's enquiring who his neighbors are, the owner replies 'Why, the bears' (ibid.). The poet notes that the travelers prepare their meals 'like hungry wolves', 'hew down the wheaten loaf' (ibid.) and end up sleeping in a 'kennel' (ibid.: 232), making the danger of animalization and savagery even more manifest. He also remarks that the 'township' lacks the attributes of civilization (mill and church, for example); their absence illustrates Frederick Jackson Turner's idea that 'the wilderness masters the colonist. [...] It strips off the garments of civilization and arrays him in the hunting shirt and moccasin. [...] In short, at the frontier the environment is at first too strong for the man' (Turner, [1921] 1953:4).

But there is a significant and marked difference, one that Wilson keeps coming back to and insisting on, between those men traveling or living in the hinterland and non-human animals. The humans have weapons, and this signals their superiority over the non-human animals. As Antoine Traisnel explains, 'With technological progress, the dominance of the human over (other) animals became more pronounced, almost self-evident' (Traisnel, 2012:5). In one section of the poem, Wilson lists all the travelers' artillery that is being admired 
by one of their hosts. This scene not only signals dominance over animals but also celebrates the new powers of American manufacture. On that account, it is interesting to point out that Wilson felt he needed to add a note explaining that Dupont was 'A celebrated manufacturer of gunpowder, on the Brandy wine, whose packages are usually impressed with the figure of an eagle' (Wilson, [1809] 1844: 224). The use of the eagle imagery, the still relatively new national emblem, plays on feelings of national pride.

Our muskets glittering in the hunter's hand;

Now poised, now levelled to his curious eye;

Then in the chimney corner set to dry.

Our clear, green powder-flasks were next admired;

Our powder tasted, handled, rubbed, and fired;

Touched by the spark, lo! sudden blazes soar,

And leave the paper spotless as before

From foaming Brandywine's rough shores it came,

To sportsmen dear its merits and its name;

Dupont's best Eagle, matchless for its power,

Strong, swift and fatal as the bird it bore.

Like Jove's dread thunderbolts it with us went,

To pour destruction wheresoever sent. (ibid.: 224)

Thus, even though danger and death do lurk in the forest, it is humans who are in fact more often than not the agents of death. The implication is that they need to gain or defend the forest territory against the encroachment of wild creatures, including Indians.

The poem thus abounds in references to hunting, from the description of hunting trophies to gruesome killing scenes. In the early nineteenth century, wild game was still extensively killed for food and the forest is depicted as some kind of giant 'meat safe'. As a matter of fact, '[T] he forests of North America were rich in a variety of mammals and birds which provided an easy supply of food and later made hunting an important part of the colonists' domestic economy' (Saikku, 1990: 4). But in The Foresters, hunting goes beyond the mere act of providing food. The hunting scenes are described graphically, appealing to all the senses. They demonstrate man's clear superiority and skill with the technology and seem almost pleasurable for Wilson and his companions:

Two whirring pheasants swept across our path, And swift as lightning flew the fiery death.

A cloud of quails in rising tumult soar;

Destruction follows with resounding roar.

From bough to bough the scampering squirrels bound,

But soon, in smoky thunders, bite the ground;

Life's gushing streams, their sable furs defile, And Duncan's stick sustains the bloody spoil. (Wilson, [1809] 1844:243) 
Even though Wilson's shooting may sometimes seem out-of-control and irrational to a $21^{\text {st }}$-century reader, it is a clear indication of the triumph of technology. Whereas Crevecoeur suggests that guns also dehumanize those who use them by distracting them from what should be their primary mission as settlers, i.e. clearing and farming the land (Crevecoeur, [1782] 2013: 37), Wilson seems indeed to argue that guns definitely give man superiority over the wild beasts of the forest. Nevertheless, as we will see in the next section, Wilson does waver between this vision of the forest as a place needing to be conquered and a place more peaceful, a place whose resources should be listed and cataloged.

\section{'CRASHING FORESTS THUNDERING TO THE GROUND'...}

Wilson systematically contrasts the wild forest with tamed nature, and presents its very wildness as a temporary state, meant to be changed by the hand of man. That is, just like his friend and mentor William Bartram before him, Wilson portrays conquered, useful, domesticated nature in a highly positive way, as 'the beneficent mother, the eternal, stable, quiet place of rest' (Bredeson, 1968: 87). His description of Bucks County, in Pennsylvania, for example, is a scene of pastoral bliss:

Through fertile Bucks, where lofty barns abound, For wheat, fair Quakers, eggs, and fruit renowned;

Full fields, snug tenements, and fences neat,

Wide-spreading walnuts drooping over each gate;

The spring-house peeping from enclustering trees,

Gay gardens filled with herbs, and roots and bees,

Where quinces, pears, and clustering grapes were

With pondrous calabashes hung between;

While orchards, loaded, bending over the grass,

Invite to taste, and cheer us as we pass. (Wilson, [1809] 1844:212)

With such enumeration Wilson points out the fertility of the land which, he argues, when tended carefully, provides plentifully for all, contrary to the 'bare black heaths' (ibid.: 209) of his native Britain. The implication is that, the natural potential being there, it is the settlers' responsibility to till the land; here Wilson silently alludes to Genesis: 'the LORD God took the man and put him into the garden of Eden to cultivate it and keep it' (Gen. 2:15).

The pastoral scenes dot Wilson's poetic landscape and stand in contrast to the dark, tall and seemingly indomitable forest. Wilson, who owned a farm in Ovid with his nephew, never quite loses his farmer's eye, continually appraising the land for its fruitfulness. In this sense, he is typical of an 'enthusiasm for nature in America during the pioneering period [that] almost always had reference to the rural state' (Nash, 1967: 33). As a result, according to Wilson, the successful, hardworking settler who manages both to exploit nature's 
potential in the valleys and to conquer the wilds becomes a generous kingly figure presiding over his domain:

When lo, emerging from the opening wood,

Midst narrow fields a little cottage stood!

$[\ldots]$

The dame's kind looks already bade us rest;

And soon the landlord, entering with his train,

Confirmed her kindness over and over again;

And now the table showed its welcome head,

With cheering fare, and rural dainties spread;

Green sparkling tea, obscured with floating cream;

Delicious salmon from the neighboring stream;

Nice cakes of wheaten flour, so crisp and good,

And piles of honeycombs, ambrosial food! (Wilson, [1809] 1844:246)

This pastoral scene clearly evokes the Promised Land, the land of milk and honey which is depicted in Exodus 3:8 and which here is a domestic enclave in the forest where the local produce, which is fit for the gods, guarantees self-sufficiency.

With its references to the advantages of cultivation of the land, The Foresters paints a portrait of America corresponding to the Jeffersonian agrarian ideal which postulates that free citizens involved in farming was the most egalitarian type of civil organization: 'Those who labor in the earth are the chosen people of God, if ever He had a chosen people, whose breasts He has made His peculiar deposit for substantial and genuine virtue' (Jefferson, [1781] 1801: 244). This idea of the egalitarian is very similar to that which Crevecoeur postulates in "What Is an American?" when he writes: 'Ye poor Europeans, ye, who sweat, and work for the great---ye, who are obliged to give so many sheaves to the church, so many to your lords, so many to your government, and have hardly any left for yourselves' (Crevecoeur, [1782] 2013: 43).Wilson seems to echo this concept in The Foresters when he insists on the direct benefits each farmer can enjoy from working the land, without lord or clergy levying taxes:

Blest with the purest air, and richest soil,

What generous harvests recompense your toil!

Here no proud lordling lifts his haughty crest;

$[\ldots]$

No thief in black demands his tenth in sheaves; (Wilson, [1809] 1844:

259)

For this egalitarian and pastoral ideal to be possible, the forest has to be cleared, a measure that, quite surprisingly, Wilson fully supports. He indeed was paradoxically seemingly promoting settlement, expansion and forest clearing while at the same time being scientifically interested in birds and deploring the loss of their habitat. 
Long may your glittering axe, with strength applied,

The circling bark from massy trunks divide,

Or wheeled in air while the wide woods resound,

Bring crashing forests thundering to the ground;

Long may your fires in flaming piles ascend,

And girdled trees their wintry arms extend;

Your mighty oxen drag the logs away,

Arid give the long hid surface to the day. (ibid.: 259)

The prime function of clearing the forest is to make space for fields and pastures, to clear the land for settlement and farming. But an additional and not altogether unwelcome side-effect of forest clearing is the disappearance of Indians, toward whom Wilson is quite ambivalent:

While fields of richest grain and pasture good

Shall wave where Indians strayed and forests stood; (ibid.: 259)

By opposing wild nature and humanized agricultural land ('fields' that 'wave'), Wilson here turns Indians into natural objects that can be disposed of in the same way as trees. The implicit message is also that those Indians, even though they were 'sons of the forest' (as opposed to the 'sons of the city' of the poem's first line) were not able to improve their natural environment and thrive. Wilson's straying Indians echo the common notion of the 'roaming' Indian that 'prove(d) the nonagrarian qualities of all Indians, who could be dispossessed because of their failure to use the earth (usufruct) according to the Old Testament God's imperative' (Bowden 1992: 188). This idea of improving nature, a by-product of $18^{\text {th }}$ century Enlightenment philosophy, probably guides Wilson in both his appreciation of European settlement and exploitation of nature as the 'Enlightenment continued the Scientific Revolution's project of mastering nature' (Wolloch, 2011:4).

This idea may also account for Wilson's scientific interest in the forest as a reservoir of birdlife to be studied, dissected and cataloged. As Pamela H. Smith and Paula Findlen argue, during the Enlightenment the investigation of nature became an "active" science, pursued by practitioners belonging to various social classes, and it 'began to involve the body; the investigator of the natural world had to observe, record, and engage with nature' (Smith and Findlen, 2002: 16). This is exactly what Wilson did on his Niagara Falls trek, which was the prelude to his later expeditions in search of bird specimens. His seemingly gratuitous killing of a hawk sailing 'serene, secure, and eyeing the expanded scene' (Wilson, [1809] 1844: 217) is thus probably part of this quest, this scientific or 'epistemological' hunting, as Traisnel calls it:

The shifting valence of the hunt from martial to epistemological finds a burgeoning archive in the emergence of natural history museums and science institutions, which depended on the products of the hunt for their specimen collections. (Traisnel, 2012: 7-8) 
Wilson, who provided wildlife specimens for Charles Willson Peale's museum in Philadelphia, certainly seems to be as valid an 'epistemological' hunter as John James Audubon, whom Traisnel chooses as his object of study.

Wilson's quest for knowledge could also take more peaceful turns, as he observed and recorded birds' feeding habits and migrations. He uses them, for instance, as time markers, to give his readers indications about the season by noting the presence of 'clouds of blackbirds' while 'far to the south our warblers had withdrawn' (Wilson, [1809] 1844: 210). The traveler's curiosity and interest in nature may thus signal a shift, or at least the underlying ambivalence that exists between exploitation of the forest's resources and appreciation of the forest per se. The poem seems indeed to build bridges between a rational, eighteenth-century view of the natural world and the budding American Romantic movement.

\section{A 'ROMANTIC' (AND PATRIOTIC?) POEM}

According to the Oxford English Dictionary, Romanticism places 'emphasis on feeling, individuality, and passion rather than classical form and order, and typically prefer(s) grandeur, picturesqueness, or naturalness to finish and proportion' (Online 1). The Foresters definitely presents the reader with the feelings of the speaker of the poem towards and reactions to the landscapes he crosses. From the start, he poses as the unfaltering hero who is going

To catch the living manners as they rose;

The exploits,fatiguesandwonderstorehearse.(Wilson [1809] 1844:211)

He even likens himself and his companions to 'Pilgrims' (ibid.: 221 or 246 for example) and, upon reaching Lake Ontario, the joy he feels is not unlike the one he felt when arriving in America years before:

Ontario is in view!

With flying hats we hail the glorious spot,

And every care and every fear's forgot.

So, when of old, we crossed the Atlantic waves,

And left a land of despots and of slaves,

With equal joy Columbia's shores we spied,

And gave our cares and sorrows to the tide. (ibid.: 265)

In the poem itself the speaker's persona is that of a guide whose mission it is to teach an increasingly urban population how to value wild nature. Its sublimity explains the multiplicity of reactions it could elicit among explorers, from an aesthetic appreciation to sheer terror.

In his Philosophical Enquiry into the Origin of our Ideas of the Sublime and Beautiful, Edmund Burke defines and explains our appreciation of objects that defy the classical laws of aesthetics in nature: 'the aesthetic of the sublime is distinguished as involving a kind of 'negative' experience or oscillation of pleasure 
and pain, attraction and repulsion, caused by a breakdown in the capacity of the imagination' (Cunningham, 2004: 550). Astonishment and terror in front of nature's wonders, Burke argues, induce an aesthetic emotion: 'The passion caused by the great and sublime in nature, when those causes operate most powerfully, is astonishment: and astonishment is that state of the soul in which all its motions are suspended, with some degree of horror' (Burke, 1757: 95). The criteria of obscurity, vastness and terror, mentioned in Burke's definition of the sublime, are all present in The Foresters, and the word sublime itself appears repeatedly. Wilson's forest perfectly illustrates Cronon's definition of eighteenth-century wilderness as 'a landscape where the supernatural lay just beneath the surface [...] expressed in the doctrine of the sublime...' (Cronon, 1995: 73). By the very act of writing such a poem and by turning the forest into an aesthetic object, Wilson moves away from a purely rational natural history approach, a shift initiated by William Bartram in his Travels and one that can also be witnessed in sections of Wilson's Ornithology.

As early as the first years of the nineteenth century, enjoyment of the wilds and woods seems to have been an essentially urban phenomenon, possible only when distance and development made the forest less threatening. To view things in a slightly more cynical way, the wilderness could be enjoyed only by 'people whose relation to the land was already alienated' (Cronon, 1995: 80) as 'it was the privilege of those far enough removed from nature to be able to see it as scenic backdrop and not, as in the case of the plain dirt farmer, in the relationship of daily antagonist' (Bredeson, 1968: 89).

And indeed at the very beginning of the poem, Wilson addresses his urban readers directly:

Sons of the city! ye whom crowds and noise

Bereave of peace and Nature's rural joys,

And ye who love through woods and wilds to range,

Who see new charms in each successive change;

Come roam with me Columbia's forests through. (Wilson, [1809] 1844: 208).

Thus, as Roderick Nash contends, 'appreciation of wilderness began in the cities' (Nash, 1967: 44). Distance from the forest, or from the wilderness in general, generates an appeal that it does not hold when the explorer is battling it. Besides, one can argue that in the early nineteenth century, the Romantic forest, silent and impenetrable, was a fabrication (Denevan, 1992: 418). Along with Williams and Denevan, Bowden contends that the impenetrable, primeval forest had already disappeared and was thus a literary construct (Williams, 1989: 33; Bowden, 1992: 188). Bowden adds that the motivation behind that fabrication was to downplay any agency the Indians may have had on the environment in order to justify dispossession (Bowden, 1992: 188). To an increasingly urban $19^{\text {th }}$ century population then, the dwindling forest could become a desirable 
literary and aesthetic object, as well as a place to be enjoyed, preserved and not just exploited or disposed of.

The sympathy created by distance may also account for Wilson's ambivalent treatment of Native Americans in the poem. The notion of ambivalence, in a colonial context, 'describes the complex mix of attraction and repulsion that characterizes the relationship between colonizer and colonized' (Ashcroft, 2007: 12). In some sections of the poem, Native Americans, the natural inhabitants of the forest according to Wilson, are presented as allies of the British during the War for Independence. Wilson implies that, as such, they deserved to be hunted down and killed, as happened during the Sullivan-Clinton expedition in 1779 that destroyed Iroquois villages and winter crops and saw members of the Six Nations relocate to Canada:

Thanks to the brave, who through these forests bore

Columbia's vengeance on the sons of gore

Who drove them howling thro' th' affrighted waste,

Till British regions sheltered them at last. (Wilson, [1809] 1844: 242)

However, when Indians are no longer perceived as a threat, Wilson can afford to sympathize with their fate and can express nostalgia at the loss of their habitat and traditional way of life:

Ah! melancholy scene, though once so dear

To the poor Indian haply wandering here,

Whose eye forlorn, amid the gushing flood,

Beholds the spot where once his wigwam stood,

Where warriors' huts in smoky pride were seen,

His nation's residence, his native green, (ibid.: 248)

Or:

Howe'er stern prejudice these woes may view,

A tear to Nature's tawny sons is due. (ibid.: 249.

As Slotkin maintains, 'Once the threat of real Indians was removed from proximity to American civilization and banished to the frontier, the mythicization of the Indian could proceed without the problems and complexities arising from the realities of Indian-white relations' (Slotkin, 1973: 356-357). Wilson's poem, just as Slotkin's passage suggests, switches to the singular, 'the Indian', and from the paradigm of the Ignoble to the Noble Savage. Once deprived of his dangerous character, the Indian came to embody pride, courage and adaptation to his environment, all the virtues that could make him a perfect American citizen (Cro, 1990: 102). Wilson's poem thus plays on the theme of the vanishing Indian, noble and brave but losing his freedom and his land (here, the vanishing forest), necessarily sacrificed in the making of America. 


\section{CONCLUSION}

Because of Wilson's dual status as a naturalist and a poet, his representation of the forest is inherently ambivalent. In typical eighteenth century scientific reasoning, his forest is at worst an obstacle to agriculture, at best a place to be managed and exploited, and its Native inhabitants to be disposed of or displaced. But this rational and expansionist outlook collides with his Romantic vision of America's forests, and landscapes in general, as the repositories of some sort of national character jeopardized by development. Upon reaching the Niagara Falls region, a significant landmark in the French and Indian war and in the War for Independence, Wilson celebrates 'Columbia's stars' (Wilson, [1809] 1844: 270) and makes the Falls a national landmark. In a mere two lines, he also captures the tension that has run throughout the poem:

The right a wilderness of woods displayed,

Fields, orchards, woods, were on the left arrayed (ibid.)

Regret for what would soon be the country's past is never far distant and complicates Wilson's apparent unreserved endorsement of progress, making him a perfect illustration of Ekirch's assertion that 'No other nation equaled the American people in their paradoxical ability to devastate the natural world and at the same time mourn its passing' (Ekirch, 1973: 189).

\section{REFERENCES}

Ashcroft B., Griffiths, G. and Tiffin, H. (2007) Post-Colonial Studies: The Key Concepts. London \& New York: Routledge.

Bowden, M. J. (1992) Invented tradition and academic convention in geographical thought about New England. GeoJournal, 26 (2): 187-194.

Bredeson, R. C. (1968) Landscape description in nineteenth century American travel literature. American Quarterly, 20 (1): 86-94.

Burke, E. (1757) A Philosophical Inquiry into the Origin of our Ideas of the Sublime and Beautiful. London: Dodsley.

Crevecoeur, J. H. St John. ([1782] 2013) Letters from an American Farmer and Other Essays. Cambridge: Harvard University Press.

Cro, S. (1990) The Noble Savage: Allegory of Freedom. Waterloo (Ontario): Wilfrid Laurier University Press.

Cronon W. (1995) The trouble with wilderness; or, getting back to the wrong nature. In W. Cronon (ed.) Uncommon Ground: Rethinking the Human Place in Nature (pp. 69-90). New York: W. W. Norton \& Co.

Cunningham, D. (2004) How the sublime became 'now': time, modernity, and aesthetics in Lyotard's rewriting of Kant. Canadian Journal of Continental Philosophy, 8 (3): 549-571.

Denevan, W. (1992) The pristine myth: the landscape of the Americas in 1492. Annals of the Association of American Geographers, 82 (3): 369-385.

Ekirch, A. (1963) Man and Nature in America. New York: Columbia University Press.

Hunter, C. (ed.) (1983) The Life and Letters of Alexander Wilson. Philadelphia: American Philosophical Society. 
Jefferson, Th. ([1781] 1801) Notes on the State of Virginia. Boston: Carlisle.

Judd, R. (2006) A 'wonderfull order and balance': natural history and the beginnings of forest conservation in America, 1730-1830. Environmental History, 11 (1): 8-36.

Nash, R. (1967) Wilderness and the American Mind. New Haven: Yale University Press.

Rothman, I. N. (1973) Alexander Wilson's forest adventure: the sublime and the satirical in Wilson's poem 'The Foresters'. Journal of the Society for the Bibliography of Natural History 6.4: 242-254.

Saikku, M. (1990) The extinction of the Carolina parakeet. Environmental History Review, 14 (3): 1-18.

Slotkin, R. (1973) Regeneration Through Violence: The Mythology of the American Frontier, 1600-1860. Norman: University of Oklahoma Press.

Smith, P. and Findlen P. (2002) Merchants and Marvels: Commerce, Science and Art in Early Modern Europe. New York: Routledge.

Traisnel, A. (2012) Huntology. Ontological pursuits and still lives. Diacritics, 40 (2): 4-25.

Turner, F. J. (1953 [1921]) The Frontier in American History. New York: Henry Holt \& Co. Williams, M. (1989) Americans and their Forests. Cambridge: Cambridge University Press.

Wolloch, N. (2011) History and Nature in the Enlightenment. Farnham: Ashgate.

Zimmer, H. (1975) The King and the Corpse, Tales of the Soul's Conquest of Evil. Princeton: Princeton University Press.

\section{INTERNET SOURCES}

[Online 1] Available from http://www.oed.com/ [Accessed on 15 January 2018].

\section{SOURCE ANALYZED}

Wilson, A. ([1809] 1844) The Foresters in Poetical Works of Alexander Wilson, the American Ornithologist. Belfast: John Henderson.

Laurence Machet ( $\mathrm{PhD}$ English, Assoc. prof.) is currently working at the University Bordeaux-Montaigne, France. She is involved in a new project 'Indigenous Peoples and the Environment' and coedits academic journal Elohi. She is currently working on $18^{\text {th }}$ century American travel writers in the Southeast.Email: Laurence.Machet@u-bordeaux-montaigne.fr 


\title{
THE SURVIVANCE IN THE LITERATURE OF THE FIRST NATIONS IN CANADA
}

\section{CHRISTOPHE PREMAT}

Stockholm University, Sweden

\begin{abstract}
The article examines the way the writers of the First Nations in Canada deal with the issue of survivance which implies a collective resilience. It is based upon a comparison between the first novel of Naomi Fontaine, Kuessipan (2011) and the poetry of Rita Mestokosho collected in How I see Life, Grandmother, Eshi Uapataman Nukum, Comment je perçois la vie, grand-mère (2011). Both writers belong to a tradition of littérature autochtone in Québec that has become more and more visible since the 1980s. If both writers share the paradigm of decoloniality, their aesthetics remains classical with the use of a minimalist style to express the beauty of the Innu way of life.
\end{abstract}

Keywords: survivance, invisibility, Innu, poetic, First Nations

\section{INTRODUCTION}

In one of his last seminars, Jacques Derrida (2000) introduced the notion of survivance, which he associated with the future of generations. Whereas the idea of survival expressed, in his view, the individual aspect, survivance could reveal a form of transgenerational solidarity. The perspective of survivance is clearly associated with the idea of loss; there is a notion of remembrance of beloved people.

But how can the survivor speak in friendship about the friend, without a 'we' slipping in indecently, incessantly? without a 'we' even demanding, in the name of friendship, to be heard, precisely? For to silence or to forbid the 'we' would be to enact another, no less serious, violence. The injustice would be at least as great as that of still saying 'we'. (Derrida, 2000: 28)

In other words, the survivance echoes the idea of a posthumous tribute and for Derrida, the first proof of an intimate solidarity emerges with the possibility of saying 'we' as a collective entity. The strong links beyond life and death are also dealt with in the literature of the First Nations, but in this case, the survivance expresses the posterity of a collective trauma. Jacques Derrida dealt with the Latin root of the word posthumous, post-humus which is something that disappears and is mixed with different elements in the soil. The First Nations is the official category used in Canada to classify all the indigenous communities such as the Innu, the Cree, Chipewyan and other communities. The emergence of indigenous literature has been attested at the end of the 1960s (Moura, 2005: 16) 
when these minorities began to claim their cultural rights in Canada (Brubaker, 2001). In the spiritual survivance of the First Nations, there is a mixture of collective memories that are re-membered and reincorporated into the actions of new generations. 'Native American Indian literature is not a newcomer in the course of literary resistance to dominance. Natives have resisted discovery and dominance for centuries, from the first stories of touch and breach of trust' (Vizenor, 2009: 8). In other words, the survivance characterizes a postgenocide attitude that all the members of these minorities have. For Vizenor, the survivance is different from the survival, it is a fundamental refusal of victimization; on the contrary, the survivance aims at reminding the ancestral traditions that help to heal the deep wounds caused by the social and historical erasure of the indigenous communities (Logan, 2014: 149).

The expression cultural genocide was used in the report of the Truth and Reconciliation Commission of Canada (henceforth: TRC) which was established as a result of the Statement of Reconciliation of 7 January 1998 to collect evidences about the residential situation of Indigenous children (TRC, 2015). The commission illustrated the institutionalization of memory as an attempt to analyze the consequences of such an official violence against First Nations communities (McDonald, 2017: 168). The hypothesis here is that literary texts from the First Nations reveal an attempt to create a counter-narrative on the daily life of the indigenous communities (Bhabha, 1994: 66) where the resistance to the official narratives is expressed in a poetic style. These writers use the language of the colonizer in order to address a message on the future of the First Nations. A counter-narrative illustrates the emergence of a literature that gives a strong voice to the indigenous communities who were deprived of expression.

This hypothesis will be tested with the help of two women writers, Rita Mestokosho and Naomi Fontaine, that are quite representative of the Innu literature in Québec. Both writers refer to the space of reservations where these communities were grouped and describe the difficulty of transmitting the core values and principles of a culture which was erased. In fact, the transmission of these values is a crucial question for the resilience of the Innu identity. The transmission needs to be ensured, this is why aesthetics is used in a pedagogical perspective (Pirbhai-Illich et al., 2017: 5). The aim of these writers is to create an alternative narrative on the life of the Innu people. They have to write themselves to avoid outside voices and a negative process of othering (Loiseau, 2010: 1012) where the Innu identity is categorized in negative public policies (revitalization, alcoholism). Gerald Vizenor, a native American Indian, showed the fundaments of a colonial narrative that is prevailing in most of Western societies. The historical periodization is founded on an initial trauma that opens up the Modern times.

The Heirs of Christopher Columbus created one more New World in their stories and overturned the tribal prophecies that their avian time would end with the arrival of the white man. The heirs warm 
the stones at the tavern with their stories in the blood. The tavern is on the natural rise of a meadow, and tribal panic holes are sown near the mount. The House of Life is on the descent to the headwaters, the burial ground for the lost and lonesome bones that were liberated by the heirs from museums. (Vizenor, 1991: 5)

All the First Nations are aware of this narrative which is transmitted throughout the generations. Some authors claimed that there was a revival of the literature of the First Nations in Canada in the 1980s with an increasing production of books (Giroux, 2008: 30). Many members of the First Nations used literary texts as forms of cultural production to re-empower the self-perception of these communities (Premat, 2017: 74). If the Innu community is often perceived in its political dimension, there is also a textual specificity in this literature. The Innu literature tends to select the poetic form as a strategic choice to express the resilience of the Innu identity. The poetic form is characterized by the use of nominal phrases, aphorisms and short meanings. In order to test this hypothesis, two recent books will be analyzed, the first book written in French by Naomi Fontaine, Kuessipan (2011, 113 pages) and the collection of poetry written in a trilingual edition (Innu, French and English) by Rita Mestokosho, How I see Life, Grandmother / Eshi Uapataman Nukum / Comment je perçois la vie, grandmère published in the same year, 2011 (95 pages). The study will focus on the comparison of the texts, the profile of publishing houses Mémoire d'encrier and Beijbom Books and some selected interviews with the authors.

\section{THE INNU LITERATURE IN QUÉBEC}

The Innu community represents today around 15000 persons divided into nine villages. They live in the region Basse-Côte-Nord along the river St. Lawrence in the Northeastern Québec. The classification of the writers of the First Nations is not easy, some scholars referring to a general term such as indigenous literature (Boudreau, 1993: 15), others preferring the term of littérature autochtone (SaintAmand, 2010; Chartier, 2015: 20) to categorize the writers of the First Nations that live in Québec (Assiniwi, 1989: 46). Assiniwi is a writer of the First Nations, he used littérature autochtone to distinguish it from the other provinces of Canada. The researchers opting for indigenous literature seem to perceive this style in a more generic way (Machet, 1999: 16) close to ethnopoetics, which means the use of poetry to express ancestral traditions (Beaujour, 1989: 210). As Gerald Vizenor wrote,

In the oral tradition, the mythic origins of tribal people are creative expressions, original eruptions in time, not a mere recitation or a recorded narrative in grammatical time. The teller of stories is an artist, a person of wit and imagination, who relumes the diverse memories of the visual past into the experiences and metaphors of the present. (Vizenor, 1984: 7) 
Ethnopoetics focuses on the performance of these artists that contribute to the transmission of values, beliefs and attitudes. For some of the writers, the term autochthonous echoes to 'Indian' and refers to the imposition of categories and names (Mestokosho, 2009; Momaday, 2010) by the colonizers (Caron, 2012: 12). As Rita Mestokosho said,

I made some research on how the Indians were categorized. There are federal departments in Canada and they classified the Indians in the department of immigrants. They did not even know where to register us, they should have left us alone. In our life of hunters, in our life of great freedom. (Mestokosho, 2009)

For Mestokosho, using those words even for literary classification is borrowing the words of the colonizers even if the word autochthonous is the official name that can be found in the Canadian administration. The writers of the First Nations do not only write, they are also journalists, moviemakers, cultural mediators and singers. Jean-Louis Fontaine (born in 1951), Louis-Karl Picard-Sioui (1976), Geneviève McKenzie-Sioui (1956), Maya Cousineau-Mollen (1960), Virginie Pésémapéo Bordeleau (1951), Georges Sioui (1948), Charles Coocoo (1948), André Dudemaine (1950), Alice Jérôme (1948), Julian Mahikan (1975), Michel Noël (1944), Jean Sioui (1948), Sylvie-Anne Sioui-Trudel (1956), Marie-Andrée Gill (1986), Christine Sioui Wawanoloath (1952) and Joséphine Bacon (1947) represent the development of this literature.

Rita Mestokosho (born in 1966) is a political representative of the community of Ekuanitshit (150 people) in the council of the First Nations and a poet. She works on the cultural development of the First Nations and has been engaged against the extractivist projects from the provincial government in the region of Côte Nord. Ekuanitshit means "place surrounded by mountains" (Mestokosho, 2009), the toponymy is important for Rita Mestokosho as these places belong to the First Nations. As a member of a tribal council, she has a seat in different assemblies from the local level to the provincial and federal ones. Her first collection of poems was published in 1995 (Mestokosho, 1995) and was reedited in 2010 and 2011 after the French writer Jean-Marie Gustave Le Clézio paid tribute to writers from the First Nations during his reception speech of the Nobel Prize in Literature in 2008 (Sule and Premat, 2011: 20). Rita Mestokosho explained that she used French to address a political message to a broader audience.

And when I wrote the poems, every word was thought in Innu before being transcribed in French. [...] I conceived them in my Innu soul. I slept on fir mats, I swam with salmon in the rivers, I know that I have all this inside me, you know. And to have the privilege of writing in French and be able to share it, I am all the more happy, because I find that poetry is a secret weapon, even if I do not like the word weapon. Poetry chose me. (Mestokosho, 2009) 
Rita Mestokosho considered poetry as an open strategy to awake the readers' emotion and empathy for the First Nations. She wrote in Innu before translating the poems into French and she perceived poetry as a genre that just transcribes experiences and deep emotions. The choice of words is very important and the Innu-Aimum language has an aggregative syntax where the words refer to a series of relations to the nature. Poetry differs from political discourses as people are more receptive and get interested in learning more about the culture and the traditions of the First Nations.

Naomi Fontaine was born in 1987 in the community of Uashat (Online 1), she became writer to understand her own history as she noticed that she did not know her ancestors (Online 2). She had access to the history of the colonizers and she needed to use literature to express the complexity of the Innu identity. According to Naomi Fontaine, literature offers a possibility to give lessons to white colonizers. The white colonizers do not know the Innu way of life, they would be lost in the forest (Online 2). It is one of the last possibilities to resist violence and humiliation. Literature is a way of giving a feeling of pride to the community. The writer Natasha Kanapé Fontaine points out that writing is an act of resistance against extreme forms of racism. 'Racism is built on the silence of those whom we reject and of whom we are afraid' (Ellis Béchard and Kanapé Fontaine, 2018: 13). Naomi Fontaine writes in French with words from InnuAimum, she inserts them into her novels to show that the First Nations cannot be reduced to a negative perception that white colonizers have. Naomi Fontaine would like to fight for the dignity of her community and shares the same ideas as Natasha Kanapé Fontaine.

No one actually needs to be punished for this racist culture. We should instead serve the community good food for the spirit. I am constantly telling Québécois and other peoples who descend from colonizers that it is not their fault. The fault lies with those who created this country on a foundation of racism and discrimination, and the government leaders who have perpetuated this system. That's a proven fact. We, the Indigenous Peoples, have known this from the beginning. We had seen it in our oracles and our camp fires at night, long before the arrival of the 'White man' on the continent. (ibid.: 11)

Fontaine and Mestokosho wrote and talked about the genocide of the First Nations. Naomi Fontaine also expressed in many interviews and conferences (Online 2) the necessity of having a decolonial attitude. A decolonial attitude means that the First Nations have to reject the oppressive system and every form of colonialism. Decolonizing takes time and this is why the Innu literature is precious to re-empower the Nations in a long-term perspective. If Rita Mestokosho and Naomi Fontaine belong to different generations, they want to transmit traditions and other ways of thinking in order to denounce the disastrous consequences of colonialism. They do not want to blame the new 
generations of white readers, they just want to open their eyes on the reality so that they can contribute to a decolonial gesture. Literature is used as a cultural empowerment for these writers.

\section{THE POST-GENOCIDE PERSPECTIVE AND THE POETIC FORM}

The poems of Rita Mestokosho are not easy to classify as they fall between an elegy for a lost world and the hope for a continuation of ancestral traditions. The poetic form is not perceived here as a 'mirroring or imitative' (Hurley and O'Neill, 2012: 7) process where the verses reflect and translate a sociological reality; it is an association of sounds that contribute to a kind of prayer. The religious aspect is maybe the most important one in Mestokosho's work, as the transmission of values to new generations is expressed in a metaphorical meditation. For instance, the poem Tshishe Manitu! illustrates this prayer with the anaphora 'May my'. 'May my heart shine brightly with joy / when it hears your name / May my eyes gaze upon / the one truth you are. / May my ears hear only the word of God' (Mestokosho, 2011: 61). The prayer associates God with the Earth and the human beings living on it, it is a general text addressed to everybody without any pragmatic intention. This poem is characterized by a feeling of absolute presence (De Raeymaeker, 1940: 32). The anaphora is here necessary in order to activate an intensity of emotions where all the senses are evoked (eyes / ears / heart). God is the recollection of all those small perceptions. 'Form is a poem's principle of life. It is protean, multiple, ever-changing. It presents itself under many different guises' (Hurley and O'Neill, 2012: 1). The prayer is all the more striking as God is presented from an outside reality ('Thus may I spread the word of God') before becoming an intimate feeling of love. 'Most important, may I never mislay the greatness of your / love in the suffering of life; instead, may I share it / with all the men and women around me' (Mestokosho, 2011: 61). The anaphora creates a fluid rhythm with an emphasis on specific syllables.

The poem Tshishe Manitu! is built around a gradation so as to invoke the divine presence that produces love. This poem is surprising as the reader is used to the celebration of natural elements in other poems by Rita Mestokosho. Here, the meditation embraces the spiritual energy of life. Tshishe Manitu! is a common expression in the Innu language in Northern Québec; it is the title of a fairy tale told to children (Online 3). More recently, Florent Vollant composed a song with this name (Online 4). Rita Mestokosho commented on the expression Tshishe Manitu in the following way:

The further I go towards the North, that is to say towards old age, the more I realize that I still have in me this hope that people can change. Maybe that's what it is, faith in God. I call it Tshishe Manitu the Great Spirit, this beautiful light, this sun that illuminates our 
lives despite everything. (Indigenous Women's Turn to Take the Talking Stick, 2018: 260)

The prayer reveals the idea of rediscovering a human path (Mistapéo in InnuAimun) where God expresses the harmony of natural elements. The North for Rita Mestokosho is the orientation of the journey where ancestral traditions recall this initial harmony. The North is the dream that animates human beings as they have to rediscover their ancestral voices.

In fact, it shows that Rita Mestokosho is inspired by a long oral tradition that celebrates a spiritual form of unity between divine and natural elements. The idea is to have a comparative poetology to analyze the literature of the First Nations. The comparative poetology is close to ethnopoetics, but it is not a mere transcription of oral traditions, it is a creative process that tries to incorporate the echo of some fundamental sounds for the Innu. Some of the poems of Rita Mestokosho appear in Innu, French, English and Swedish such as the poem A Poet Wild and Free. The first verse of the poem in Innu shows recurrent sounds: 'Nitshituteti tshetshi nishtuapataman innium' (Mestokosho, 2011: 45) / 'I set out to battle life and reign supreme' (ibid.: 47). These sounds are very ancient; they belong to the language Innu-Aimum; there are no vowels and these sounds were always transmitted through oral traditions before being transcribed into the written language. In Canada, there was a standardization of the Innu language at the end of 1989 (Mollen, 2006: 23) with an uniformization of the written language. The Innu-Aimum language is characterized by the distinction between inanimate and animate classes of nouns; there are neither feminine nor masculine forms. Innu-Aimum is an aggregative language where the derivation form is used to mark the aspect of the meaning. Moreover, the determiner is included in an aggregative form at the end of the word. The qualification of the type of action is concentrated in the word. The verbs are a prevailing grammatical category and even the colours are expressed by animate or inanimate verbs. As a matter of fact, the translation from Innu-Aimum into English or French is problematic as these variations of perceptions are lost. The choice of a poetic form is also linked to the difficulty of translating a mixture of perceptions that exists in Innu-Aimum meanings. The repetition of the sounds in the poems creates a feeling of diffusing and diffracting possible images of the Innu Being. Jean Baudrillard, in his work on image and simulacrum, also dealt with the choice of words in poetic texts.

In fact, the theme-word is diffracted throughout the text. In a way, it is 'analysed' by the verse or the poem, reduced to its simple elements, decomposed like the light spectrum, whose diffracted rays then sweep across the text. (Baudrillard, 2017: 219)

The sense of diffraction characterizes the Innu texts as they progressively enlighten the world. The "theme-words" do not represent fixed entities, but contribute to the transmission of deep feelings associated with elements of the surrounding world. Each page could be read as a separate poem where places, objects and persons have existence. Some of the First Nations writers define 
their literature as a form of meditation (Assiniwi, 1989: 46) or a story-telling process (Vizenor, 1984: 7) where the truth of the First Nations can be expressed. Assiniwi wrote a saga to tell how the genocide happened and its consequences on the existence of the First Nations (Assiniwi, 2000: 275).

The publishing houses have a key role as they give a voice to this type of literature. This is the case for the publishing houses Mémoire d'encrier for Naomi Fontaine and Beijbom Books for Rita Mestokosho. The publishing house Beijbom Books was founded by the Swedish journalist, Karl Beijbom who has been active since the 1970s. He received a prize for his engagement in journalism in 1974 (Online 5) and created the publishing house Beijbom Books AB in 2009 (Online 6). He is well-known for his originality in journalism; the jury's motivation for his prize in 1974 pointed out that 'he succeeded in transforming Arbetaren into a multicultural and non-orthodox forum for a free cultural and political debate at a time of polarization and press death' (Online 7; translation mine). Karl Beijbom published poetry, aphorisms and novels and paid attention to multilingual translations and relations between foreign languages. This is why Beijbom books edited a first version of Mestokosho's book in French, Swedish and Innu (Mestokosho, 2010) and later a version of the book in English, French and Innu (Mestokosho, 2011). Moreover, the multilingual version was made for several types of readers, but at the same time it contributes to a form of intercultural reading. The intercultural reading evokes an empathy for other means of expression. In this perspective, this intercultural reading is important in order to have an intercultural understanding and a de-centered view of the diversity of cultures (Lau, 2016: 11). The publishing house Mémoire d'encrier of Montréal is specialized in the promotion of cultural diversity with an emphasis on the stream of litterrature autochtone.

The novel Kuessipan by Naomi Fontaine was translated into English; the word Kuessipan means 'your turn'. It is a fundamental address to the Innu community in order to imagine the future. The novel was written in French and is composed of a series of short paragraphs reflecting the mental and physical barriers of the reservation. The style of the novel is close to a lament where short phrases reveal the difficulty for an Innu to live as an Innu. The meaningless surrounding of the world enlightens the condition of the young Innu generation. The Innu community is colonized by other categories that destroy their possibility of imagining a future. The reservation is suggested at the beginning of the novel with the fog that represents an unknown place.

Dense fog. The poor visibility makes the drivers slow down. Sometimes they put on their flashers to help each other get oriented. The road is wet. No one takes a chance on passing. In the dark, you see better with the headlights on low. It won't last more than a few minutes, an hour. (Fontaine, 2013: 10)

The metaphors and the metonymies prevail in the text of Naomi Fontaine to circumscribe the space of the reservation. As Sojcher wrote, 'if poetry is 
a space that opens up in language, if through it words speak again and meaning becomes significant again, it is because there is between everyday language and rediscovered speech a shift of meaning, metaphor' (Sojcher, 1969: 58). There is a density in the style of Naomi Fontaine where common expressions reveal the shift in perceptions. In addition to this, the short sentences ('the road is wet') anchor the scene. The reservation is perceived as an intermediate space where nobody dares to stay. The time is also uncertain; the duration seems to create a form of suffering ('It won't last more than a few minutes, an hour'). The first picture of the reservation is associated with darkness ('dense fog' / 'the dark'), something which is unknown, obscure. The cars are like modern objects that go through those invisible spaces. The reservation is a form of a small and liminal space (den Toonder, 2017: 133-146) where the borders are not perceived. The drivers would slow down when they penetrate this space. The metaphorical aspect of the paragraph is striking; there is the presentation of the social invisibility of this space (Bhabha, 1994: 52). The book is a denunciation of the way the reservation is created as a negative space. These small phrases introduce a dense rhythm which is much more efficient than a discourse on the situation of the Innu community. The sociological situation of the community is dealt with thanks to this poetic style where the phrases are something between aphorisms and verses.

They blamed the fog. It was the usual mist you get on May evenings. The damp wind off the sea carries grey clouds over the road from Uashat to Mani-utenam. The fog must have been thick, opaque, and impenetrable. It must have been a black night, dark and moonless. The other cars shouldn't have been there. He should have been the only one on the road, finding his way, moving through the humid air'. (Fontaine, 2013: 10)

The use of personal pronouns is significant with a difference between 'they' and 'he'. The road that he takes is not the same road that the drivers take. In other words, there is a distinction of perceptions in this environment; the road is the way that drivers take but it is also a metaphor for spiritual destiny. The meaningless destination is due to the emergence of other categories that prevent the achievement of this spiritual journey. Naomi Fontaine has used all the personal pronouns in French (' $\mathrm{Il}$ ', ' $\mathrm{Il}$ ', ' $\mathrm{Je}$ ', ' $\mathrm{Tu}$ ') to create a mixture of narratives. In Innu-Aimum, the nouns imply a direct relation from one human being to the other such as the word Kuei which would mean 'Hello my deep friend' (Ellis Béchard and Kanapé Fontaine, 2018: 9).

The moral pattern prevails in the indignation ('the other cars shouldn't have been there. He should have been the only one on the road') to point out the different cultural perceptions of the destination.

The feeling of in-between indicates the social invisibility of these communities that are segregated into those Northern reservations. The nominal sentences illustrate the difficulty of seeing the way out. 'Fear, inexperience, 
speed, recklessness, taking chances - a way out' (ibid.). There is a reference here to several perceptions: the fear and the inexperience are associated with the driver, but it also emphasizes the challenges that the community has to face. This is why those short phrases are very powerful as they multiply the possible associations. The narrative is poetic in its way of compressing the sentences to express a very tough reality.

I wish you could meet the girl with the round belly. The one who will raise her children on her own. Who will scream at her man when he cheats on her. Who will cry all alone in the living room, who will change diapers all her life. Who will look for work at thirty, finish high school at thirty-five, who will start living too late, who will die too soon, completely exhausted and unsatisfied. Of course I lied. I threw a white veil over the dirt. (Fontaine, 2013: 11)

The social fatality is here highlighted by the use of anaphora 'who will' as if there was a curse. The author explicitly includes the reader in the book and proposes an image of what an Innu woman's life looks like. The future is like a repetition of the current condition and the lament denounces the negative perception of Innu life. In reality, the decolonial perspective is absolutely essential in this book. The reader can have access to the social misery of the people living in the reservation, but also needs to deconstruct the usual categories of perception when it comes to the presentation of the reservation and the community. Naomi Fontaine gives an access to feelings and emotions that are shared by different generations of Innu. The focus is not on characters but on perceptions. The classical attributes of a novel do not appear, Kuessipan has a minimalist aesthetics that reflects a decolonial vision (Bhaba, 1994: 12).

Naomi Fontaine's poetic style is original as it creates different states of perception depending on the cultural reading that can be made. The Innu are used to being perceived as a specific target in the domain of public policies. As a matter of fact, they are often represented by the words such as alcoholism, violence and single mothers, but the reality is that the community never had the possibility to develop self-perception strategies. Rita Mestokosho named the presence of the technical colonization with the presence of machines in the poem A People Without Their Land: 'His sadness will be vast as the sea / For he'll have seen the land die under his feet / Devoured first by men and machines / To construct a new city's streets' (Mestokosho, 2011: 69). The poem is a tribute to the communities of the First Nations where the land is considered as a Being in itself, the support of the Innu way of life. Here, the accusation of the poem is strong as the colons are denounced in their tendency to erase the past and the future of the Innu community.

'In a place that lacks support and respect / You'll stagnate my child, and you already do / Your ambition and thirst for power bring death / But, despite that, my spirit will win through' (ibid.: 69). 
The spirit is the element of survivance that is impossible to dominate; it represents a deep form of liberty. In this context, the essence of colonialism is perceived in power relations. The children can be segregated and dominated, but the spirit is unalienable.

The urbanization of the world is here characterized by a territory dispossession. In this perspective, Naomi Fontaine described the city as an impersonal and rootless space (Fontaine, 2011: 29). The poetic form is necessary in both works to point out a feeling of loneliness between two antithetical paradigms, but there is another possible breath in the dynamics of resilience.

\section{SURVIVANCE AND RESILIENCE}

Not only is the poem an efficient literary genre to break the flow of colonial narratives, it is also a strong mode of resilience for the First Nations. The poetry is efficient as it reminds the reader of their own traditions with specific attention being given to the environment. Jean-Marie Gustave Le Clézio contributed to the acknowledgement of Rita Mestokosho in his Nobel speech in 2008 (Mestokosho, 2011: 11).

Rita's voice touches our hearts because it is natural and accessible and there is nothing affected about it. She speaks for the creatures which live alongside us in the world and which we must respect, the salmon in the river, the bear in the forest, and the smooth pebbles in the streams. There is muted pain, like the low sound of the wind, the murmur of trickling water. The call of the horizon, the recollection of wide-open spaces one crossed by the nomads as they hunted and gathered wild plants. (Mestokosho, 2011: 11)

The poetry of Rita Mestokosho reconnects the reader to simple and important feelings that include human beings and natural elements into the world. In her poems, there are correspondences between the Innu spirit and other beings that the reader needs to look at. It is as if the Innu had to forget what they have learnt in order to see their own environment. The loyalty to the environment is constitutive of the Innu identity. It is also possible to find quotes that describe the simple way of being in the world in the novel of Naomi Fontaine when she writes about the salmon in the river (Fontaine, 2011: 46). The silence is opposed to the noise of modern life in order to see and hear the other beings such as salmon. Being away from this peculiar way of life is a source of unhappiness and Mestokosho's poem 'Innu' is the first poem that reveals this absolute necessity.

'With the unique smell of the woods / Ingrained so deep it is in your bones / You dwell alone with your thoughts / But from the way you act and live / I sense you miss your way of life' (Mestokosho, 2011: 17).

The relationship between the bones and the thoughts is decisive here, as the rediscovery of simple feelings re-identifies and re-empowers the Innu 
way of life. There is a form of moral injunction introduced by a pronoun which is a collective entity ('You' can be a 'We' which is not limited to the Innu community) and a message close to a kind of aphorism (Bell, 1997: 8). An aphorism is a fragment of text that contains a general truth that can be transmitted from one generation to the other. The aphorism is not presented with a distance; it is a personal and intimate injunction with a specific message. Here, the political dimension of the poem prevails.

'Your message is to protect the land / I'll protect it for as long as I live with it / But I won't neglect to learn / Your message which is so sacred / And share it with the world...' (Mestokosho, 2011: 17).

The poem encourages a specific attitude which is illustrated by the anaphora ('Your message' / 'protect') and the negative injunction ('I won't neglect to learn'). This is exactly what Rita Mestokosho told us in an interview given in 2009.

We have the responsibility to take care of ourselves. And above all, to teach each person we meet, the essential message of caring for the land, because it is the most beautiful legacy that we will give to our children, our grandchildren. (Mestokosho, 2009)

Writing poetry is a political act to preserve the environment. At the same time, the Innu have to remain Innu if they do not want to lose their identity and the link to the land. The resilience is powerful as it shows another way of defining what thinking means. To some extent, the prayers of Rita Mestokosho have moral injunctions for the actions, but describe a very meditative approach close to what the philosopher Heidegger calls the meditative thinking. The idea is not to impose an interpretation from a western philosopher to a specific corpus of literature of the First Nations, it is rather a way of connecting this literature to other philosophical works to show that it expresses in a much better and efficient way what Heidegger theorized. The distance between cultures can activate a perception of linguistic and literary resources that are available in order to translate emotions (Online 8).

If we explicitly and continuously heed the fact that such hidden meaning touches us everywhere in the world of technology, we stand at once within the realm of that which hides itself from us, and hides itself just in approaching us. That which shows itself and at the same time withdraws is the essential trait of what we call the mystery. I call the comportment which enables us to keep open to the meaning hidden in technology, openness to the mystery. (Heidegger, 1966: 55)

There is an attitude of finding where the human being accepts the noncalculability of the world. The openness to the mystery is necessary in order to rediscover the complexity of the world and the interrelations between different kinds of being. Nature hides behind some visible natural elements; it is an invitation to refresh the perception of the world. The aim is not to make 
an essentialist interpretation of these poems but rather to reveal a meditative attitude where the words refer to the beauty of the surrounding world. Gerald Vizenor uses transcultural boundaries in order to activate the emotions of the readers. He compared the indigenous poetry with haiku in the way the poems catch attitudes and motions (Vizenor, 2014: XI).

The universal message of Mestokosho's poetry is striking here as the survivance is not only the problem of the First Nations; it is a common legacy. This is why her poetry has been used as a universal and moral injunction to avoid the perpetual exploitation of natural resources to satisfy artificial and useless needs. In the case of Naomi Fontaine, it is more problematic as there is the description of an intermediate space, the reservation, which falls between natural landscapes and megacities. It is difficult to retain young Innu on these reservations, but at the same time, they need to be together in order to invent the modalities of resilience. The novel by Naomi Fontaine is characterized by a deep feeling of loneliness marked by the use of ellipsis that creates a rupture of narrative voices. 'Il fait des sourires à l'enfant, lui demande qui est son père. Il répond: Je n'ai pas de père' ['He smiles at the child, asks who his father is. He answers: I do not have a father'.] (Fontaine, 2011: 17; translation mine). The continuity between the indirect speech and the free indirect speech is interesting, as it points out the absence of the father, which is a recurrent problem in the Innu community. The ellipsis is here marked by the use of colons. Naomi Fontaine never used the dot dot dot in the novel to express ellipsis, which is striking, as the dot dot dot is a classical way of indicating the omission of words (Toner, 2015: 152).

This is also why many women writers address the men so that they take their own responsibilities in reshaping the ancestral links. In this perspective, women writers re-empower the community by regretting the wandering of men. In addition to this, there is an implicit reference to the system of residential schools in Québec with the question of child abuse. The absence of fathers is a recurrent problem for this community which is reinforced by the ellipsis in Naomi Fontaine's text. If there is an absence of fathers; it means that there is a strong difficulty to transmit a cultural legacy. The Innu as a community are forgotten and neglected such as expressed in the following extract where the Catholic cemetery and the Baptist church of the reservation are presented:

The Catholic heart, established since the time of the Jesuits, still beats in the Innu soul; the only religion learned, acquired, almost traditional as the priesthood goes back far in the memories of the nation. The only forgotten memory: the emancipation of the Innu at the age of the first letters. The event: the kidnapping of Indians who never asked to be white. Their scattered children, taken elsewhere during the hard months of the school year to give, they say, a meaning to their intelligence. (Fontaine, 2011: 49; translation mine)

In this excerpt, the ellipsis reveals the historical erasure of the Innu, who disappear after several waves of colonization. As a First Nation, the Innu are 
deprived of their past and their future is unsecure as the children were taken to residential schools where they had to learn the categories of the colonizers. According to the anthropologist Maurice Godelier, the colonization as a general process is expressed in three different domains, the religion, the education and the administrative and political system (Godelier, 2017: 122). Godelier was working on one of the last communities discovered in New Guinea, the Baruya. Here, the process is similar to the Innu identity being ignored. The style of Naomi Fontaine is ironical when she writes 'the only forgotten memory' because the erasure of the Innu memory is the biggest scandal of modern times. The genocide is mentioned by a metonymy that suggests the systematic oblivion (Ellis Béchard and Kanapé Fontaine, 2018: 27).

The reported speech ('they say') illustrates a process of othering where the Innu do not have anything to say on their History which is written by the colonizers. The process of othering is defined in discourse analysis as showing the linguistic modalities of the difference between we and they (Van Dijk, 1993). Here, the Innu are perceived as people without a proper identity. If they have an identity, it was provided by the first colonization which resulted in the adoption of Catholicism.

The denunciation of residential schools is all the more important as the young generations were deprived of having access to their own culture. The resilience to cultural erasure is possible if the generations are able to communicate with each other. The Truth and Reconciliation Commission in Canada officialised the negative impact of residential schools on the First Nations. In the poems of Mestokosho, the resilience is made possible with a spiritual regeneration of the Innu community. Resilience helps to heal the wounds of the past such as it is noticeable in the poem 'Guardian of the Earth'. 'In the bottomless well of my silence / I found again my childhood exuberance / A well in which I'd sunk without trace / In which my life might have been effaced / If I hadn't rallied and seen sense' (Mestokosho, 2011: 57). The topic of the erasure is also present but the regeneration implies a form of rebirth, the verses indicate the necessity of connecting to the 'Great Spirit' (ibid.) in order to find a new strength.

In Kuessipan, the reservation is also a metonymy that echoes the social invisibility of the Innu people. The metonymy shows that the reservation is a word that refers to the way of life of Innu communities. In other words, this is the current location of the Innu community which is not idealized by Naomi Fontaine. The dilemma here is that most of young Innu would like to travel and escape the fatality of this space which is perceived as a colonial confinement.

It is easier to be nobody in big cities. All these people that you meet do not know anything about you. They look at you distractedly while thinking about something else. It has hardly been a few months since you left the reservation, the village that knows you, your family, your friends to move in incognito in the nothingness of this city. (Fontaine, 2011: 29; translation mine) 
The anonymity of modern cities breaks both the ancestral links of the Innu and their relation to the reservation. These novels represent a certain decolonial tendency that is prevailing in the literature of the First Nations. In an article published in 1994, the philosopher Étienne Balibar questioned the notion of cultural identity and its place in different debates. He proposed our antinomies where the notion of cultural identity is framed, first the opposition subjective/ objective, second the opposition universal / singular, third the opposition elites / mass, and last the opposition between permanent and evolution (Balibar, 1994: 55). The decolonial paradigm would be a way of deconstructing the categories imposed during a colonizing process to rebuild a form of permanent identity. The idea of resilience implies a strategy of re-empowerment that these women writers use to protect this wounded identity. The other difficulty is that the discourse on the recognition of cultural identity tends to be a part of a metanarrative of national identity. If the Canadian authorities are willing to allocate funds to reinforce the transmission of these cultures, these First Nations are still perceived in their otherness. Rita Mestokosho and Naomi Fontaine use the French language to echo the process of resilience.

\section{CONCLUSION}

The literature of the First Nations contributes to the recognition of a cultural identity which has survived after the genocide. Even though these minorities were granted more cultural rights in Canada, this literature is expressed by the choice of the poetic form as the most efficient way to reconnect these communities to their environment and their traditions. The poetry of Rita Mestokosho implicitly denounces the colonization and the destruction of the Innu way of life. Anaphora and metonymy are powerful stylistic figures to question the difference between the Innu world and the colonizers' categories. Naomi Fontaine has a concise style with the use of nominal sentences, ellipsis and metonymies. The chapters are like short paragraphs that mix different levels of narratives. Both writers denounce the traumatism linked to the absence of men and their books illustrate the emergence of new women writers that share these characteristics in this literature. They are representative of the stream of littérature autochtone that has emerged since the 1970s (Jeannotte, et al., 2018), and they enlighten a decolonial paradigm with a necessity of encouraging a new intercultural reading to be able to think with other categories. As Kwok-Ying Lau wrote, 'the socalled primitive cultures would also play an important role in the exploration of the life-world' (Lau, 2016: 8). The analysis of the poetic style reveals an efficient strategy in remembering oral traditions. Naomi Fontaine's novel finds an echo in the poetry of Rita Mestokosho as if these genres gave an echo to ancestral sounds and cultural habits. In this perspective, their work highlights a form of ecofeminism (Shiva et al., 2014: 128) where the women of the First Nations protect the ancestral values. In a nutshell, they play a key role as they re-empower these communities in a postgenocide era. 


\section{REFERENCES}

Assiniwi, B. (1989) La littérature autochtone d'hier et d'aujourd'hui (Indigenous literature yesterday and today). Vie des arts, 34 (137): 46-49.

Assiniwi, B. (2000) The Beothuk Saga. Toronto: Penguin Random House. Translated from French into English by W. Grady.

Balibar, É. (1994) Identité culturelle, identité nationale (Cultural identity, national identity). Quaderni, 22: 53-65.

Baudrillard, J. (2017) Symbolic Exchange and Death. London: Sage Publications (First published in French in 1976 as L'échange symbolique et la mort).

Beaujour, M. (1989) 'Ils ne savent pas ce qu'ils font' . L'ethnopoétique et la méconnaissance des 'arts poétiques' des sociétés sans écriture ('They do not know what they do', The ethnopoetics and the ignorance of the 'poetic arts' of societies without writing.) L'Homme, 29 (111): 208-221.

Beaujour, M. (2017) De la poétologie comparative (On comparative poetology). Paris: Garnier.

Bell, M. (1997) Aphorism in the Francophone Novel of the Twentieth Century. Montréal : Queen's University Press.

Bhabha, H. K. (1994) The Location of Culture. London and New York: Routledge.

Boudreau, D. (1993) Histoire de la littérature amérindienne au Québec (History of native literature in Québec). Montréal: les éditions de 1'Hexagone.

Brubaker, R. (2001) Au-delà de l'identité (Beyond identity). Actes de la recherche en sciences sociales, 139 (1): 66-85 (Translation into French by F. Junqua).

Caron, J. (2012) La plume autochtone / émergence d'une littérature (The native pen / emergence of a literature). Lettres québécoises, 147: 12-15.

Chartier, D. (2015) L'urgence de lire (les écrivains autochtones) (The urgence of reading (indigenous writers)). Littoral, 10: 20.

DeRaeymaeker,L. (1940) Recueillement métaphysique (Metaphysical contemplation). Revue philosophique de Louvain, 65: 21-40.

den Toonder, J. (2017) Narrative dynamics of liminality in Naomi Fontaine's Kuessipan (2011) In S. L. Brandt (ed.) In-Between - Liminal Spaces in Canadian Literature and Cultures, Vol. 20, Canadiana (pp. 133-146). Frankfurt am Main: Peter Lang.

Derrida, J. (2000) Lyotard and us. Parallax, 6 (4): 28-48.

Ellis Béchard, D. and Kanapé Fontaine, N. (2018) Kuei my friend, a conversation on race and reconciliation. English translation by D. Ellis Béchard and H. Scott. Vancouver: Talon Books.

Fontaine, N. (2011) Kuessipan. Montréal: Mémoires d'encrier.

Fontaine, N. (2013) Kuessipan. English translation by David Homel. Vancouver: Arsenal PULP Press.

Giroux, D. (2008) Éléments de pensée politique autochtone contemporaine. Politique et Sociétés, 27 (1): 29-53. Available from https://doi.org/10.7202/018046ar [Accessed on 20 November 2018].

Godelier, M. (2017) Suivre Jésus et faire du business, une petite société tribale dans la mondialisation (Following Jesus and making business, a small tribal society in the globalization). Vincennes: Thierry Marchaisse.

Heidegger, M. (1966) Conversation on a country path about thinking, In Discourse on Thinking (pp. 58-90). Translated by J. M. Anderson and E. H. Freund. New York: Harper and Row Publishers.

Hurley, M. and O’Neill, M. (2012) Poetic Form: An Introduction. Cambridge: Cambridge University Press. 
Indigenous Women's Turn to Take the Talking Stick, They Are Putting Quill to Paper to Share Their Vision of Sustainable Development (2018) Canada: First Nations of Québec and Labrador Sustainable Development Institute.

Jeannotte, M.-H., Lamy and J. and St-Amand, I. (eds.) (2018) Nous sommes des histoires: réflexions sur la littérature autochtone (We are narratives: reflections on indigenous literature). Translated from English into French by Jean-Pierre Pelletier. Montréal: Mémoire d'Encrier.

Lau, K.-Y. (2016) Phenomenology and Intercultural Understanding Toward a New Cultural Flesh. Cham: Springer International Publishing.

Logan, T. E. (2014) Memory, erasure, and national myth. In A. Woolford, J. Benvenuto and A. L. Hinton (eds.) with a forword by T. Fontaine Colonial Genocide in Indigenous North America (pp. 149-165). Durham: Duke University Press.

Loiseau, P. (2010) Introduction furtive au droit civil innu (Furtive introduction to Innu civil law). Revue internationale de droit comparé, 62 (4): 1009-1020.

Machet, B (1999) La poésie amérindienne (Native poetry). Coaraze: éditions L'Amourier.

McDonald, D. B. (2017) Coming to terms with the Canadian past: truth and reconciliation, indigenous genocide and the post-war German model. In M. Gabowitsch (ed.) Replicating Atonement. Palgrave Macmillan Memory Studies (pp. 163-184). Available from https://10.1007/978-3-319-65027-2_7 [Accessed on 20 November 2018].

Mestokosho, R. (1995) Eshi Uapatamam Nukum (How I see Life, Grandmother). Québec: Piekuakami.

Mestokosho, R. (2010) Hur jag ser på livet, mormor, Eshi Uapataman Nukum, Commentje perçois la vie, grand-mère (How I see Life, Grandmother). Göteborg: Beijbom Books.

Mestokosho, R. (2011) How I see Life, Grandmother, Eshi Uapataman Nukum, Comment je perçois la vie, grand-mère. Göteborg: Beijbom Books.

Mollen, Y. (2006) Transmettre un héritage: La langue innue (Transmitting an inheritance: the Innu language). Cap-aux-Diamants, 85: 21-25.

Moura, J.-M. (2005) Littératures francophones et théorie postcoloniale (Francophone literatures and postcolonial theory). Paris, PUF.

Pirbhai-Illich, F., Pete, S. and Martin, F. (eds.) (2017) Culturally Responsive Pedagogy, Working Towards Decolonization, Indigeneity and Interculturalism. Basingstoke: Palgrave Macmillan.

Premat, C. (2017) Les traces numériques de la survie de la littérature des Premières Nations au Canada (Digital traces of the survival of First Nations literature in Canada). Intercâmbio, 10: 72-96.

Saint-Amand, I. (2010) Discours critiques pour l'étude de la littérature autochtone dans l'espace francophone du Québec (Critical discourses on the study of native literature in the Francophone space of Québec). Études en littérature Canadienne. Available from https://journals.lib.unb.ca/index.php/SCL/article/ view/18321/19750 [Accessed on 10 January 2019].

Shiva, V., Salleh, A. and Mies, M. (eds.) (2014) Ecofeminism. England: Zed Books.

Sojcher, J. (1969) La métaphore généralisée (the generalized metaphor). Revue internationale de philosophie, 87 (1): 58-68.

Sule, F. and Premat, C. (2011) La transmission des fondamentaux d'une culture minoritaire: le cas de l'oeuvre de Rita Mestokosho (The transmission of the fundamentals of a minority culture: the case of Rita Mestokosho's works). Le langage et l'homme: Revue de didactique du français, 46 (1): 17-27.

Toner, A. (2015) Ellipsis in English Literature. Cambridge: Cambridge University Press. 
[TRC] Truth and reconciliation commission of Canada (2015) The Survivors Speak: A Report on the Truth and Reconciliation Commission of Canada (pp 1-209). Canada: Library and Archives Canada Cataloguing in Publication.

Van Dijk, T. A. (1993) Principles of critical discourse analysis. Discourse and Society, 4: 249-283.

Vizenor, G. (1984) People Named the Chippewa. Minneapolis: University of Minnesota Press.

Vizenor, G. (1991) The Heirs of Columbus. Middletown: Wesleyan University Press.

Vizenor, G. (2009) Native Liberty: Natural Reason and Cultural Survivance. Nebraska: University of Nebraska Press.

Vizenor, G. (2014) Favor of Crows: new and Collected Haiku. Middletown: Wesleyan University Press.

\section{INTERVIEWS}

Mestokosho, R. (2009) Interview recorded with Christophe Premat and Françoise Sule (10 October) and translated into English by C. Premat. The interview was originally published on the website http://www.franskaspraket.eu which ceased to exist in 2015.

Momaday, S. (2010) Scott Momaday. Entretien avec N. Scott Momaday (Interview with N. Scott Momaday), 15 December. Centre audiovisuel de l'Université de ToulouseLe Mirail. Available from https://www.canal-u.tv/video/vo_universite_toulouse le_mirail/entretien_avec_n_scott_momaday.800 [Accessed on 30 January 2019].

\section{INTERNET SOURCES}

[Online 1] https://www.babelio.com/auteur/Naomi-Fontaine/114684 [Accessed on 30 January 2019]

[Online 2] https://www.franceculture.fr/conferences/maison-de-la-recherche-en-sciences-humaines/le-regard-neuf-ou-etre-ne-innu-aujourdhui [Accessed on 21 January 2019]

[Online 3] http://www.roxanemartin.com/conte-harpe.html [Accessed on 20 November 2018].

[Online 4] http://www.missioncheznous.com/903-2/ [Accessed on 20 November 2018].

[Online 5] https://www.storajournalistpriset.se/\#year70-tal [Accessed on 20 November 2018).

[Online 6] http://beijbombooks.se/ [Accessed on 20 November 2018].

[Online 7] https://www.storajournalistpriset.se/\#year70-tal [Accessed on 20 November 2018].

[Online 8] https://www.franceculture.fr/emissions/la-conversation-scientifique/la-notion-didentite-culturelle-t-elle-un-sens-0 [Accessed on 22 January 2019].

Christophe Premat (Dr. pol. sc., Assoc. prof. in Cultural Studies in French) is currently working at Stockholm University. He is the head of the Center for Canadian Studies at Stockholm University and his research interests include discourse analysis, Francophone literature and memory studies. Email: christophe.premat@su.se 


\title{
SONGS OF LIFE AND DEATH IN WALKER PERCY'S LANCELOT (1977)
}

\author{
ANASTASIJA ROPA \\ Centre for Arthurian Studies, Bangor University (UK)
}

\begin{abstract}
Cultures of life and death are central to the writing of American Southern novelist Walker Percy (1916-1990), and they are drawn with special force in his early novel Lancelot (1977), where songs and music deepen the reader experience of the cultural landscape of life and death. The present article combines methods of historically informed literary criticism and song analysis to examine Walker Percy's presentation of life and death in the novel. The conclusion is that certain musical genres, such as popular music, folk song, and classical music are associated with particular manifestations of the cultures of life and death in the novel.
\end{abstract}

Key words: Walker Percy, post-religious, culture of death, popular song, folk song, soundscape

\section{INTRODUCTION}

Culture of life or culture of death? These issues are central in all of Walker Percy's fictional and much of his non-fictional writing, but especially so in his early novel Lancelot, originally published in 1977 (references in this article are to a subsequent edition, Percy, 1978). Joseph Donald Crowley and Sue Mitchell Crowley (1990) describe it as a 'novel about death', indicating a certain stance that critics tend to take towards this novel, unusual in style and atmosphere. However, it seems that the novel is not so much about death and dying as about learning to accept death as part of life and to build new life 'in the ruins'. Music is an integral part of this learning, signalling instances when the narrator struggles to rationalize his experience. Moreover, songs (including Creole folklore), instrumental music and other forms of soundscape deepen the reader's understanding of the cultures of death and life in the 'post-religious' world of the 1970s America, vividly portrayed in Lancelot.

The opening pages of the novel offer a typical example of Percy's soundscapes. A man is standing at the window and pointing to his guest the view: on All Souls' Day, the Lafayette cemetery in New Orleans presents a lively sight, with women industriously putting the tombs in order, the entire families coming together for the occasion, possibly talking and even singing. What the man hears is the rustling of leaves, hollow like popcorn (Percy, 1978: 9): death is a spectacle, like a movie in the cinema next door. Percy's main character, Lancelot Andrewes Lamar, concludes about the shallowness of modern involvement with existential issues: 'Death and sex treated unseriously and money seriously' (ibid.: 23). $\mathrm{He}$ 
makes the conclusion because of what he sees, hears and imagines looking out of the window: this example shows how, in Percy's novel, references to sound and music are not innocent, but invariably lead the narrator to make observations on death and love. Listening to music, remembering it, playing or singing are all means of reducing post-traumatic stress associated with death, as has been stressed by studies in music therapy (see Garrido et al., 2015). Another issue which is important to stress when reading Percy's fiction is 'the problem of language', to which he gives considerable attention in his non-fiction writings, especially in the section on language and literature in Signposts in a Strange Land and in The Message in the Bottle (Percy, 1975, 1991).

Throughout the novel, Percy cites children's rhymes (counting rhyme, Percy, 1978: 186-187, Cajun rhyme, ibid.: 233), popular songs (ibid.: 20, 124125) and folk songs, including Oh Shenandoah (ibid.: 238), as well as referring to instrumental works (the 'Limelight' theme, ibid.: 10-11, Beethoven, ibid.: 124, 152, Chopin, ibid.: 162). Other examples of soundscape include the rustling of dry leaves on the cemetery, mentioned above, which, according to the narrator, resembles popcorn (ibid.: 9). At the climax of the narrative, Lancelot describes the screeching of wooden structures in his old manor house during the hurricane on the night of the explosion, using allusions to music. As he sits in the pigeonnier, he listened to the 'organ sounds of the wind in the holes of its loft' (ibid.: 245). Inside the manor, he heard how the 'great timbers sang and popped overhead' (ibid.: 256), even referring to a 'bass roaring and soprano shrieking' (ibid.: 257), as if the house had its own chorus. Indeed, songs and music provide the background and, in many cases, the medium, for tackling the issues of dying and loving.

Although Percy's works, including Lancelot, have been the subject of numerous scholarly studies, no one has yet examined the role of music in the narrative. The present article argues that songs and music are an important component in the novel, providing the analogue of liturgy in the narrative told by an unreligious, at times even blaspheming narrator. A Catholic novelist writing in the 'post-religious' world, Percy uses what Bradley R. Dewey has aptly described as the 'indirect method of persuasion' (Dewey, 1985: 126). Percy employs metaphors and allusions to convey his evangelising message to the readers, and music is essential in this process. Percy's 'music of death', whether Creole, country of classical, thus are best considered bearing in mind the culture of Southern 'Arthurian' chivalry, which is largely profane yet characterized by occasional flights into medieval Christian spirituality. Accordingly, in describing 'the upperclass white Southerner', Percy remarks that 'he was raised on the Christian chivalry of Walter Scott, but it was a Christianity which was aestheticized by medieval trappings and a chivalry which was abstracted from its sacramental setting' (Percy, 1978: 84-85).

Percy's references to music in the novel are numerous and can be divided into three groups: classical instrumental music, popular songs, and folk songs. It is remarkable that references to song and music usually occur in discussions of death and love, often next to the very words. The death can be physical or 
spiritual, just as love is either carnal or manifestly divorced from any association with physical sexuality, and certain kinds of music seem to be linked with certain kinds of death and love.

\section{CONTEXT AND OUTLINE OF THE NOVEL}

Lancelot, the fourth of Walker Percy's published novels, deals with the social and psychological problems of the United States of America after the sexual revolution. The title alludes to medieval Arthurian romances, where Sir Lancelot is one of the main heroes. Confusingly, although the main character, Lancelot, draws numerous parallels between his past and the Grail quest, his attempts are retrospective and unsystematic (Ropa, 2014a, 2014b). In the medieval Arthurian tradition, the Grail quest is the privilege of the most virtuous individuals, and its accomplishment is rewarded by a vision of divine mysteries. On the contrary, Percy's Lancelot aspires to a vision of pure evil taking place in this world.

The novel is set in the early 1970s in the American South. The narrative is presented in the form of monologue delivered by the main character, Lancelot Andrewes Lamar, member of the Southern gentry, former lawyer, alcoholic and, as the reader comes to suspect, a murderer. Lancelot is confined to a psychiatric clinic in New Orleans, where he is visited by his college friend Percival (ordained Father John). Father John is a failed priest, who seems to have lost his faith and is working with psychiatric patients.

Over a series of visits, Lancelot tells his friend the story that led to his confinement in the clinic. The central element in his narrative is the unfaithfulness of his second wife Margot, whom he married because of her sexual appeal and, probably, money. Lancelot gradually discovers that Margot has repeatedly cheated on him with two film directors, and that even their daughter, Siobhan, has a different father. Percival (and the reader) also hears how the film crew, who came to Lancelot's manor Belle Isle to make a cheap film about the supposed life in the antebellum South, perverted Lancelot's elder daughter Lucy. Lancelot finally took revenge on Margot and the film crew by blowing the manor with his wife, her second lover and two members of the film crew with whom Lucy had sexual relations.

While telling of his past, Lancelot also explains his new philosophy of life and his plans for the future, mentioning his growing love for his co-patient, a victim of mass rape Anna. At the end of the novel, Lancelot is cleared of all charges and is about to be released from the clinic, though certain psychological issues remain unresolved. On the last pages of the novel, when Father John speaks a few words (the only words in the novel not by Lancelot), Lancelot appears to be on the threshold of a revelation, finally realising the meaning of the word 'freedom', which he heard in a song early in the novel.

Walker Percy drew on the chivalric heritage of the Old South and, in Lancelot, he explores elements of the Southern Gothic to a larger extent than in any of his 
other novels. Being a Roman Catholic, Percy probably found the religious and Eucharistic elements of the Grail quest appealing, but, writing in a post-Christian culture, he makes his main character claim that he seeks not God or 'good', but its opposite, evil, the 'Unholy Grail' of sexual sin (Percy, 1978: 144). Percy's Lancelot is manifestly unheroic, unlike his namesake. Alan Lupack and Barbara Lupack explain that Percy was inspired by Lanier's 'The Boy's King Arthur, one of the first books he ever read', a juvenile illustrated edition based on Malory's Morte Darthur. Percy himself wrote in a letter to Alan Lupack that 'the provenance of my Lancelot [...] is The Boys [sic] King Arthur and most importantly the marvellous illustrations' (Lupack, A. and Lupack, B. T., 1999: 229). Percy's view of Arthurian literature is partially filtered through the prism of nineteenth-century Romantic medievalism, but he uses the Grail quest to comment on the moral challenges of the modern world, such as sexual promiscuity, political corruption and psychological alienation. These, for Percy, are all instances of 'death in life' and, what is remarkable, scholars, particularly David Benson, have argued that similar problems lead to the destruction of Arthur's kingdom in Thomas Malory's Morte Darthur, from which Percy drew inspiration (Benson, 1996: 234-235).

Remarkably, in the mind of Percy's Lancelot, moral and political corruption, alienation and the solitary quest for the meaning of life are closely associated with certain soundscapes or absences of sound. Thus, music and sound can not only facilitate one's understanding of the above phenomena but also divert the 'quester'. Accordingly, Lancelot realises that his obsession with watching certain television programmes at established times was an unconscious way of avoiding the crucial encounter with one's self, of not thinking about one's relations with life and death:

I stood up. Can a man stand alone, naked, and at his ease, wrist flexed at his side like Michelangelo's David, without assistance, without diversion, without drink, without friends, without a woman, in silence? Yes. It was possible to stand. Nothing happened. I listened. There was no sound: no boats on the river, no trucks on the road, not even cicadas. What if I didn't listen to news? I didn't. Nothing happened. I realised I had been afraid of silence. (Percy, 1978: 70, emphasis mine)

Percy uses the Grail quest to hint at the need for spiritual development inherent in every individual, believers as well as unbelievers. Indeed, critics have remarked on Percy's tendency to offer his readers a religious message through main characters who themselves have little or no use for God. Kieran Quinlan describes Percy as 'the last Catholic novelist' (Quinlan, 1996). However, Percy's strategy is more sophisticated than simply 'preaching' to his readers: instead, he presents flawed characters, who are struggling for the truth, for the evangelic revelation, while outwardly denying Christianity. The internal struggle of Percy's principal characters is often laid out before the reader, so that, like Lancelot, they seem to be making a confession about their inability to cope with life in the contemporary world. In fact, Lewis Lawson claims that Percy's 'fiction 
tended toward (veiled) confession [...] while the non-fiction tempted him toward (veiled) evangelization' (Lawson, 1996: 7). At the same time, Percy never openly presents his readers with a confession or a sermon, unless Lancelot's subversive 'confession' to his friend Percival should be regarded as such.

\section{SONG OBJECTS AND THEIR TYPOLOGY IN WALKER PERCY'S LANCELOT}

On the most general level, it seems that any piece of music and song can be therapeutic and alleviate fear of death, mourning and grief. However, researches have highlighted the fact that 'individual differences in personality and coping style can moderate participant responses to [music and art] therapies' (Garrido et al., 2015: 1). In Lancelot, it is apparent that, for the main character and narrator at least, certain types of music are emblematic of spiritual decay and death, while others are associated with violence, liberation and, possibly, even resurrection. This sub-section is devoted to defining the types of music mentioned in Lancelot or 'played' in the characters' imagination, prior mapping them to certain images of death and dying in the subsequent sections.

The novel contains numerous references to song and music objects, which fall broadly in either of the two categories described Jean-Nicolas De Surmont as author's (signed) and traditional (popular) music. De Surmont, however, warns about the historical, cultural and subjective ambiguities inherent in the categories and in the terms used to refer to songs and music themselves. According to De Surmont, the 'song object' can be defined as the 'objet, sur le plan esthétique, d'une activité perceptive et d'une activité d'interprétation du concret sonore varié' (De Surmont, 2010: 11) [subject, on the aesthetic plane, of perceptive and interpretative activity of particular sound variation]. Ferdinand de Saussure speaks of 'acoustic imagery' ('image acoustique') to signify song objects. In the present article, I employ the term 'song' to mean vocal or vocalized (sung) works, whether accompanied by instrumental music or not, 'music' to mean instrumental pieces performed without vocalization and 'song-object' in reference to both vocal and instrumental works.

Before discussing the use of song objects in discourse on death in Lancelot, i t would be useful to clarify terminology related to their (ethno) musicological status. De Surmont stresses the dichotomy and interaction between the 'learned' and the 'popular' domain in song object production and consumption, as well as in scholarly discussions of song objects (ibid., 2010: 80-94). Indeed, in Lancelot, the main character continuously alludes to this dichotomy as if it was self-evident, even though Lancelot himself does not use the terms 'learned' and 'popular'. When describing the enthusiasm of his second wife Margot for symphony concerts, he remarks that Margot enjoyed western country music much more, implicitly pigeonholing her pretended and true tastes within the categories of the learned and the popular (Percy, 1978: 124). 
Meanwhile, the term 'popular' is far from being clear or unambiguous. In reference to music, it can mean one or several characteristics of song objects: folkloric (song objects belonging to oral tradition), commercially popular or simply beloved by many people. To distinguish between different meanings of the term 'popular song', De Surmont proposes the use of terms 'oral tradition song' ('chanson de tradition orale') as opposed to 'signed song' ('chanson signée'). The latter is defined as song 'dont l'auteur et le compositeur sont connus, écrite et souvent née dans un contexte éditorial, tantôt de nature nettement commerciale (populaire), tantôt plus savante, c'est-à-dire à texte, d'auteur' (De Surmont, 2010: 17) [for which the author and composer are known, written and often conceived in editorial context, sometimes purely commercial (popular), at other times more learned, an author's song]. Oral tradition songs are also classified as 'oral poetry', in distinction from 'learned poetry', to use the terms employed by Paul Bénichou ('poésie orale' as opposed to 'poésie lettrée') (Bénichou, 1970: 10). Paul Zumthor explains that, conventionally, song is an oral poetry genre: 'La chanson est un genre (sans doute éminent et d'usage universel) de ce que l'on nomme par convention la poésie orale' (Zumthor, 1983: 18) [Song is a genre (naturally prominent and universally used) of what is conventionally know as oral poetry]. In Lancelot, while the songs are presented to the audience in written format, in much the same way as they would be presented in collections of folkloric songs or in music record inserts, they are characterised by aural or oral ways of reception and performance for the main character.

\section{MUSIC AND ITS FUNCTIONS IN LANCELOT}

Three songs are quoted in the novel, and they represent different aspects of 'popular' song objects. The first song to appear in the novel, Me and Bobby McGee (1969), written by Kris Kristofferson, is author's song in the sense that it was created in editorial context and its author is known (Daniel, 2012: 193; Kristofferson, 1969). It was sung first by Janis Joplin, appearing in her posthumous album Pearl (released 1971) and instantly becoming the top hit: it is the only Joplin's song to enjoy massive commercial success, no doubt because of its associations with the singer's untimely death. The song was subsequently performed by Kristofferson, which was also a success (Miller, 2009). Thus, this 'author's' song is popular in the sense of being commercially successful. Interestingly, David Daniel argues that the song is 'an example of the traditional ballad form' and notes that 'it has been covered by dozens of recording artists' (Daniel, 2012: 193). Likewise, in Lancelot, the song enters the 'oral tradition' category: the main character first hears it sung by an unknown young woman in blue jeans, and, in the episode, no reference is made to the song's commercially available versions.

Later in the novel, Lancelot recollects listening to the same song while driving with Margot: this time, the song is firmly set in the context of its market 
dissemination and consumption. Lancelot even names the singer, Kristofferson (Percy, 1978: 124), though associations with the original singer, Joplin, would probably be apparent to the novel's early audience. It is possible that reference to Kristofferson is used exactly to avoid association between Joplin and the novel's female character, Margot, both of whom are from Texas. After all, Margot and Lancelot appear in the situation in which it would be easy to imagine Janis Joplin and someone from the world of song production, possibly even Kristofferson himself, with whom Joplin had a brief affair. In the novel, Margot and Lancelot are in the car, Margot at the wheel, Lancelot caressing and kissing her. They stop in a secluded spot, drink whiskey and make love.

The motif of 'freedom', introduced in the couplet quoted by Lancelot, reappears throughout the novel: when Lancelot reads the word 'free' on a sign he glimpses from his window, the reader is likely to remember that 'Freedom's just another word, Lord, for nothing left to lose' (ibid.: 124). In an interview, Kristofferson explained that he meant that double-edged nature of freedom, when the pain of the loss more than equals the pleasure of the gain' (Cartwight, 2010: n. p.). Freedom, which Margot tried to attain in company of the film crew, is also evoked in one of her last conversations with Lancelot, a conversation that takes place on the eve of a hurricane, when Lancelot and Margot have already taken drugs (Percy, 1978: 224). Margot dies the same night, not of drug overdose, but in the gas explosion arranged by her husband. While the association between Margot and Joplin is simultaneously suggestive and deceptive, the link between the song, death, love and freedom is crucial. The song, which was commercially successful and performed by a number of singers after Joplin's death, is sung by yet another unknown girl at the beginning of Percy's novel, marking the beginning of its entry within the 'popular' domain in more than one sense.

The notion of freedom in the novel often appears in the context of emptiness and even deprivation (the condition when there is 'nothing to lose'). Indeed, Lancelot spends a year in confinement after losing everything - his wife, his ancestral home and even his children, and all this year he is contemplating the sign containing the word 'Free'. The situation is highly ironic because Lancelot is anything but free, being physically confined to a clinic and spiritually entangled in his weird theories and resolved conflicts. However, for Walker Percy, the situation is pregnant with possibilities, like a desert waiting for the first spring rain to burst into flowers, as Percy explains in his self-interview 'Questions They Never Asked Me' (Percy, 1978: 423; 1991). The state of being in-between signals the passage from between stages in Kierkegaardian philosophy, in Lancelot's case this being the threshold of the aesthetic stage. The aesthetic stage is characterised by a person's awareness of emotions, his own and other people's, as well as physical sensations and feelings. Throughout the novel, Lancelot lacks this kind of awareness, as he is largely insensitive both to physical and emotional pain he causes and experiences. This numbness or, as Lancelot himself describes it, coldness, is characteristic of his psychological disorder, which music, and songs in particular, help to cure. 
Apart from $\mathrm{Me}$ and Bobby McGee, a popular song in the sense of being commercially successful, there are song objects that are 'popular' in the other sense, that of belonging to the oral tradition. Historically, these songs have been defined as 'originating with the people' or 'destined to the people' (De Surmont, 2010: 80-94). Their original writer, composer or singer is not known, and they often exist in more than one variant. Naturally, a song object composed by an author can pass into the domain of oral tradition, and there are hints that, within the novel at least, Me and Bobby MacGee might be on the way of becoming an oral tradition song. Performed by an anonymous girl on the opening pages of the novel, it is not identified by the narrator as the country western hit that provided the backdrop for his lovemaking to Margot (Percy, 1978: 20).

The song's melancholic, bluesy tone, its association with Joplin's death, and its leitmotif of freedom all make it a perfect medium for the characters and the readers to reflect on the relations between freedom, death, and life. The songwriter, Kristofferson, confesses having cried when he heard the song recording by Joplin on the day of her death (Miller, 2009: n. p.). Such a natural, spontaneous expression of emotions, however, is far from Lancelot's mind, as he tries to rationalise the death of both his wives by reference to either science or theology. Thus, the death of his first wife Lucy from leukaemia is simple: 'Her blood turned to milk - the white cells replacing the red cells' (Percy, 1978: 88). Margot's death, in turn, is 'tragic', but hardly 'unthinkable', as Lancelot reserves the term 'unthinkable' for her sexual infidelity (Percy, 1978: 16): for him, she seems to be dead the moment he learns about her adultery, a revelation which surprisingly awakens him from his own mental lethargy. Thus, he becomes 'free' to act, 'revived', through the fact of his wife 'dying' for him as the woman he loves. This is at least one of the meanings of the line 'Freedom's just another word, Lord, for nothing left to lose' (ibid.: 124). The invocation of God reminds the reader that, apart from freedom act as one pleases, there is also spiritual freedom, that is, freedom from sin, freedom to choose life over death, the Holy Grail of love over the 'Unholy Grail' of sexual sin (ibid.: 144).

Till the very end, Lancelot misses the true significance of the song and of freedom. He needs the visual prompt of a sign 'Free \& Ma B', which can be read not only as 'Free and Accepted Masons' Bar', etc., but also, and more meaningfully, as 'free and may be' (ibid.: 2, 270). Moreover, Lancelot needs the presence and, up to the very last page, silent support of his boyhood friend and priest/physician Perceval/Father John, to reveal the true reading of the sign and of the song in his life. Abandoning prejudices, conceit and pride, as well as 'easy' carnal pleasures ('Feeling good was easy, Lord, when Bobby sang the blues', ibid.: 124), one can attain true freedom, overcoming the loss of one's beloved people or part of one's self.

There are two oral tradition rhymes in the novel, both performed by children and overheard by the narrator. Lancelot associates one of them with the topic of his obsession, namely, sexual activity, and the other, on which he provides 
no commentary, forebodes his own crimes and his spiritual 'death'. The first is a skipping rhyme, which children perform under Lancelot's window, and thus not a song object, though it can be discussed as part of the novels' soundscape. Remarkably, Lancelot makes an unlikely association between children 'doing "hots" while skipping and the other meaning of the word 'hots', which refers to sexual arousal (Percy, 1978.: 188). Subsequently, he proceeds to denouncing innocence as non-existent, which is justified in the sense that, in Catholic theology, children, just as their parents, are part of the fallen matter, bearing the weight of the original sin. For Lancelot, sin means sexual sin, which leads to its own kind of death, 'orgasm', just as in traditional theology the original sin leads to death.

In view of Lancelot's fanciful interpretation of the skipping rhyme, it is surprising that he does not comment on the memory or vision he had on the night of the hurricane, prior to the explosion of Belle Isle. In the episode, he saw a girl in a white dress dancing Fais-do-do and singing a Cajun rhyme about a ram going to a slaughterhouse:

\section{Mouton, mouton - et où vas-tu? \\ A l'abatoire. \\ Quand tu reviens? \\ Jamais - Baa! (Percy, 1978: 233; emphasis in the original)}

Lancelot notes that, even then, he remarked the oddness of the girl's appearance, as there were no Cajun families in the area (ibid.: 233). What he does not mention is that the girl might be a hallucination (he later sees several ones, induced by the drug a member of the film crew gave him). In fact, her song is actually about Lancelot going to his own death - not a physical, but a moral and spiritual one - by entering his old manor. The song, being of oral tradition, supposedly reveals 'folk wisdom'. Being sung in the Creole dialect, it instantly captures imagination - both Lancelot's and the readers' - by its sense of oddness, out-ofplaceness, as this is the only passage in the entire novel that is not in English. Lancelot ignores the warning, and he fails to make sense of it one year later, as he recounts the episode to his friend.

Fais-do-do is a French lullaby, supposedly originating from the French 'dormir', but it is also a name for a pre-World War II Cajun dancing party (Scarborough, 1925). Thus, the text of the song Lancelot overhears is both evocative of death as sleep and highly suggestive in more than one sense. Sung at night, on the eve of the hurricane, by a mysterious girl in white, it harkens back to Lancelot's previous 'Big Sleep' (Percy, 1978: 112), during which he preferred to be unaware of Margot's infidelity, and to his subsequent 'lethargy', when 'the past [didn't] seem worth remembering' (ibid.: 1). The song thus makes the reader connect the notions of death as sleep and of a person's continuous journey towards death, as well as the association between sleep and the rituals of passage, which, according to Baumgartner, is prominent in medieval Arthurian and Grail literature that Percy used as his source. 
A third song that appears in the novel is Oh Shenandoah, a famous oral tradition song of which many variants exist. Interestingly, an early recorded version was sung by an African American singer, Paul Robeson (1936). Later, Robeson was lynched, and it is tempting to think that Percy had that version in mind, given Lancelot's previous activism in the defence of the 'Negro' rights. The song Oh Shenandoah is an oral tradition song, of uncertain origin, and even its meaning is not entirely undisputed, though Shenandoah is supposed to be the daughter of an Indian chieftain addressed by a white trader. The song is classified as a river shanty, but it has enjoyed popularity unrivalled by any other river shanty. For Percy's Lancelot, the song is the emblem of the Southern chivalry and of his new society, a military anthem that harkens back both to the original purity of the States and to the purification in hand, as he envisages the 'Third Revolution' to begin in the Shenandoah Valley (Percy, 1978: 238).

Ironically, the song addressing a woman, an idealised indigenous lady, Shenandoah, is sung by Lancelot prior to a speech in which he discards the virtue and morality of all women, whose 'happiness and the meaning of life itself is to be assaulted by a man' (ibid.: 239). Again, the oral tradition song can be interpreted in two completely opposite ways: while Lancelot sees only its association with the Southern homosocial chivalry and its imminent destruction of all that is 'rotten' in the contemporary states, the song also celebrates womanhood and meekness, a longing for peace and unity, a longing for life.

Song objects belonging to the 'popular' category (both oral tradition songs and commercially successful songs with known authors) can be interpreted in more than one way when used by the main character of the novel to make sense of life and death. In the novel, these songs invite the reader to independent reflection, to interpreting them within the context, as the song texts quoted in the novel are insufficient for interpreting them as independent units. Taken within the context, the songs, which often do not refer to death explicitly, turn out to reflect on both life and death, on the relation between freedom and individual choice, on loving and dying, and on coming to terms with death, both other people's and one's own.

The novel also contains numerous references to instrumental music, most often, classical pieces, with the exception of the 'Limelight' theme, which Lancelot enjoyed with his first wife, Lucy. These musical pieces are often associated with spiritual inertia, lack of authenticity and abstraction. Thus, Margot 'plays' a Southern lady and listens to symphony concerts, although her true passion is for country western (Percy, 1978: 124). In turn, Lancelot drinks, reads Chandler and listens to Beethoven in his 'abstracted' state (ibid.: 152). In fact, in other Percy's novels, the abstracted, lost male main character also likes listening to classical music (Love in the Ruins (1971), The Second Coming (1980)). It seems that classical music, with its healing potential, may be selected unconsciously by Percy's main characters who feel depressed or 'lost' in life; indeed, classical music is usually selected by music therapists for patients from most age groups (Grocke 
and Wigram, 2007: 47). The association between classical music and a Southern gentleman belonging to the past, often 'lost' in his dreams or abstracted from reality may have been suggested to Percy by his experience as adolescent in the house of his relative, 'Uncle Will'. Percy recollects how he used to set up concerts for Uncle Will in the living room, where there was 'the Capehart, a huge automatic phonograph, one of the first of its kind and surely the only one in town, and an even larger record cabinet packed with albums of 78s, from Bach to Brahms' (Percy, 1978: 64).

Certainly, Uncle Will's manor could not be far from Percy's mind when he describes, in Lancelot, the film shot at Belle Isle. In the film, a Southern gentleman, a cuckolded husband of a librarian played by Margot, and, in many ways, a replica or caricature of the novel's main character, plays Chopin on the piano and becomes 'lost' in his illusions (ibid.: 162, 210). Somewhat more positively, Lancelot recollects dancing with his first wife Lucy to the 'Limelight' theme, which he describes as his first 'falling in love' (ibid.: 10). Again, the motif of falling in love while dancing appears in Percy's other novels, where it is not unequivocally positive or authentic: in The Last Gentleman (1966), Will Barrett cannot realise who or what he is despite his apparent success with a girl to whom he is attracted.

In all, it seems that, within Percy's Lancelot, only popular music, in either of its two meanings, as oral tradition or commercially successful music, can lead to revelation and authenticity. Instrumental music is more often than not associated with escapism, abstraction and an attempt to avoid the sensitive issues in one's life, particularly the existential questions of one's origin, identity and death.

\section{MUSIC AND DEATH IN LANCELOT}

Much of Percy's writing, both fictional and non-fictional, is informed by what scholars have described as 'the culture of life' and 'the culture of death' (Zapatka, 2000: 321; Montgomery, 1993), which is particularly true in case of Lancelot. Early in the novel, Lancelot describes to his friend Percival the view from his room, which overlooks 'a corner of Lafayette Cemetery' (Percy, 1978: 2). On Percival's second visit, Lancelot describes the activities in progress at the cemetery on All Souls' Day, as 'a pretty scene' (Percy, 1978: 8). For a year, Lancelot has been observing the cemetery daily, and, when he is to leave the hospital, he turns to the cemetery again, remarking that 'the cemeteries here [in New Orleans] are more cheerful than the hotels and the French Quarter' (ibid.: 270). As it has already been mentioned in the introduction, sounds which Lancelot hears, or imagines hearing, at the cemetery, are instrumental in building the atmosphere of cheerful, unconcerned preoccupation with death, which, as argued further in this section, is in sharp contrast with Lancelot's own morbid interest in death and the process of dying. 
Percy sets Lancelot in a culture which has distinctive rituals about death, a complex of Catholic and Creole rituals, and the effect of these rituals resembles the effect of medieval rituals connected with death. Funerals and All Souls' Days provide an occasion for families to get together and engage with the memories of the past or with their family history. Cleaning the tombstones and adorning the place with flowers while singing songs is such a mundane activity that it tempers the atmosphere of the sublime. Death is domesticated and, to an extent, divested of its mystery; the effect is different from the one produced when the awareness of death is repressed, as often happens in modern society (Utter, 1982). Lancelot notes that in New Orleans young people are so unconcerned with death that 'Some of them even sleep in the oven crypts, shove the bones aside and unroll their sleeping bags, a perfect fit' (Percy, 1978: 270). This irreverent behaviour signals that the process of familiarization may have gone too far and that the young generation may discard the values and morals of their parents as easily as their ancestors' bones.

Moreover, physical death, represented by the cemetery and the activities therein, is for Lancelot emblematic of the spiritual and imaginative 'deadliness' which he sees in the society around him. He asks, for instance, looking at the activities in the cemetery: 'Tell me why that should be, why two thousand dead Creoles should be more alive than two thousand Buick dealers?' (ibid.: 270). At this moment, Lancelot forgets that a year ago he himself was 'dead' and only the discovery of Margot's infidelity put an end to his lethargy. Interestingly, Lancelot also compares his own sensitivity (if sensitivity it is) about the issues of love, sex and death with the relative indifference of his son, who 'lusts after, loves' a 'certain kind of guitar' and does not care about the girl with whom he has sex (ibid., 1978: 16-17). The question, which Lancelot himself never addresses, is what music his son will play on the guitar or will he even play it much, or does he just want to possess it as a valued object.

Meanwhile, despite being 'alive', neither Lancelot nor Percival have a way of coping with death at the beginning of the novel. Whereas the women whom Lancelot sees from his window have a set of rituals rendering death bearable, such as scrubbing the tombs, singing and praying on All Souls' Day, both Percival and Lancelot are incapable of this easy, habitual way of dealing with the phenomenon. Lancelot tells his friend how he has noticed earlier the same day a woman ask Percival what could have been 'Only one thing under the circumstances. To say a prayer for the dead' (ibid.: 9). Percival's refusal prompts Lancelot to conclude: 'So something went wrong with you too' (ibid.). Lancelot thinks that Percival is having a vocational crisis, being in love with a woman. Another possibility, which does not occur to Lancelot, is that Percival may be having the same problems coping with reality as Lancelot is experiencing. It is an indicator of Percival's overcoming his crisis that, at the novel's end, he kneels at a tomb to pray.

Lancelot meets references to death not with refusal, but with morbid curiosity. He conceptualizes death in much the same way as love, as a physical occurrence which can be explained by scientific methods. Indeed, to Lancelot, death is 
merely a natural phenomenon, which can be grasped by scientific observation. Gary Ciuba points out that Lancelot 'continuously applies the methods and reasoning of science to areas like sex and the sacred, which by his own admission are ineffable' (Ciuba, 1985: 107). Death is another ineffable phenomenon which Lancelot fails to grasp with his materialistic methodology. Imitating scientific practice, he observes death drily, keeping his distance even when the dying person is his wife (Lucy, Margot) or when he is killing another man (Jacoby). In this respect, playing music and singing songs, both those which engage with death and others, provides a welcome contrast to Lancelot's pseudo-scientific preoccupation with death and dying.

One example of Lancelot's peculiar, unnaturally detached attitude to death is his description of the death of his former wife Lucy from leukaemia: 'How curious that she should grow pale, thin, weak, and die in a few months! Her blood turned to milk - the white cells replaced the red cells' (Percy, 1978: 88). Utter maintains that Lancelot's response to Lucy's death is that of a scientist confronted with an unfamiliar phenomenon (Utter, 1982: 120). In a sense, Lancelot's reaction is characteristic of contemporary technological and materialist society. According to John Desmond, Lancelot realizes the flaws of scientific reasoning, discerning that 'modern culture [...] has tried to reduce evil to an empirical datum', yet he makes the mistake of trying to investigate metaphysical realities, such as death, evil and love with scientific techniques (Desmond, 1986: 104). Furthermore, Robert Brinkmeyer states that 'Lance wants to see evil much as a scientist wants to see a chemical reaction in a test tube, and his experience reduces persons to objects' (Brinkmeyer, 1987: 37).

Remarkably, Lancelot seems to have genuinely loved his first wife, as he remembers nostalgically their first dates, making particular reference to the music associated with these occasions:

At first I thought that 'being in love' was the only thing. Holding a sweet Georgia girl in your arms and dancing to the 'Limelight' theme in the Carolina mountains in the summer of '52, out of doors, with the lightning bugs and the Japanese lanterns. (Percy, 1978: 10)

However, it is possible that Lancelot was more in love with the idea of femininity, a certain atmosphere that accompanied their dates, at least initially, because he does not name his wife. He is more particular about the second time when they listened to the music: 'Driving with Lucy Cobb through the Carolina summer night with the top down and the radio playing the "Limelight" theme' (ibid.: 11). Lancelot refers to his dead wife in a very formal way, using her name and her maiden surname, which is hardly a way to describe one's beloved person. The 'Limelight' theme is associated with both his love and his loss of Lucy, just as Me and Bobby McGee reminds Lancelot of his relations with his second wife, Margot. Indeed, any music can become associated with sorrow, bereavement, death, and mourning. It can also bring out repressed or unacknowledged feelings and emotions, becoming the catalyst of both pain and healing. 
Singing and music in general appears at turning points in Lancelot's life, and it is also associated with revolutionary actions and outcomes. One of his recurring visions is of a mountain ranger, who hears the singing of Oh Shenandoah, which signals the upcoming revolution and the beginning of a new, purified age. Appropriately for a war anthem, the song is performed to the rhythm of marching: 'There is a cadence and a dying away to the sound' (ibid.: 238). The two couplets cited or chanted by Lancelot, use the vocabulary of love and affection:

Oh Shenandoah, we long to see you

How we love your sparkling waters

And we love daughters

[...] Oh, Columbia, our blessed mother (ibid.: 238).

Prompted by Percival's question about women, Lancelot subsides into mad ravings about women's desire to be raped and men's destiny to violate them. This conclusion induced by Lancelot's traumatic experience of his wife's infidelity, but it may also be an attempt to rationalise his own violent actions at Belle Isle, which included rape and murder. Indeed, as I have mentioned before, any song object can become associated with death and violence or mourning, depending on the individual experience

While the action of singing, which implies emotional involvement, introduces a humane note in Lancelot's dreams of a 'new life' in a new world, the detached, scientific tone in which Lancelot invokes death is particularly alarming because of the 'third revolution' that he envisages. Speaking of his third revolution, just before claiming that there will be no need for killing anyone, Lancelot 'prophesies' that the 'country is going to turn into a desert and it won't be a bad thing' (Percy, 1978: 168). He explains that 'Deserts are clean places. Corpses turn quickly into simple pure chemicals' (ibid.). His words indicate that, for him, death is an abstraction in spite, or because, of the fact that he has had a very immediate experience of it. Lancelot probably feels that he can function as a sane being only if he refuses to recognize death as a tragedy, so that the murders he committed remain abstract, cushioned in the language of science and metaphor.

Nevertheless, Lancelot's 'new life' does not resemble, contrary to his claims, the life of 'survivors', but the existence of 'the living dead' (ibid.: 38-39). Indeed, Erich Fromm explains that sensitivity is essential for a sane, unalienated person, because 'The effort to avoid [pain and sorrow] is only possible if we reduce our sensitivity, responsiveness and love, if we harden our hearts and withdraw our attention and our feeling from others, as well as from ourselves' (Fromm, 1991: 201). Likewise, Garrido et al. contend that 'Among the disturbing effects at both clinical and sub-clinical levels of trauma may be emotional numbing, reexperiencing the event, survivor guilt and feelings of responsibility, anger, and heightened arousal levels' (Garrido et al., 2015: 1). Remarkably, music, singing and other creative activities are considered to be among the means of overcoming emotional trauma and in some cases have been successfully applied as treatments for psychological trauma (see Garrido et al.). 
When Lancelot distances himself from the pain of Margot's infidelity, he ceases to function as a healthy individual. As he forgets or, to use his own words, 'does not want to remember' the night when Belle Isle exploded, he stays in a mental hospital for a year without getting better. Only when he is able to speak to Percival and relate his experience, is Lancelot healed, at least apparently, as he announces: 'I'm leaving today. They're discharging me. Psychiatrically fit and legally innocent' (Percy, 1978: 270). Lancelot's words sound ironic: although the reader may for a moment believe that Lancelot is 'fit' to function in society and is even saner than his psychiatrist (ibid.), the second part of the statement, 'legally innocent', is manifestly untrue. Lancelot's discharge follows on his telling Percival about Jacoby's murder; as a result, the reader's impression is that, in the world of Lancelot, the concepts of innocence and sanity are distorted.

The person who can recognise and diagnose Lancelot's sickness is Percival. As a priest and psychiatrist, Percival would know that his friend is psychologically and spiritually sick. According to Lawson, Percy learned from experience that 'there are several different aspects to illness, not merely a physical, not merely a physical and a mental, but a physical and a mental and a spiritual' (Lawson, 1972: 31). In his ability to perceive Lancelot's sickness holistically, as a combination of physical, mental and spiritual aspects, Percival becomes very similar to Percy the author, who believed that a novelist should be the diagnostician of social malaise (Lawson, 1972). One symptom of Lancelot's sickness, characteristic of modern society as a whole, is that he still perceives death as an abstract category. He has observed Percival recognizing and accepting death in its relation to the individual, when the priest prayed for the dead at the cemetery. However, death remains associated with mythology for Lancelot, as he alludes to Sodom, the Assyrians and the Spartans in describing contemporary American society: 'How many Spartans would be needed to take these 200 million Athenians? Ten thousand? A thousand? A hundred? Twelve? One?' (Percy, 1978: 277). Despite his earlier assertions that there will be no need to kill, Lancelot does not appear to baulk at the thought of manslaughter. Nevertheless, he needs the vocabulary of myth and ancient history (Assyrians and Jews, Sparta and Athens), abstract terminology ('destroy' instead of 'kill') and pejorative words 'Russkies' and 'Chinks' to justify his intentions (Percy, 1978: 277). Human life for him is quantifiable, because he does not perceive the 200 million people he proposes to 'destroy' or 'take' (ibid.) as human beings. Lancelot also refers to the song Oh Shenandoad, which is symbolic in the context of the Southern culture, in order to rationalise or justify his past and envisaged violence and death-dealing.

Happily, an alternative vision can be glimpsed in the actions of Percival, who, at the novel's end, prays for another member of his community. By means of prayer, the dead and the living are joined as one community, which is an important notion in medieval Christianity generally and in the Arthurian romances in particular. This union is achieved, in many ways, through different types of music. While Oh Shenandoah constitutes a link between Lancelot's historical past and his noble Southern ancestry, the Cajun rhyme he hears or 
dreams of provides a link to his other ancestors, the practical-minded, cheerful Creoles.

Classical music largely has negative associations in the novel, often being linked, in Lancelot's speech, to decay and decadence, but it also can evoke powerful emotions and memories. In many cases, classical music provides an inauthentic venue of escapism: Lancelot listens to Beethoven while drinking and reading Raymond Chandler, while the character in the film made at Belle Isle, Lipscombe, is given to playing Chopin on the piano. Likewise, Margot's interest in classical music is probably pretended, an affectation of the Southern 'aristocratic' lifestyle as she sees it, and Lancelot believes that her enjoyment of country music was far sincerer. In this case, it is both sad and ironic that the soundtrack Lancelot remembers in connection with their love-making is Janis Joplin's Me and Bobby McGee, Joplin's single hit with which she made it to the radio tops posthumously. The song is about betrayal and loss that, unexpectedly, leads to a sort of tragic liberation, just as Margot's betrayal death has left Lancelot free to begin a new life and to live authentically, rather than drowning his consciousness in routine drinking and mindless activities. For Lancelot, the song is emblematic of love and sexuality, and he imagines that his friend, Perceval/Father John, is in love with an unknown girl whom Lancelot watches singing the song. The readers never find who the girl is or whether she even sings the song except in Lancelot's imagination, but her singing creates a chain of continuity between her the two dead and - apparently - promiscuous women, Janis Joplin and Lancelot's Margot.

\section{CONCLUSION}

As Lancelot plans to begin a 'new life' with a 'new woman', the victim of rape and his fellow patient, in the evocatively named State of Virginia, he needs to create a new language or a new medium of expression. Throughout the novel, he attempts at communicating with his neighbour by tapping on the wall, but he soon realises the limitations of this method. However, when he enters the room next door and tries to speak with the girl he realises still more acutely the inadequacy of the old language. It seems that the solution to the main character's inability to communicate his feelings, ideas and visions in the existing language could have been solved through bypassing the medium of words altogether, and using, for instance, the language of music and song. A tendency in this direction is signalled using the oral tradition song Oh Shenandoah, but, like Me and Bobby McGee, it may be misunderstood or inadequately interpreted, rendering void its healing effect. Moreover, past experiences can change the meaning and healing potential of song objects: Me and Bobby McGee is, for Lancelot, about betrayal and loneliness, but so is, in a sense, the 'Limelight' theme, associated with Lancelot's dead wife Lucy.

In fact, no final musical solution to Lancelot's dilemma of a new language is offered, just as his new life is only hinted or promised but never drawn explicitly in the novel. In his later commentary on the grail quest motif, however, Walker 
Percy outlines his own vision of what may follow upon Lancelot's entry on the Holy Grail quest: a desert is flowering and blossoms springing out of barbed wire (Percy, 1978: 422-423). This vision, based in the medieval romance aesthetics and theology, is also in line with Kierkegaardian existentialism as embraced by Percy himself. Thus, for Percy, and in his novel Lancelot in particular, songs of death can be transformed into songs of life as the individual passes from the aesthetic to the ethical stage, from culture to nature, from the search for consumerist heaven to the search of God. In this passage, author's song objects, especially classical instrumental music, are synonymous with the aesthetic stage, while popular and oral tradition song objects are close to the ethical stage. In turn, the music of nature or soundscapes represents the dawning of the aesthetic stage and the victory of life over death.

\section{REFERENCES}

Baumgartner, E. (1981) L'Arbre et le Pain. Essai sur la Queste del Saint Graal. Paris: SEDES.

Bénichou, P. (1970) Nerval et la Chanson folklorique. Paris: Librairie José Corti.

Benson, D. C. (1996) The Ending of the Morte Darthur. In E. Archibald and A. S. G. Edwards (eds.) A Companion to Malory (pp. 221-240). Cambridge: D.S. Brewer.

Brinkmeyer, R. (1987) Walker Percy's Lancelot: Discovery through Dialogue. Renascence, 40 (1): 30-42.

Cartwight, G. (2010) Turn Out the Lights: Chronicles of Texas during the 80s and 90s. Austin: University of Texas Press.

Ciuba, G. (1985) The Omega Factor: Apocalyptic Visions in Walker Percy's Lancelot. American Literature: A Journal of Literary History, Criticism, and Bibliography, 57 (1): 98-112.

Crowley, D. and Crowley, S. M. (1990) Walker Percy's Grail. In V. Lagorio and M. L. Day (eds.) King Arthur Through the Ages (pp. 255-277). New York: Garland.

Dale, C. (1980) Lancelot and the Medieval Quests of Sir Lancelot and Dante. Southern Quarterly, 18 (3): 99-106.

Daniel, D. (2012) Thoughts on 'Me and Bobby McGee' and the Oral and Literary Traditions. In C. Pence (ed.) The Poetics of American Song Lyrics (pp. 193-198). Mississippi: University Press of Mississippi.

Desmond, J. (1986) Love, Sex and Knowledge in Walker Percy's Lancelot: A Metaphysical View. Mississippi Quarterly, 39 (2): 103-109.

Dewey, B. (1985) Walker Percy Talks about Kierkegaard: An Annotated Interview. In L. Lawson and V. Kramer (ed.) Conversations with Walker Percy (pp. 101-128). Mississippi: University Press of Mississippi.

Fromm, E. (1991) The Sane Society, $2^{\text {nd }}$ ed. London: Routledge.

Garrido S., Baker, F. A., Davidson, J. W., Moore, G. and Wasserman, S. (2015). Music and trauma: the relationship between music, personality, and coping style. Frontiers in Psychology, 6 (977). DOI: 10.3389/fpsyg2015.00977.

Grocke, D. E. and Wigram, T. (2007). Receptive Methods in Music Therapy: Techniques and Clinical Applications for Music Therapy Clinicians, Educators and Students. London and Philadelphia: Jessica Kingsley Publishers. 
Kristofferson, K. and Foster, F. (1969). Me and Bobby McGee.

Lawson, L. (1972) Walker Percy: The Physician as Novelist. South Atlantic Bulletin, 37: $58-63$.

Lawson, L. (1996). Neurobiology and Psychoanalysis in the Work of Walker Percy. In L. Lawson (ed.) Still Following Percy (pp. 3-13). Mississippi: University Press of Mississippi.

Lupack, A. and Lupack, B. T. (1999). King Arthur in America. Woodbridge: D. S. Brewer. Miller, S. (2009) Kristofferson: The Wild American. London: Omnibus Press.

Montgomery, M. (1993) Walker Percy and the Christian Scandal. First Things. Available from https://www.firstthings.com/article/1993/04/004-walker-percy-and-thechristian-scandal [Accessed on 17 September 2018].

Quinlan, K. (1996) Walker Percy: The Last Catholic Novelist. Louisiana: Louisiana State University Press.

Robeson, P. (1936) Oh Shenandoah. Available from https://archive.org/details/PaulRobeson-collection-111-120. [Accessed on 17 September 2017].

Ropa, A. (2014a?). Representations of the Grail Quest in Medieval and Modern Literature (Unpublished doctoral thesis). Country: Bangor University.

Ropa, A. (2014b?) An Alternative History of the Grail Quest. Bulletin du centre d'études médiévales d'Auxerre | BUCEMA, 18 (2). Available from http://cem.revues. org/13538 [Accessed on 12 September 2018]. DOI: 10.4000/cem.13538.

de Saussure, F. (1922) Cours de linguistique générale, 2nd ed. Paris: Librarie Payot.

Scarborough, D. (1925) On the Trail of Negro Folk-songs. Harvard: Harvard University Press.

De Surmont, J.-N. (2010) De la poésie vocale à la chanson. Vers une théorie d'objet-chanson. Lyon: ENS Éditions.

Utter, G. H. (1982) The Individual in Technological Society: Walker Percy's Lancelot. Journal of Popular Culture, 16 (3): 116-127.

Zapatka, F. (2000) Sentiment, Science and Thanatos in the Work of Walker Percy. Life and Learning, 10: 321-336.

Zumthor, P. (1983) Introduction à la poésie orale. Paris: Seuil.

\section{BOOKS ANALYSED}

Percy, W. (1966) The Last Gentleman. New York: Straus and Giroux.

Percy, W. (1972) Love in the Ruins: The Adventures of a Bad Catholic at a Time Near the End of the World. New York: Dell Publishing.

Percy, W. (1975) The Message in the Bottle: How Queer Man Is, How Queer Language Is, and What One Has to Do with the Other. New York: Farrar, Straus.

Percy, W. ([1977] 1978) Lancelot. New York: Avon Books.

Percy, W. (1980) The Second Coming. London: Panther.

Percy, W. (1991) Signposts in a Strange Land. P. Samway (ed.). New York: Farrar, Strauss.

Anastasija Ropa $(\mathrm{PhD})$ is associate member of the Centre for Arthurian Studies of the Bangor University (UK); her interests include Arthurian Studies and medieval literature. Email: Anastasija.Ropa@lspa.lv. 


\title{
THE FUZZY CONCEPT OF IDIOM AND WHAT IT MIGHT MEAN FOR BILINGUAL DICTIONARIES
}

\author{
ANDREJS VEISBERGS \\ University of Latvia, Latvia
}

\begin{abstract}
Linguistic categories were developed as tools for describing language systems and making them easier to learn. However, like many theoretical concepts and systems, they do not fully represent the real world and, in some cases, seek to imprison linguistic units within a well-ordered system - a procrustean bed as it were. Besides, although the most general categories are universal, the lower-ranking ones are often language-specific. Idiom (or phraseologism) is a very unclear linguistic concept, subject to never-ending debate. However, a strict adherence to categorisation is observable in practical bilingual lexicography and phraseography. This may lead to unwanted compartmentalisation and a skewed product. The conventional practice in bilingual lexicography is to provide B-language idiom equivalents or analogues for A-language idioms and B-language lexical items for A-language words. B-language idioms are not normally provided for A-language words and vice versa. This reflects thinking in terms of structures, rather than of semantic equivalence. The sharp demarcation of structures in dictionaries erects needless barriers by imposing the theoretical concepts of idiom, compound, derivative and metaphorical lexical item on to practical lexicography. The phrase-compound-derivative-idiom divide is often quite arbitrary and changes over time. Moreover, the only functional equivalent for a word is often an idiom and vice versa.
\end{abstract}

Key words: phraseologism, idiom, lexeme, bilingual dictionaries, category, equivalence

\section{INTRODUCTION}

Integrating phraseology into bilingual dictionaries involves several lexicographical conventions: marking idioms or phraseological blocks, use of labels, choice of equivalents, and so on (Farina, 2009; Mogorrón, 2011; Xia, 2015). The conventional practice in bilingual lexicography is to provide B-language idiom equivalents or analogues for A-language idioms and B-language lexical items for A-language words. Occasionally, in the absence of any corresponding idioms in the B-language, a lexical item or explanation may be provided. However, B-language idioms are not normally provided for A-language words. This reflects thinking in terms of structures, rather than of semantics (or semantic equivalence). The issue of lexical correspondences for idioms is not much discussed as it breaches the boundaries between linguistic categories, whereas equivalence requires remaining within the same category. 
Idiomatic features (metaphor, figurativeness, opacity) are not unique to idioms; they can also be embodied in lexical structures, especially in derivatives or compounds. For example, English idiomatic phrasal and postpositive verbs, which are frequently fully idiomatic, tend to correspond to prefixated verbs in many languages. Other types of phraseological units frequently carry a meaning that can be better expressed in a single word or nonidiomatic phrase in the other language. Conversely, an English idiom would be the best equivalent for these nonidiomatic lexemes, derivatives or phrases. The dictionary must also take account of its target audience, level of sophistication, directionality and purpose, of course. However, lexicographers should think more in terms of equivalence of meaning, not structures, words or phrases (Atkins and Rundell, 2008). I believe that dictionaries should be 'much more phrasal than they currently are' (Granger, 2008: 1353).

\section{LINGUISTIC CATEGORIES AND CONCEPTS}

Linguistic categories were developed as tools for describing language systems and making them easier to learn, analyse and compare. However, like many theoretical concepts and systems, they do not fully represent the real world and, in some cases, seek to imprison linguistic units within a well-ordered system a procrustean bed as it were. This, first of all, is not scientific as it distorts reality; second, such scholarly absolutism does not reflect the multiplicity and elasticity of reality; and, third, it tends to impose concepts and categories of one language on to others, though many categories are at least partially language-specific. There are many ludicrous historical examples of nonexistent categories being invented for some languages because they existed in another, for example, the retention of the Latin and Old English declension systems in modern English. Today's lingua franca English also seems to exercise an overwhelming influence on dominant conceptual frameworks - 'a conceptual cage' (Wierzbicka, 2014: ix). This, though, is certainly not the case as regards the concept of idiom, an opaque term in English, a natural word rather than a term in fact. The rationale behind these knowledge and pattern transfers is readily understood: they are ready-made and widely accepted, and apparently simple concepts and models are always attractive. They appear to solve categorisation issues easily. Many linguistic phenomena do indeed fit these general international models, but not fully and not always. Hardly any linguistic category illustrates these problems better than idioms and phraseologisms with their numerous terms and classifications. We understand a category to be a set of entities, for example, we can collect a set of idioms and refer to them as a category. We understand a concept to be a mentally possessed idea summarisable in a definition (see more on concepts and categories in Haspelmath, 2007, 2010; Moravcsik, 2016; Lehmann, 2018). Idiom or phraseologism is a prototypical concept, relatively clear at the centre, very blurred on the margins. It is a defined concept. But, since the definitions vary, the scope of the concept and category differs as well. 


\section{IDIOMS: THE THEORETICAL CONCEPT}

Idiom or phraseologism (Cowie, 1998) is a relatively new linguistic concept. In many languages, the unclear term phrase has been and is used to designate a wide range of multiword combinations.

In this paper, we use the terms idiom and phraseologism synonymously, in keeping with the broadly accepted meaning of both terms. We are aware that the term idiom is often used in a narrower sense, as a subtype of phraseologism possessing less predictable meaning, a more frozen and holophrastic unit. The broad understanding of idiom presumes that it includes various subcategories, each of which gives more prominence to some of the main features and might have some other extra features. The broad understanding of the concept seems to be advantageous both theoretically (rather than attempting to categorise a multitude of units, a necessarily imprecise exercise since each exhibits one or another fundamental trait to some extent) and in practice (in phraseography, lexicography, corpus linguistics, text processing and the pedagogical sphere). Differentiating between various types of multiword units (idioms and collocations, free combinations, and various subtypes of transitory formation) is not easy (Bentivogli and Pianta, 2002; Oppentocht and Schutz, 2003: 219; Nuccorini, 2003: 367; Veisbergs, 2012) and generally does not make much practical sense.

Apart from the core units, phraseologisms or idioms thus also include the following subtypes:

- Binomials - two-component phrases: bag and baggage, odds and ends, high and dry,

- Proverbs - didactic, metaphorical advisory sayings: a stitch in time saves nine, like father like son,

- Sayings - informal, concise observations: time flies, accidents happen,

- Catchphrases - short, oft-repeated slogans: softly, softly catchee monkey, make love not war, it takes two to tango,

- Phrasal or postpositive verbs - break down, come up with, come on,

- Clichés - burning question, head and shoulders above, good clean fun, of the first magnitude

- Pragmatic idioms - phrases determined by social situation: many happy returns of the day, how do you do?

- Hedges - to be exact, be that as it may, to wit, by and large.

In addition, there are some marginal and obfuscated linguistic categories like abbreviated idioms $O T T$ (over the top), which have multiplied in internet abbreviations (combining features of idioms and abbreviations), some of which have entered into use: FML (fuck my life), LMAO (laughing my ass/arse off), SMH (shaking my head), MILF/milf (mother I'd like to fuck). Casting the net 
further might yield subclasses even more puzzling and controversial in theory, e.g. the one-word phraseologism (Ein-Wort-Phraseologismus) in German (a contradiction in itself) (Burger et al., 2007: 18) which calls the basic criteria of idioms into question (see below, under 3.2. Multiword criterion).

The theoretical debate on the concept of idioms (phraseologism, phraseological unit, idiomatic expression) and their classifications is never-ending. Most idiom classifications tend to focus on broadness of concept, frozenness and the differentiation between idioms and nonidiomatic formations. However, the authors of encyclopedia of Phraseology maintain that open boundaries and category fuzziness make any exhaustive classification or terminology of phraseology impossible (Burger et al., 2007: 15). Similarly, there is no hope for a 'unitary theory of idiom comprehension' (Glucksberg, 2001: 72). This is echoed by an experienced lexicographer: the issue may be interesting, but is not particularly rewarding in practice: Atkins concludes that 'our language is so fine and flexible and subtle and complex that such a task seems doomed to failure' (Atkins, 2008: 47). Corpus analysis, as can be seen in the study by Moon (1998), drives us to look at 'fixed expressions and idioms' together since collocations also present a cline (Cowie, 1998: 20; 2008: 164-165). To conclude: 'idiom is an ambiguous term, used in conflicting ways' (Moon, 1998: 3).

In order not to get bogged down in terminological issues, a working definition of idiom follows. Idioms or phraseologisms constitute a subcategory of fixed or stable multiword expressions, units or items, the other major group being fixed word combinations (collocations) with no semantic reinterpretation. Idioms are collocations in that they 'behave as phrases, albeit with certain constraints' (Glucksberg, 2001: 69). Idioms are usually expected to comply with three fundamental criteria: they are fixed, they are multiword combinations and they possess some degree of figurative, transferred or metaphorical meaning. Each of the three main criteria is a continuum that is relative, subjective and varied. Does the combination of the three criteria make idioms so special that their equivalents in contrastive studies and bilingual lexicography must always be idioms?

There is the somewhat imprecise idea of 'semantic plus value': 'many idioms, merely by their nature as idioms, have a semantic plus value' (Gouws, 1996: 70). However, there is no 'semantic plus' for all the idioms as a linguistic category (that should be preserved in cross linguistic transfer, see below). Rather, it 'stems from the specific cultural background or cultural reference' (Gouws, 1996: 70). In other words, these are idioms that possess some cultural specificity, which might be difficult to transfer to a different language. That being said, many words, collocations and supratextual features (such as Japanese haiku style, or particular stanza or meter types) also possess such 'semantic plus value' and are difficult to transfer. 


\section{IDIOM CRITERIA}

\subsection{THE STABILITY/FIXEDNESS CRITERION}

Fixedness (as opposed to variability) is a relative trait. Idiom components may change over time (diachronic change), but this can be discounted as all language units change over time. However, idioms also exhibit synchronous variability. They often tend to have many lexical component variants: to raise the devil/ hell/the roof/Cain, to put one's back/heart/oneself into sth, to bang/hit/knock one's head against a (brick) wall; not to lift/stir/raise a finger. They also tend to have quantitative variants in that elliptical forms are possible: the last straw (that breaks the camel's back), (to draw/pull) a red herring (across sb's path/track).

A good example of instability can be seen in bad/good press (criticism/praise in the media (NB: not only in printed press)). This expression is often varied, for example, the adjective bad may be replaced by other adjectives. In addition, the phrase is usually preceded by a limited set of verbs, which are often considered to be part of the idiom (in dictionaries), normally get, receive, have. The indefinite article is also optional.

- Banks have lately received a lot of bad press about their conduct.

- He often had such a terrible press, yet everyone who met him liked him.

- The fans of the Manchester City football team get a fantastic press.

Many idioms not only have single optional components, but actually presume alternative components (usually adjectives) from a restricted or virtually unrestricted set, e. g. make (some/ no/ not any/ little/ perfect) sense of; take the (easy/ simplest/ quickest/ coward's) way out. This poses a problem for lexicographers: while two or three optional components can be introduced with an oblique in the headphrase or entry, having a limited but extensive list of these components might make it difficult for the user to identify the fixed elements in a long string of words (Cowie, 1976: xxii). Corpus linguistics contributes to the idea that the concept of stability is relative, for example, Gries defines stability as a greater simultaneous occurrence of components than would occur on the basis of chance alone (Gries, 2008).

Finally, idioms can undergo transformations contextually (Veisbergs, 1996; Naciscione, 2010) and are frequently used in this form. There seem to be differences of convention and norm as regards this phenomenon in various languages, to some extent affected by the flective/analytical language divide, but also by tradition and expectancy norm (Veisbergs, 2007: 240; Veisbergs, 2018:137), e. g. the proverb a bird in hand is worth two in the bush could undergo various transformations according to the user's wishes:

- A bird in hand, I thought. (ellipsis or allusion),

- So priceless a bird... (addition and ellipsis), 
- A bird in hand in the economic bush. (insertion and ellipsis),

- Why chase two birds when one is up for grabs? (allusion),

- A competent minister in hand is worth many generals in the bush. (substitution).

Some more extreme cases leave little of the original idiom in place, sometimes merely a single word or just the structure.

Can these instances be theoretically viewed as varying uses of a single idiom? When we change a word virtually beyond recognition we normally consider it a new word. However, in the case of idioms the initial form (however blurred) is kept clearly in mind.

It is worth noting that collocations demonstrate a similar stability gradience (Van der Meer, 2000: 127), tending to be fixed, and restricted to various extents in semantic and morphological ways. Thus, the fixedness criterion should not be viewed as absolute.

\subsection{THE MULTIWORD CRITERION}

The multiword-unit criterion (polylexicality) is relative as a result of divergent spellings (together or separate) and often also normativising tendencies (LevinSteinmann, 2007: 37) which can change the linguistic status of the unit. The compound/idiom divide is quite arbitrary and often changes over time, e.g. in English from honney moone to honeymoon. Cheapskate combines skate, which began to appear in print in the US at the end of the nineteenth century, almost simultaneously meaning a worn-out horse, a mean or contemptible person, and a second-rate sportsman, with cheap, to signify tight-fistedness. For a time it was used as a phrase cheap skate, then blended into a compound. In many languages two-component nominal idioms often tend to fuse into a compound with the passage of time, e.g. Latvian grēka äzis > grēkāzis (scapegoat), thus nominally leaving the category of idiom. For some expressions, the spelling is not stable synchronically either, illustrated by the English saying: 'when in doubt, hyphenate'. It must be emphasised that in most cases there is no change of meaning accompanying this graphical change (a change of stress in pronunciation might be present).

A broader view offered by statistics and corpus linguistics shows that reality does not go by 'preformulated linguistic concepts' like idiom. Many multiword expressions defy the strict syntactical and morphological divide (Hüning and Schlücker, 2015). For example, the extremely common German prefix verbs, e.g. aufgeben (to give up) can be viewed either as a single unit or as two words, depending on the kind of sentence they appear in, e.g. Er will den Plan aufgeben, Ergab den Plan auf. There is a functional overlap between syntax and morphology (or the lexicon). A similar phenomenon can be observed in Latvian. Verbal meanings are generally differentiated through the use of a wide range of prefixes, e.g. sist (to beat): sasist (to break), iesist (to hit), piesist (to attach), nosist (to kill). 
However, in some cases postpositive particles (adverbs: apkārt, cauri, garām,

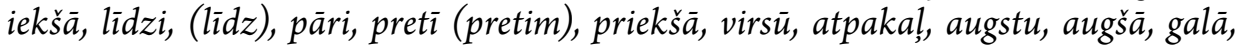
iepakal, klāt, kopā, laukā, nost, projām (prom), rinkîi, tālu etc.) are used for creating different meanings, e.g. sist nost (to kill), dzivot nost (to waste), beigt nost (to kill), spiest nost (to crush), iet nost (to wash out, to be removed); celt päri (to transfer), iet pāri (to overflow), plūst pāri (to overflow), palikt pāri (to remain); sist cauri (to beat through), strāvot cauri (to permeate); dzīivot lìdzi (to empathise). Often they are practically equivalent to the corresponding prepositional verbs: nosist, nodzivot, nobeigt, nospiest, noiet, pārcelt, pāriet, pārplūst, pārpalikt, caursist, caurstrāvot, lidzdzivot. In other cases a verb with a different preposition might correspond to the postpositive phrase, e. g. izjaukt: jaukt lauka (to take apart), uzsliet: sliet augša (to put up). Both groups can be idiomatic, but the first would nominally fall under the category of idioms, the second under derivative verbs.

The fickleness of the dichotomy of multiword phrase and compound is further illustrated by some close formations of a semantic set, e.g. underdog (loser), top dog (boss; winner). Semantically these are parallel formations, etymologically going back to the same source, dogfights. Similarly, English tightfisted and close fisted, or Latvian maitasgabals [piece of carrion]; (henceforth square brackets indicate literal translations) - bastard; rada gabals [piece of relative] - kinsman. The second items are idioms, but the first are lexical units. Semantically equivalent units can come in various forms, for example, the meaning of a hardworking person can be expressed in a single stem lexical unit (beaver), compound (dogsbody) and idiom (eager beaver, busy bee).

Semantically (and etymologically) identical creations in various languages have semantically identical full equivalents falling under a range of structural categories (words, compounds, collocations and idioms). Formations with two or three separate components in one language may occur as a single item in another. Thus, English honeymoon has the following counterparts:



The expression is an idiom in five of the eight languages and a compound in three, purely as a result of spelling. Similarly, English Don Juan has both idiomatic and compound correspondences. In Latvian, it used to be a phrase (dons Žuans), but now has blended into a compound (donžuāns).

An idiomatic German three-component compound Dünnbrettbohrer [literally, a thin-board drill - used to mean a lazy or stupid person] borrowed in Latvian as plānā galdina urbējs has become an idiom perfectly corresponding 
to the three main criteria. It could theoretically have become a two-element phrase (with the first two components blending), but not a three-component lexical unit as these are extremely rare in Latvian. Spelling rules are determined by each language's norms and conventions (and are subject to change). It has been noted that in interlingual comparison a compound in German often corresponds to a phraseological word combination in other languages (Burger, 2007: 103). This reveals the serious limitations of the standard idiom theory, which tends to disregard the issue of the language level below idiom. Čermak points out that, while the standard discussion of idioms focuses on collocations, with some theorists talking of sentence idioms, 'very few are prepared to go in the opposite direction, namely, below the word level' (Čermak, 2007: 20). Identical contents may be rendered either as a combination of separate forms (split hairs, cut corners) or of morphemes inside a lexical idiom, i.e. in a single word (hair-splitting, cornercutting). Similar cognates: to pick sb's pocket and pickpocket.

Idiom theory is also dominated by a Eurocentric view, disregarding polysynthetic languages. While the existence of idioms is most probably universal, their formal manifestations depend on the character of the language. Noting that some European languages prefer compounding, Čermak concludes that 'too narrow a delimitation of the field of idioms is wrong' (Čermak, 2007: 20) and suggests that the defining feature should be multicomponent character.

Finally, frozen or fossilised phrases like of course, not at all, to wit, by and large, in a measure, in part, all of a sudden function as one-word items and the spaces have no linguistic significance.

Some theorists (cf: Chafe, 1968; Gouws, 1991; Botha, 1992) emphasise that words and idioms share a common trait in that they both exist as a single semantic unit. Zgusta (1971: 154) talks about 'parallelism between multiword units and words', which is suggestive of giving them independent entry status, which is echoed by Sinclaire (2010). It is well known that some phrases are lexical and behave like lexical items (Bejoint, 2010: 308). Thus, the multiword criterion is not absolute either.

\subsection{THE IDIOMATICITY/TRANSPARENCY CRITERION}

This feature of idioms has caused the most theoretical and terminological discussions as regards the term itself. But idioms are not all equally nontransparent: idiomaticity is scalar (Bruckmeier, 2017: 152). There is a touch of idiomaticity (in the broad sense) in many collocations that would not qualify as idiomatic under close scrutiny: 'idiomaticity is present in all the multiword 'expressions' that are chosen 'at one go' by the language user' (Bejoint, 2000: 211). Multiword phrasal expressions are part of the mental lexicon (Jackendoff, 1995: 165). To escape this conundrum an emphasis on naturalness (McCarthy, 1988) or typicality (Hanks, 1988) may be useful.

Besides, figurativeness is often subjective, depending on the individual's knowledge, experience and to some extent also perceptiveness, thus the phrase 
to have a hair of the dog (to take alcohol to cure a hangover) is fully opaque to anyone ignorant of its origin. The full phrase is to have a hair of the dog that bit you, which is already more comprehensible as a metaphor. For someone knowing the full history of the term (the old wives' tale that a clump of hair from the dog that had bitten you, when rubbed on the wound, would help it heal faster) the phrase might be almost transparent. In turn, the phrase (can't) have your cake and eat it is a fairly logical statement that could be classified as a transparent metaphor. Some simple similes: as cold as ice is transparent, swear like a trooper and curse like a fishwife is less transparent and as large as life is fully idiomatic.

Sometimes idiomaticity or nonidiomaticity may be distinguished only from context, and even then not quite clearly. For example, the phrase to shake hands may be nonidiomatic (direct meaning) or idiomatic, and sometimes contextually unclear. There is thus no clear boundary between collocations and idioms, it is a cline. The degree of idiomaticity is not connected to the length or complexity of the idiom, nor to its function. Idiomaticity is not unique to idioms, it can be present in compounds, derivatives and root lexemes (Rio-Torto, 2012) as well as in the language levels above idioms.

Finally, idiomaticity is not distributed symmetrically and equally in all languages. For example, to trumpet is just as figurative as to shout from the housetops, and the corresponding Latvian item is a metaphorical lexeme izbazūnèt [to out+trombone]. It is noteworthy that the musical instrument's noun and verb (bazūne, bazūnett) are not idiomatic in Latvian, it is the prefix that confers idiomatic meaning to the derivative verb. In any case, the Latvian lexical item is the closest equivalent to the English idiom and vice versa.

To conclude this part: first, fundamental concepts and fundamental terms can vary from language type to language type (Burger et al., 2007: 13); and second, all traits of idioms tend to be graded or scalar. This in my opinion has some consequences for dictionaries.

\section{EQUIVALENCE, CONTRASTING IDIOMS}

Equivalence is a concept that, after 2000 years of dominating translation issues, has been seriously called into question in modern times. It has come to be seen as unsuitable as a basic concept in translation theory, as well as imprecise and ill defined (Snell-Horby, 1988), offering too many interpretations, and having various imprecise, subjective and unclear attributes (dynamic, formal, semantic, communicative, full, partial, imitative, functional, statistical, etc.) (Chesterman, 1997: 9-10, 2016). Translation theory has since been largely preoccupied with seeking broader text similarity rather than focusing on unit equivalence (which in a way is similar to what we suggest below).

However, in bilingual lexicography, which mostly contrasts two language elements without context, the term cannot be thrown overboard, it is necessary and inevitable: 'equivalence is the axis about which the activity of translation 
turns (Kromann et al., 1991: 2717) and it can be full, partial or surrogate equivalence, or nonequivalence' (ibid.: 2718). We may, generally, assume that perfect or total equivalence (lexical, grammatical, pragmatic, discursive and cultural) is rare and limited to those language units that can be translated into another language invariably, subject to the test of backtranslation, in all contexts. This would cover some symbols, technical terms, figures and numbers, some monosemantic lexemes and perhaps some simple phrases. Full equivalence (with some deviation from total equivalence) is relatively frequent in related languages with similar cultural backgrounds but rare in typologically different languages (Cristinoi, 2016: 100).

Idiom equivalence is usually viewed within the framework idiom versus idiom. There are various types of idiom similarity, mostly discussed in relation to translation, and various methods of translation and substitution can be used: full and partial equivalence, paraphrase, loss or omission, loans, calques, compensation with an emphasis on finding an adequate solution (Corpas, 2000).

Idiom equivalence is also researched in contrastive linguistics and linguistic phraseology. Researchers generally agree that several parameters must be taken into account: semantic, syntactic, pragmatic (Dobrovol'skij, 2000a) stability, connotations and valency (Korhonen, 2007: 577). Generally, 'functionally adequate equivalents' should be sought (Dobrovol'skij, 2000b: 169), a term which additionally encompasses any relevant combinatorial properties (Dobrovol'skij, 2000b: 182), as some idioms of similar mental image and lexical structure might not be fully replaceable. Equivalence is not always monosemantic (which users think is standard), sometimes there are differing denotational and connotational equivalents (Duval, 2008: 274). Similar image idioms (Schemann, 1991: 2792) present the risk of false friends or pseudoequivalents: deceptively identical idioms carrying different meanings.

As stated, idiomatic features (metaphor, opacity) can also be embodied in lexical structures, especially in derivatives or compounds. For example, English phrasal verbs, which are frequently fully idiomatic, tend to correspond to prefixated verbs in many languages. There can even be a certain regularity between the English postpositions and German, Latvian or Russian prefixes (see below). Other types of phraseological units occasionally carry a relatively simple idiomatic meaning that can be expressed in a word: neck and neck (even, level), on the nail (immediately), by and large (generally) and, where the other language has a corresponding lexeme, it is a full equivalent. The idea of idiom-word equivalence is not new: for a time the Soviet school even had the bold theory that phraseological units necessarily had word equivalents (Vinogradov, 1947; Babkin, 1970). This is often not the case, but occasionally it is, and occasionally even in languages in contrast. 


\section{THE RELEVANCE OF THE ABOVE FOR BILINGUAL DICTIONARIES}

When describing the fuzziness of the concepts and terminology of phraseology in the introduction to the encyclopedia of Phraseology, the editors state that the 'phraseological work could adjust to phraseographic and phraseodidactic practices' (Burger et al., 2007: 18). The editors also point out that, when phraseology was first studied, there was a 'tendency to circumscribe the research field for purposes of consolidation' (Burger, 2007: 11) while later corpus linguistics produced the opposite tendency. Indeed, it seems that it is better to adapt the theory to the more complex reality and to users' needs than to force reality into line with an imperfect theory.

Korhonen suggests that idioms can be contrasted either on the basis of denotative meaning (semantic equivalence which presumes corresponding units (passende Einheiten) will be found) or by contrasting corresponding morphosyntactic-lexical structures (Korhonen, 2007: 575). The latter is important mostly because it presumes there are false-friend idioms which learners must learn (ibid.: 584).

Idiom treatment in general bilingual dictionaries covers various theoretical issues, prominent among which is the choice of primary component (keyword) under which to place the idiom (Schemann, 1991: 2790-1, Yong and Peng, 2007, Mulhall, 2010). It is well known that users are not sure where to find idioms (Atkins and Varantola, 1998: 30). In bilingual dictionaries, the theoretically insoluble choice of lexicographic equivalents should be tackled on an individual basis, finding and choosing equivalents, analogues and explanations. The problems professional translators face are many and the wider the choice offered, the better. However, the issue of idiom equivalence 'plays a remarkably small role within theoretical discussions' (Faro, 2004: 83) and tends to focus mostly on the degree of equivalence of the units offered (Potgieter, 2006).

There are certain conventions governing the treatment of idioms in bilingual lexicography (Bejoint, 2000: 220). In bilingual dictionaries, the A-language idiom is normally provided with an idiom equivalent or analogue in the B-language if any exists. If none exists, an explanatory definition is used, or sometimes a lexeme is provided to explain the idiom. This seems a reasonable solution. Occasionally it is suggested that supplying an idiom counterpart is dangerous, as it may not function as an equivalent in all possible contexts. However, a backtranslation check can resolve this issue.

In a subchapter on 'equivalents of idioms' in Svensén's book on lexicography, he plainly states 'idioms in the source language must as far as possible be paralleled in the target language by idioms with the same content' (Svensen, 1993: 156). Thus, the general rule is: idiom for idiom.

It is not always possible, nor should it be mandatory: language structures differ, and, as we have seen above, so do ideas about some linguistic concepts, such 
as idiom and compound. Some researchers have been more cautious, pointing out that the issue of idiom lemmatisation is a never ending one, to a large extent because the definition of idiom is so unclear and the idiomatic cline precludes universal and clear solutions. However, it is a fundamental issue (Harras and Proost, 2005: 277). Lubensky and McShane talk of 'unused idioms' with no phraseological equivalents (though they speak of a phraseological dictionary, which in itself presumes a huge and unnecessary emphasis on structure) (Lubensky and McShane, 2007: 926). However, it is true that languages in contrast do feature idioms which have no idiom counterparts. Granger (2018: 21) notes the tendency to translate multiword units by multiword units rather than single-word equivalents. This is another case of 'categorial bias' (Granger and Lefer, 2012).

Bilingual dictionaries cannot generally serve L1 and L2 speakers equally well because their space is limited. Equivalents will most likely never be mutually replaceable, while explanations would take up too much space. Schemann talks of interlingual synonyms (Schemann, 1989: 1022). So, we look at functional equivalence which involves a number of factors: cognitive, preferred metaphorisation type, frequency, nationally specific elements, mental images and domains (Dobrovol'skij, 2000b: 172-173). Structure should come last. Dictionaries should aim at a 'similar image' (Schemann, 1991: 2792), or functional equivalents evoking 'mental images from the same conceptual domain' (Lubensky and McShane, 2007: 925). A similar image can be carried by different structures.

\section{THE LEXICOGRAPHICAL TRADITION EXEMPLIFIED}

In the absence of functional phraseological equivalents, dictionaries tend to offer lexical or nonidiomatic equivalents as an inevitable and reasonable solution. For example, for the English idiom to have the hair of the dog (to have a drink to alleviate a hangover) the following is usually offered: German ein Konterbier trinken [to drink a counterbeer], Latvian saläpities [to mend oneself], Russian onoxмелиться [to unhangover oneself]. This is optimal as these are the closest semantic correspondences. One could expect the English idiom as the best equivalent for these lexical items or collocations in the reverse variant. However, we usually see nonidiom equivalents, sometimes even cumbersome constructions: to take a drink the morning after, to cure a hangover. This illustrates a general phenomenon or pattern of bilingual dictionaries: the B-language part is always less idiomatic than the A-language part.

Lexical items and entries are normally provided with lexical counterparts. When the focus is on the B-language (active dictionaries), several equivalents are often given and, in very rare cases when it is the only possible option, a compressed idiom such as a postpositive or phrasal verb might appear. This again reflects thinking in terms of structures rather than of semantics or semantic equivalence. 
Comparing parallel bilingual dictionaries (e.g. Collins English-GermanEnglish Dictionary) we see a prominent shift towards nonidiomatic solutions:

to put oneself in (to) sb's hands sich jdm anvertrauen, sich jdm anvertrauen to entrust oneself to sb.

dog's dinner or breakfast Schlamassel,

Schlamassel mix-up; mess.

to force sb's hand $j d n z w i n g e n$

jdn zwingen to force sb to do sth

fall out sich (zer) streiten

zerstreiten to quarrel

tongue-in-cheek ironisch (gemeint)

ironisch ironic, ironical

Or in the Pons English-German-English Dictionary:

top dog boss

boss boss

aufs Haar exactly

exactly genau

(sich über etw) in die Haare geraten/kriegen to quarrel/squabble (about sth)

to squabble (about/over sth) sich (über/um etw) zanken

in this/sb's neck of the woods in diesen/jds Breiten

in unseren/diesen Breiten in our part/these parts of the world.

fall out (with smb) sich (mit jdm) (zer)streiten sich mit jdm zerstreiten to quarrel with smb (over sth)

as mad as a hatter total verrückt sein

verrï̈kt sein to be/become mentally ill

red herring Ablenkungsmanöver

Ablenkungsmanöver diversion.

These examples fail the test of backtranslation. It is interesting to note that studies of translated text corpora show more stale phraseology and a preference for concrete rather than idiomatic use (Baker, 1996). Are these hard facts (and to some extent the poor equivalence of the translations) not at least partly the result of what the dictionaries offer? Atkins and Rundell have stated that it is the semantic content and the collocational needs that need to be matched, and that in the case of phraseology 'only the message really matters' (Atkins and Rundell, 2008: 469-472). By implication this means that our choice of 
equivalents should not be ruled by structures. In real language and lexicographic practice these strict demarcations may be more burden than asset.

In my opinion, the rigid focus on categories (so often unclear and fuzzy) in dictionaries is wrong, as it erects barriers (nonexistent in reality) between idioms, compounds, collocations, derivatives and metaphorical lexical items, all of which are mere theoretical concepts. Instead, we should be focusing on meaning and register. In language pairs in contrast there are cases where the only perfect equivalent for a word is an idiom and vice versa. Failing to provide it distorts the equivalence of meaning, for example, dictionaries with English as B-language generally have much less idiomatic material in English and, as a result, English translations and usage are often more bookish, less 'typical' (Hanks, 1988), more Latinised than natural English usage. It is, however, well known that 'idiomaticity facilitates communication' (Bejoint, 2000: 216).

\section{PROPOSAL AND CAVEATS}

I think an A-language word might have not only B-language lexical equivalents but also a B-language idiom or two. Sometimes an idiom might be the only adequate equivalent. An A-language idiom in turn might have a B-language collocation or lexical counterpart that would be a better semantic match than an idiom with a divergent analogous image. Sometimes an idiom might have a good mix of equivalent words, phrases and idioms.

This seems advantageous since there is often no corresponding idiomatic material available to lexicographers. Sometimes a lexical item is the only corresponding item. This flexible approach to the idiom-word divide would tear down the conventional barriers of lexicographical thinking and practice. Thus, idiomatic material seems more natural in the B-part of a dictionary than we are used to.

All the above involves several caveats: not everything is universal. A smallscale dictionary providing one or two general equivalents will not have much space for idioms other than short frozen phrases. Directionality is of importance: if the dictionary is monofunctional (meant for speakers of one language) (Kromann et al., 1991: 2713) and active (aimed at native speakers looking for foreign equivalents), numerous correspondences are often welcome. Equivalents for words may be words, collocations and idioms. In passive dictionaries the B-part is often more explanatory, without equivalents. The passive/active divide, of course, is also not always clear and dictionaries are rarely targeted at one audience only (Berkov, 1996). In addition to full equivalence, equivalent combinatorial properties should also be sought (Dobrovol'skij, 2000b: 182), as some idioms or words of similar mental image might not be fully replaceable. Specific language pairs also carry certain linguistic idiosyncrasies, such as prefix versus postposition dominance in verb distribution. Frequency and currency must also be taken into account. 


\section{CONCLUSIONS}

Idiomaticity pervades our languages; it is not an exclusive trait of idioms but is present below and above the idiom level. Dictionaries should reflect this pervasiveness in order to be trustworthy tools for their users. Since the concept of idiom is rather blurred and Eurocentric it should not be allowed to govern natural language reflection. The corpus approach leads to the dynamic integration of phraseology into lexis and grammar, and suggests that purely isolationist or compositional views of the lexicon are sterile (Moon, 2007). The sharp division between structures in dictionaries erects needless barriers by imposing the theoretical concepts of idiom, compound, derivative and metaphorical lexical item on to practical lexicography. The phrase-compoundderivative-idiom divide is often quite arbitrary and changes over time. Thus, a more liberal mix of lexemes and idioms in bilingual dictionaries would be of benefit to their users. Lexicographers have for some time been trying to integrate phraseological aspects of language into dictionaries, arguing that dictionaries should be much more phrasal, more pattern-driven or more phrasecentred. I cannot but agree with this trend. When faced with a choice between structural conventions and semantic common sense, we should prefer the latter. Lexicographers should think more in terms of equivalence of meanings, not structures, words or phrases.

\section{REFERENCES}

Atkins, B. T. S. and Varantola, K. (1998) Language learners using dictionaries: the final report on the EURALEX/AILA research project on dictionary use. In B. T. S. Atkins (ed.) Using Dictionaries: Studies of Dictionary Use by Language Learners and Translators. Lexicographica Series Maior, Number 88 (pp. 21-81). Tübingen: Max Niemeyer Verlag.

Atkins, B. T. S. (2008) Theoretical lexicography and its relation to dictionary-making. In T. Fontenelle (ed.) Practical Lexicography (pp. 31-50). Oxford: OUP.

Atkins, B. T. S. and Rundell, M. (2008) The Oxford Guide to Practical Lexicography. Oxford: Oxford University Press.

Babkin, A. M. (1970) Russkaja frazeologiya, jejo razvitije I istochniki. Leningrad: Nauka.

Baker, M. (1996) Corpus-based translation studies: the challenges that lie ahead. In H. Somers (ed.) Terminology, LSP and Translation: Studies in language engineering in honour of Juan C. Sager (pp. 175-186). Amsterdam: John Benjamins.

Bejoint, H. (2000) Modern Lexicography. Oxford: Oxford University Press.

Bejoint, H. (2010) The Lexicography of English. Oxford: Oxford University Press.

Bentivogli, L. and Pianta, E. (2002) Detecting hidden multiwords in bilingual dictionaries. In A. Braasch and C. Povlsen (eds.) Proceedings of the Tenth EURALEX International Congress, EURALEX 2002, II (pp. 785-793). Kopenhagen: Center for Sprogteknologi.

Berkov, V. (1996) Passive vs. active dictionary. A revision. In M. Gellerstam et al. (eds.) Proceedings of the $7^{\text {th }}$ EURALEX International Congress (pp. 547-550). Göteborg: Göteborg University. 
Botha, W. (1992) The lemmatization of expressions in descriptive dictionaries. In H. Tommola, K. Varantola, T. Salmi-Tolonen and J. Schopp (eds.) EURALEX '92 Proceedings I-II (pp. 493-502). Tampere: Department of Translation Studies, University of Tampere.

Bruckmeier, E. (2017) Getting at GET in World Englishes. Berlin/Boston: Walter de Gruyter.

Burger, H., Dobrovol'skij, D., Kuehn, P. and Norrick, N.R. (2007) Phraseology: Subject area, terminology and research topics. In H. Burger, D. Dobrovol'skij, P. Kuehn and N. R. Norrick (eds.) Phraseologie. Vol. 1 (pp. 10-19). Berlin, New York: Walter de Gruyter.

Burger, H. (2007) Semantic aspects of phrasemes. In H. Burger, D. Dobrovol'skij, P. Kuehn and N. R. Norrick (eds.) Phraseologie. Vol. 1 (pp. 90-109). Berlin, New York: Walter de Gruyter.

Chafe, W. (1968) Idiomaticity as an anomaly in the Chomskyan paradigm. Foundations of Language, 4: 109-127.

Chesterman, A. (1997) Memes of Translation. Amsterdam, Philadelphia: John Benjamins.

Chesterman, A. (2016) Memes of Translation. The spread of ideas in translation theory. Amsterdam: Benjamins.

Corpas, P. G. (2000) Accerca de la (in) traducibilidad de la fraseologia. In P. G. Corpas (ed.) Las lenguas de Europa: estudios de fraseologia, fraseografia y traducción (pp. 483-522). Granada: Comares.

Cowie, A. P. and Mackin, R. (1976) Oxford Dictionary of Current Idiomatic English. Vol. 1. London: Oxford University Press.

Cowie, A. P. (1998) Introduction. In A. P. Cowie (ed.) Phraseology (pp. 1-20). Oxford: Oxford University Press.

Cowie, A. P. (2008) Phraseology. In Th. Fontanelle (ed.) Practical Lexicography (pp. 163-167). Oxford: Oxford University Press.

Cristinoi, A. (2016) Translation between typologically different languages or the Utopia of Equivalence. In L. Ilyinska and M. Platonova (eds.) Meaning in Translation: Illusion of Precision (pp. 99-109). Newcastle upon Tyne: Cambridge Scholars Publishing.

Čermak, Fr. (2007) Idioms and morphology. In H. Burger, D. Dobrovol'skij, P. Kuehn and N. R. Norrick (eds.) Phraseologie. Vol. 1 (pp. 20-26). Berlin, New York: Walter de Gruyter.

Dobrovol'skij, D. (2000a) Idioms in contrast: A functional view. In P. G. Corpas (ed.) Las lenguas de Europa: estudios de fraseologia, fraseografia y traducción. (pp. 367388). Granada: Comares.

Dobrovol'skij, D. (2000b) Contrastive Idiom Analysis: Russian and German Idioms in Theory and in the Bilingual Dictionary. International Journal of Lexicography 13 (3): $169-186$

Duval, A. (2008) Equivalence in bilingual dictionary. In T. Fontenelle (ed.) Practical Lexicography (pp. 273-282). Oxford: Oxford University Press.

Farina, A. (2009) Problèmes de traitement des "pragmatèmes" dans les dictionnaires bilingues. In M. Heinz (ed.) Le dictionnaire maittre de langue (pp. 245-264). Berlin: Frank \& Timme.

Faro, K. (2004) Idiomatische Aequivalenzprobleme: Ein ikonoklastische Zugang. In H. Gottlieb and J.E. Mogensen (eds.) Dictionary Visions, Research and Practice (pp. 83-95). Amsterdam/Philadelphia: John Benjamins. 
Gouws, R. H. (1991) Toward a lexicon-based lexicography. Dictionaries: Journal of Dictionary Society of North America, 13: 75-90.

Gouws, R.H. (1996) Idioms and collocations in bilingual dictionaries and their Afrikaans translation equivalents. Lexicographica 12: 54-88.

Glucksberg, S. (2001) Understanding Figurative Language. Oxford: OUP.

Granger, S. and Paquot, M. (2008) From dictionary to phrasebook? In E. Bernal and J. DeCesaris. Proceedings of the XIII EURALEX International Congress (pp. 13451355). Barcelona: Universitat Pompeu Fabra, Institut Universitari de Lingüística Aplicada.

Granger, S. and Lefer, M.A. (2012) Towards more and better phrasal entries in bilingual dictionaries. In Proceedings of EURALEX 2012 (pp. 682-692). Oslo: University of Oslo.

Granger, S. (2018) Has lexicography reaped the benefit of the (learner) corpus revolution? In J. Čibej, V. Gorjanc, I. Kosem and S. Krek (eds.) Proceedings of the XVIII EURALEX International Congress Lexicography in Global Contexts 17-21 July 2018, Ljubljana. (pp. 17-24). Ljubljana: University of Ljubljana.

Gries, S. T. (2008) Phraseology and linguistic theory: a brief survey. In S. Granger and F. Meunier (eds.) Phraseology. An interdisciplinary perspective (pp. 3-25). Amsterdam/Philadelphia: Benjamins.

Hanks, P. (1988) Typicality and meaning potentials. In M. Snell-Hornby (ed.). ZuerLEX' 86 Proceedings (pp. 37-47). Tübingen: Francke Verlag.

Harras, G. and Proost, K. (2005) The lemmatisation of idioms. In H. Gottlieb, J. E. Mogensen and A. Zettersten (eds.) Symposium on Lexicography (pp. 277-291). Tübingen: Max Niemeyer Verlag.

Haspelmath, M. (2007) Pre-established categories don't exist. Consequences for language description and typology. Linguistic Typology, 11: 119-132.

Haspelmath, M. (2010) Comparative concepts and descriptive categories in crosslinguistic studies. Language, 86 (3): 663-687.

Hüning, M. and Schlücker, B. (2015) Multi-word expressions. In P. O. Müller, I. Ohnheiser, S. Olsen and F. Rainer (eds.) Word-Formation. An International Handbook of the Languages of Europe (pp. 450-467). Berlin/Boston: De Gruyter Mouton.

Jackendoff, R. (1995) The boundaries of the lexicon. In M. Everaert, E.-J. Van Der Linden, A. Schenk and R. Schreuder (eds.) Idioms: Structural and Psychological Perspectives (pp.133-165). Hillsdale (New Jersey): L. Erlbaum Associates.

Korhonen, J. (2007) Probleme der kontrastiven Phraseologie. In H. Burger, D. Dobrovol'skij, P. Kuehn and N.R. Norrick (eds.) Phraseologie. Vol. 1 (pp. 574-589). Berlin, New York: Walter de Gruyter.

Kromann, H.-P., Rüber, T. and Rosbach, P. (1991) Principles of bilingual lexicography. In Fr.J.Hausmann, O. Reichmann, H.E. Wiegand and L.Zgusta (eds.) Wörterbücher, Dictionaries, Dictionnaires. An International Encyclopedia of Lexicography, Vol. 3 (pp. 2711-2728). Berlin, New York: Walter de Gruyter.

Lehmann, C. (2018) Linguistic concepts and categories in language description and comparison. M. Chini and P. Cuzzolin (eds.) Typology, Acquisition, Grammaticalization Studies. Milano: Franco Angeli. Available from https://www. christianlehmann.eu/publ/lehmann_ling_concepts_categories.pdf [Accessed on 15 October 2018].

Levin-Steinmann, A. (2007) Orthographie und phraseologie. In H. Burger, D. Dobrovol'skij, P. Kuehn and N. R. Norrick (eds.) Phraseologie, Vol. 1 (pp. 36-41). Berlin, New York: Walter de Gruyter. 
Lubensky, S. and McShane, M. (2007) Bilingual phraseological; dictionaries. In H. Burger, D. Dobrovol'skij, P. Kuehn and N. R. Norrick (eds.) Phraseologie, Vol. 2 (pp. 919-928). Berlin, New York: Walter de Gruyter.

McCarthy, M. (1988) Questions of naturalness in language. English Language Research Journal (New Series): 2: 47-60.

Mogorrón, H. P. (2011) Compétences phraséologiques et traitement des expressions figées dans les dictionnaires. In M. van Campenhoudt, T. Lino and R. Costa (eds.) Passeurs de mots, passeurs d'espoir: lexicologie, terminologie et traduction face au défi de la diversité (pp. 517-535). Paris, Éditions des archives contemporaines.

Moon, R. (1998) Fixed Expressions and Idioms in English. A Corpus-Based Approach. Oxford: Oxford University Press.

Moon, R. (2007) Corpus linguistic approaches with English corpora. In H. Burger, D. Dobrovol'skij, P. Kuehn and N. R. Norrick (eds.) Phraseologie, Vol. 2 (pp. 10451059). Berlin, New York: Walter de Gruyter.

Moravcsik, E. A. (2016) On linguistic categories. Linguistic Typology, 20: 417-426.

Mulhall, Chr. (2010) A Semantic and lexical-based approach to the lemmatisation of idioms in bilingual Italian-English dictionaries. In A. Dykstra and T. Schoonheim (eds.) Proceedings of the XIV EURALEX International Congress (pp. 1355-1369). Afûk, Ljouwert: Fryske Akademy.

Naciscione, A. (2010) Stylistic Use of Phraseological Units in Discourse. Amsterdam: Benjamins.

Nuccorini, S. (2003) Towards an 'ideal' dictionary of English collocations. In P. van Sterkenburg (ed.) A Practical Guide to Lexicography (pp. 366-387). Amsterdam/ Philadelphia: John Benjamins.

Oppentocht, L. and Schutz, R. (2003) Developments in electronic dictionary design. In P. van Sterkenburg (ed.) A Practical Guide to Lexicography (pp. 215-227). Amsterdam/Philadelphia: John Benjamins.

Potgieter, L. (2006) Die bewerking van idiome in tweetalige woordeboeke. LEXICOS, Vol. 16: 180-192.

Rio-Torto, G. (2012) Lexical idiomaticity and word processing. In A. Fábregas, E. Felíu, J. Martin García and J. Pazó (eds.) Los limites de la morfología. Estudios oferecidos a Soledad Varela Ortega (pp.397-412). Madrid, Universidad Autónoma de Madrid (col. Estudios 147).

Schemann, H. (1989) Das phraseologische Wörterbuch. In Fr. J. Hausmann, O. Reichmann, H. E. Wiegand and L. Zgusta (eds.) Wörterbücher, Dictionaries, Dictionnaires. An International Encyclopedia of Lexicography, Vol. 1 (pp. 1019-1032). Berlin, New York: Walter de Gruyter.

Schemann, H. (1991) Die Phraseologie in zweisprachigen Wörterbuch. In Fr. J. Hausmann, O. Reichmann, H. E. Wiegand and L. Zgusta (eds.) Wörterbücher, Dictionaries, Dictionnaires. An International Encyclopedia of Lexicography, Vol. 3 (pp. 2789-2794). Berlin, New York: Walter de Gruyter.

Sinclair, J. (2010) Defining the definiendum. In de Schryver, G.-M. (ed.) A Way with Words: Recent Advances in Lexical Theory and Analysis. A Festchrift for Patrick Hanks (pp. 37-47). Kampala: Menha Publishers.

Snell-Hornby, M. (1988) Translation Studies. An Integrated Approach. Amsterdam and Philadelphia: John Benjamins.

Svensen, B. (1993) Practical Lexicography. Oxford, New York: Oxford University Press.

Van der Meer, G. (2000) Further ways to improve the active dictionary: Collocations, non-morphological "derivations", grammar. In J. E. Mogensen, V. H. Pedersen and A. Zettersten (eds.) Symposium on Lexicography, 9 (pp. 125-141). Tübingen: Max Niemeyer Verlag. 
Veisbergs, A. (1996) Idiom transformation, idiom translation and idiom dictionaries. Lexicographica, Series Maior, 76 (pp. 241-246). Tübingen: Max Niemeyer Verlag.

Veisbergs, A. (2007) Occasional and systematic shifts in word-formation and idiom use in Latvian as a result of translation. In J. Munat (ed.) Lexical Creativity, Texts and Contexts, Vol. 58 (pp. 239-263). Amsterdam and Philadelphia: John Benjamins.

Veisbergs, A. (2012) Phraseological Borrowing. Berlin. Logos.

Veisbergs, A. (2018) Word-formation Pattern Borrowing in Latvian. Baltic Journal of English Language, Literature and Culture, 8: 129-148. DOI: https://doi. org/10.22.364/BJELLC.08.2018.09.

Vinogradov, V. V. (1947) Ob osnovnyh tipah frazeologihskih edinic. In V. V. Vinogradov (1977) Izbrannije trudi (pp. 162-189). Moskva: Nauka.

Wierzbicka, A. (2014) Imprisoned in English: The Hazards of English as a Default Language. Oxford: Oxford University Press.

Xia, L. (2015) Corpora and collocations in Chinese-English dictionaries for Chinese users. English Language Teaching, 8 (10): 162-167.

Yong, H. and Peng, J. (2007) Bilingual Lexicography from a Communicative Perspective. Amsterdam: John Benjamins.

Zgusta, L. (1971) Manual of Lexicography. Prague: Academia / The Hague, Paris: Mouton.

Andrejs Veisbergs (Prof., Dr. habil. philol.) is currently working at the University of Latvia. He is a Consultant of Oxford English Dictionaries and an accredited European Union interpreter. His research interests include lexicography, idioms, language contacts, translation and interpreting. Email: Andrejs.Veisbergs@lu.lv 
Baltic Journal of English Language, Literature and Culture. Volume 9, 2019

Published by University of Latvia Press

Aspazijas bulvāris 5, Rīga, LV-1050, Latvia apgads@lu.lv

Printed by SIA “Eiro Print” 